UNIVERSIDAD NACIONAL DE LA PLATA

FACULTAD DE HUMANIDADES Y CIENCIAS DE LA EDUCACIÓN SECRETARÍA DE POSGRADO

\title{
ENTRE EL IRSE Y EL VOLVER: RECONFIGURACIÓN EN LAS PRÁCTICAS ESPACIALES DE CAMPESINOS RETORNADOS EN LOS MONTES DE MARÍA.
}

Caso Vereda VillaColombia y Borracheras, Departamento de Sucre, Colombia (2004-2012).

Byron Giovanny Ospina Florido

Tesis para optar por el grado de Magíster en Ciencias Sociales

Directora Carmen Andrea Becerra, Centro Nacional de Memoria Histórica

Codirector Héctor Luis Adriani, Universidad Nacional de La Plata

La Plata, 29 de Agosto de 2013 
A Victoria y a Pepe, mis raíces campesinas 


\section{TABLA DE CONTENIDO}

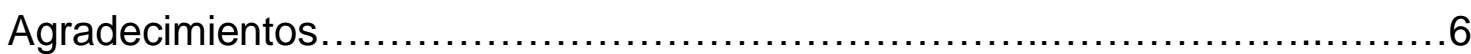

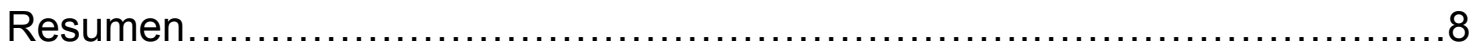

INTRODUCCIÓN

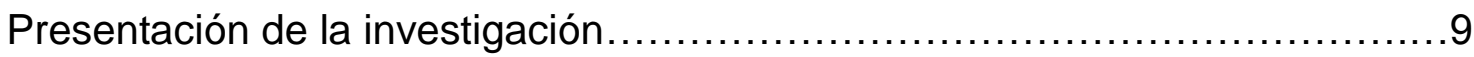

Desplazamiento y retorno: el devenir del campesinado .......................... 14

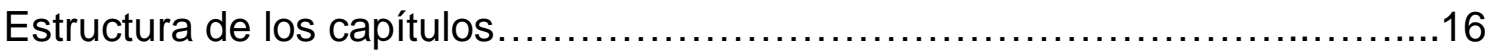

CAPITULO I. El retorno como objeto de estudio ............................17

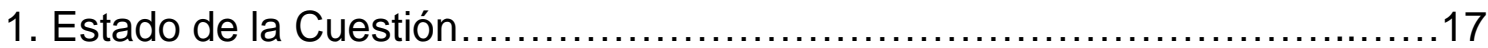

1.2. Consideraciones Metodológicas.........................................

CAPITULO II. Espacio y prácticas espaciales como marcos interpretativos

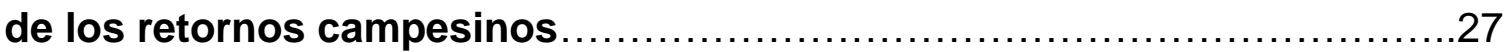

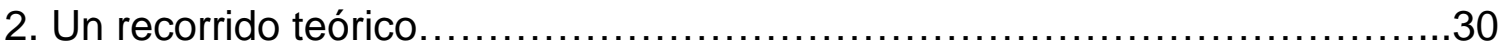

2.1.1. El espacio y lo espacial..........................................30

2.1.2. La producción social del espacio social............................33

2.1.3. La estructura material en las prácticas espaciales..................37

2.2. Una lectura de los retornos campesinos desde las prácticas espaciales....41

2.2.1. Acerca de las configuraciones y las reconfiguraciones.............41

2.2.2. El movimiento en el espacio: espacializando y territorializando el retorno campesino......................................................

2.3 ¿Desplazado, retornados o campesinos? La pregunta por el sujeto........48

CAPITULO III. Espacios, pobladores e historias de la montaña de María.

3. En las entrañas de la montaña: aproximación geohistórica..................52

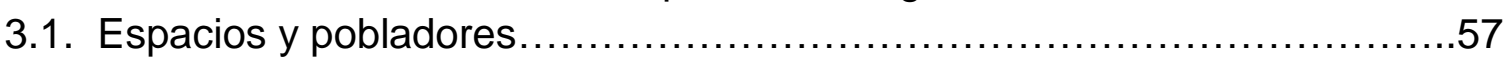

3.1.1 Organización espacial indígena.................................58

3.1.2 Palenques o espacios de libertad...............................60

3.1.3. El Estado colonial y el control espacial...........................63

3.1.4. La Hacienda, un modelo que pervive.............................64

3.1.5. El campesino costeño: Aproximación sociohistórica...............70

3.2. A propósito de la organización espacial y la construcción de espacialidad de los campesinos montemarianos......................................... 78

CAPÍTULO IV. Entre el irse y el volver: el desplazamiento.................81

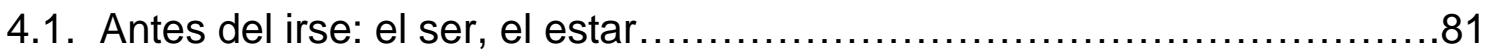




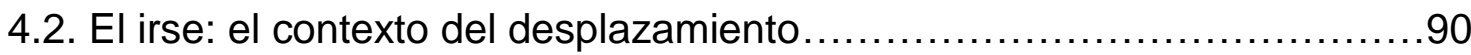

4.2.1. Los avatares de la montaña de María......................... 90

4.2.2. Disputa y confrontación armada..............................92

4.2.2.1. Insurgencia en la montaña de María....................93

4.2.2.2. Ejércitos privados y el paramilitarismo...................95

4.2.2.3 La consolidación de los actores: la confrontación entre los "paras" y las FARC..........................................97

4.2.2.4. El saldo de la violencia............................... 100

4.3. El irse: historia de un éxodo.............................................. 105

4.3.1. Sobreviviendo en medio del desarraigo......................110

CAPITULO V. Entre el irse y el volver: el retorno........................114

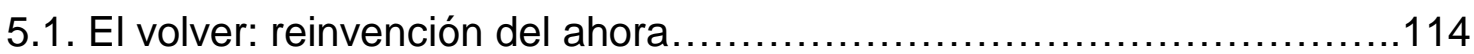

5.1.1. El contexto del volver........................................ 114

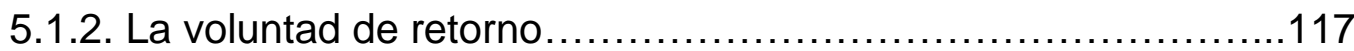

5.2. Familias campesinas retornadas: sentidos y prácticas espaciales en juego

5.2.1. Reconfiguración de prácticas espaciales.....................130

5.2.2. Prácticas campesinas en medio del retorno.....................131

5.2.3. Prácticas de apropiación y dominio espacial....................141

CAPÍTULO VI. Consideraciones finales.

6.1 Retornos, prácticas y campesinos en Los Montes de María...............155

6.1.1. A propósito de las prácticas espaciales........................160

6.2. Retornos, campesinos e investigación.............................. 162

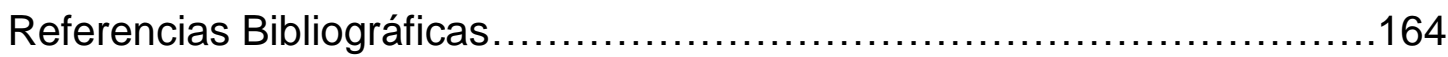




\section{Índice de mapas, tablas, cuadros y gráficos}

Mapa 1. Región Caribe y Subregión de Los Montes de María.......................10

Mapa 2. Municipio de Ovejas en el Departamento de Sucre......................12

Mapa 3. Área de estudio. Veredas de VillaColombia y Borracheras en el Municipio de Oveja ............................................................. 13

Mapa 4. Clasificación por zonas de Los Montes de María..........................51

Mapa 5. El Caribe colombiano prehispánico. Grupos aborígenes caribeños....58

Mapa 6. Zonas de explosión / zonas de recepción. Veredas VillaColombia y

Borracheras.

Mapa 7. Organización espacial Vereda Borracheras. 1997-2000 (antes del desplazamiento) ........................................................... 150

Mapa 8. Organización espacial Vereda Borracheras. 2006-2013...............152

Tabla 1. Recuperaciones de tierra. Departamento de Sucre. Década del

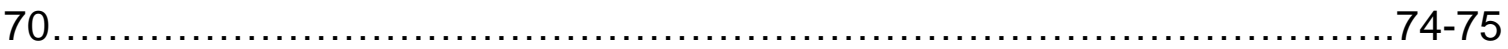

Tabla 2. Desplazamiento forzado. subregión de los Montes de María 2000-2010

Tabla 3. Casos de masacres subregión de los Montes de María 20002010

Gráfico 1. Masacres en la Subregión de Los Montes de María. Periodo 19932009 102

Figura 1. Modelo de análisis. Variables analíticas ..............................25

Figura 2. Momentos de la producción del espacio..................................33

Cuadro1. Matriz de Prácticas espaciales según Harvey...........................36

Cuadro 2.Caracterización de los Paisajes Campesinos y del Agronegócio 


\section{AGRADECIMIENTOS}

A todos los hombres y mujeres de Los Montes de María, en especial aquellos campesinos y campesinas que compartieron conmigo parte de su experiencia, de su memoria y de su lucha histórica por la tierra. A los compañeros y compañeras de ASOCARES, por permitir que me acercara a sus angustias y esperanzas. A Carmelo Márquez le agradezco su guía y su compañía, pues sin su abnegado compromiso, no hubiese podido recorrer los senderos y las historias de VillaColombia y Borracheras.

Al Programa de Formación, Capacitación y Becas Internacionales del Ministerio de Educación de la República de Argentina, en especial al programa de becas Roberto Carri, les agradezco la oportunidad que me brindaron al apoyar mi estadía en la Argentina. A Lorena Yaber, gracias por su interés y por su continua colaboración a todos los becados del programa.

A mis directores de tesis, Luis Adriani y Andrea Becerra, les agradezco por aligerar con sus oportunos cometarios, el siempre pesado trabajo de escritura.

Al Instituto Latinoamericano para una Sociedad y un Derecho Alternativo ILSA, gracias por apoyar gran parte de mi trabajo de campo por Los Montes de María. A Andrea y a Fabián gracias por confiar en mi trabajo, a ustedes les debo muchas de las reflexiones que hicieron posible este documento. La coherencia de su trabajo y la rigurosidad de sus análisis fueron la mejor escuela por la que he pasado.

A Jenny, Cami y Catalina, gracias por ofrecerme su más sincera amistad, sin ustedes, sus risas, consejos y compañía el recorrido por la Argentina hubiese sido más tortuoso.

A los hermanos Ullon, les debo mi más sincera gratitud por permitirme ser parte de sus vidas, expectativas, alegrías y logros. La Argentina musical, cultural, la Argentina de a pie, se las debo a ustedes. Las tardes de tereré y la melodía de misionerita desde ya hacen parte de mi paso y de mi memoria por el Sur.

De igual manera, le agradezco a Johanna, Javier, Laura y a todos los surconscientes por permitirme encontrar en ellos un apoyo incondicional. 
A Caro y a Clau, su lucidez y amistad siempre me fortalecerán.

Finalmente y no por ello menos importante, le agradezco a mi familia, en especial a mi madre y a mi hermana, gracias por estar junto a mí en los buenos y en los no buenos momentos. Desde siempre su apoyo me ha hecho lo que soy. 


\section{Resumen}

El presente trabajo aborda, desde el estudio de caso, los procesos de retorno campesino en la subregión de Los Montes de María ${ }^{1}$. Estos procesos fueron estudiados a partir de la identificación y análisis de las reconfiguraciones en las prácticas espaciales de dos comunidades campesinas que después tres y cuatro años de desplazamiento forzado, deciden en el 2004 y de manera colectiva retornar a sus veredas de origen, a saber: VillaColombia y Borracheras en el municipio de Ovejas, departamento de Sucre.

El análisis de la temporalidad y la espacialidad de los procesos de retorno campesinos, nos permiten concluir que en medio de dicho proceso estas familias campesinas se han visto en la necesidad de ajustar sus modos de producción y de reproducción social, reconfigurando en medio de ello, los sentidos que sitúan los sistemas de representaciones, apreciaciones y acciones que constituyeron y constituyen sus prácticas espaciales y por ende, su modo de vida campesino en relación con las formas en que apropian y controlan su espacio.

Palabras claves:

Prácticas espaciales; Espacio social; Retorno campesino; Desplazamiento; Reconfiguración.

\footnotetext{
${ }^{1}$ La presentación y localización de la subregión se hará en el siguiente apartado y en el capítulo III.
} 


\section{ENTRE EL IRSE Y EL VOLVER: RECONFIGURACIÓN EN LAS PRÁCTICAS ESPACIALES DE CAMPESINOS RETORNADOS EN LOS MONTES DE MARÍA. Caso Vereda ${ }^{2}$ VillaColombia y Borracheras, Departamento ${ }^{3}$ de Sucre, Colombia}

(2004-2012).

\section{INTRODUCCIÓN}

\section{Presentación}

Dentro de las dinámicas que ha adoptado el conflicto armado en Colombia, es incuestionable que el crimen del desplazamiento y el consecuente abandono forzado de tierras y territorios han sido la mayor causante de la crisis y la tragedia humanitaria en el país.

Así, el desplazamiento forzado ha estado atado a las diferentes facetas y dinámicas del conflicto, estando vinculado especialmente a los actores armados y sus estrategias de posicionamiento y expansión territorial. Justamente durante el periodo 1997-2002, se observa que los dos principales actores en confrontación lanzan una contraofensiva que intensifica de manera exponencial el conflicto. Por un lado, las FARC-EP intentan reposicionar su proyecto político y militar a través del desdoblamiento de sus frentes, aumentando su presencia en ciertas zonas estratégicas, mientras que los paramilitares, y sobre todo después de la unificación en las denominadas Autodefensas Unidas de Colombia -AUC, disputan el control territorial a las FARC-EP, consolidando su presencia a través de masacres, homicidios selectivos, desapariciones forzadas y otras acciones intimidatorias que buscaban imponer un control social sobre poblaciones [ubicadas en zonas] de influencia guerrillera, (...) en zonas de

\footnotetext{
${ }^{2}$ La organización territorial de Colombia se encuentra conformada administrativamente por un distrito Capital, 32 departamentos y 1.123 municipios. Las veredas son entidades territoriales que pertenecen a una unidad territorial, como lo es un municipio. Las veredas principalmente comprenden zonas rurales y poseen, entre 50 y 1200 habitantes. Para nuestro caso, las veredas de VillaColombia y Borracheras son entidades territoriales pertenecientes al municipio de ovejas, departamento de Sucre.

${ }^{3}$ Los departamentos son los entes más importantes a nivel territorial, gozan de autonomía en el manejo de los asuntos relativos a su jurisdicción y funcionan además como organismos de coordinación entre la nación y los municipios.
} 
cultivos ilícitos y corredores estratégicos, particularmente en el norte, centro y oriente del país. (Acción Social, sf:3).

Como consecuencia de esta contraofensiva, se generaliza el desplazamiento forzado a lo largo y ancho del territorio nacional, generando para este periodo (1997-2002) 1.916.588 víctimas ${ }^{4}$, ubicando desde ese entonces al país como uno de las principales naciones con mayor número de refugiados internos. De acuerdo con Ibáñez estimaciones del IDNM (Centro de Monitoreo de desplazamiento Interno, por su sigla en inglés) calculan que la población desplazada [para el 2008] en todo el mundo ascendía a 24,5 millones de personas. Colombia contribuye entonces con un $14.3 \%$ de los desplazados en el mundo y ocupa el segundo lugar, después de Sudan, en número de personas desplazadas (Ibáñez, 2008:11).

Hay que considerar también, que el fenómeno de expulsión de personas no solo creció de manera constante por lo menos hasta el año 2009, sino que además logró expandirse a lo largo del territorio nacional. Durante 1995, solo 35 municipios ${ }^{5}$ del país fueron expulsores de población, y en 2002 dicha cifra ya ascendía a 949, es decir un poco más del 90\% de los municipios del país eran expulsores de población. (...) el fenómeno no se circunscribe, por ende, a unos municipios apartados del país. Por el contrario, es un fenómeno generalizado que se extiende a lo largo de la geografía colombiana. (Ibáñez, 2008:11-12).

Hay que señalar que esta expansión modificó tras de sí, dinámicas y formas de relacionamiento locales y regionales, alterando lo procesos de poblamiento y los relacionamientos de los sujetos tanto en términos interpersonales, como institucionales. Entre las regiones más golpeadas por el desplazamiento forzado, encontramos el Caribe colombiano y dentro de éste, la subregión de los Montes de María (mapa 1).

\footnotetext{
${ }^{4}$ Datos obtenidos por el Sipod y Registro Único de Víctimas (RUV), precesados por el Observatorio del Programa Presidencial de DDHH (2013). Otros datos calculan que entre 1996 y 2002 se generaron 2.014.893 desplazamientos forzados. Ver informe Basta ya! (2013:71)

${ }^{5}$ La entidad fundamental de la división político administrativa colombiana es el municipio, el cual se divide a su vez en veredas, corregimientos, inspecciones de policía y caseríos. El municipio está regido por un alcalde y un consejo municipal, elegido por voto popular para un período de tres años
} 
Mapa 1. Región Caribe y Subregión de Los Montes de María.

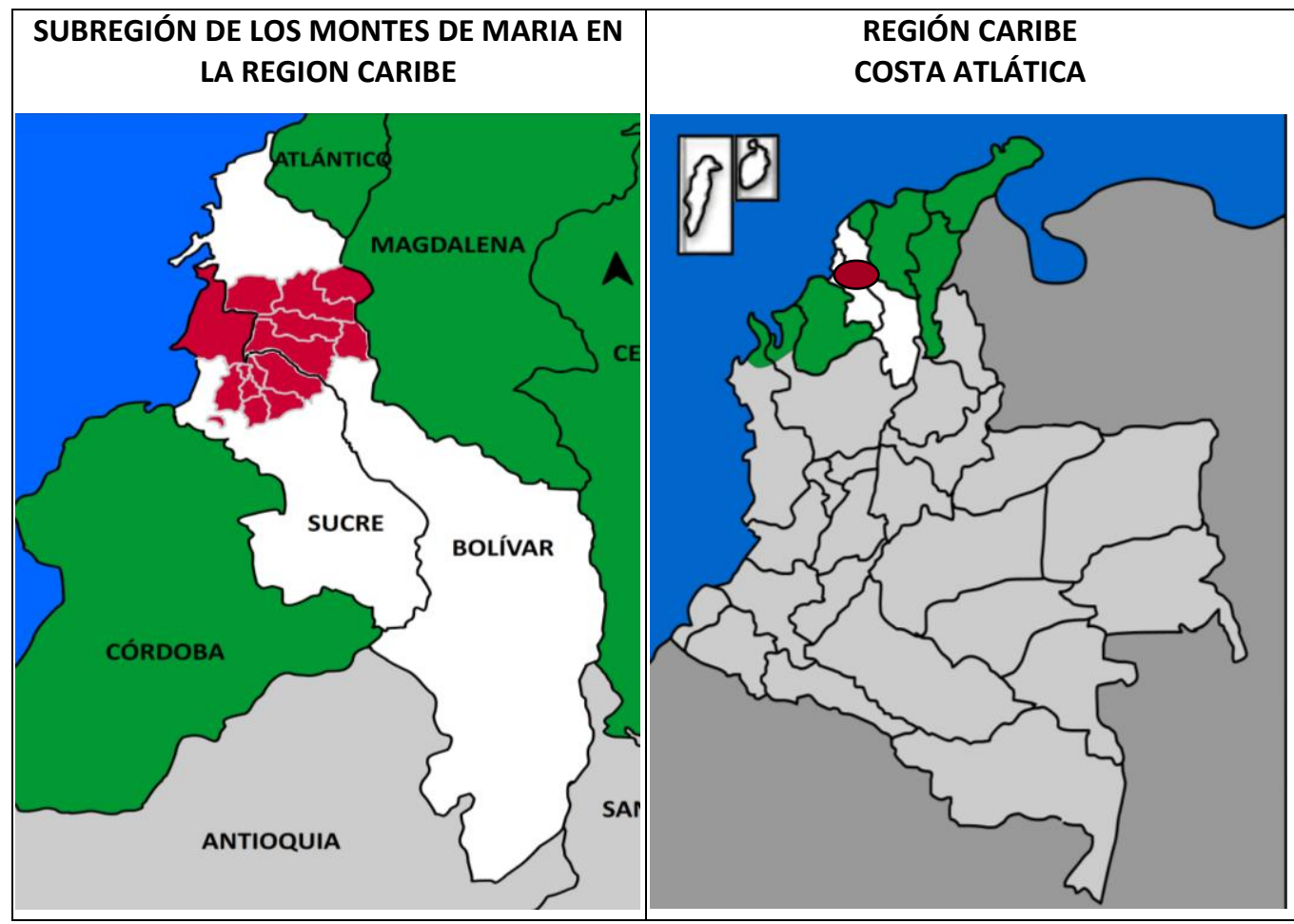

Fuente. Elaboración propia con base en datos IGAC.

Esta subregión, conocida también como serranía de San Jacinto, está compuesta por 8 municipios del departamentos de Sucre $^{6}$ y 7 municipios del departamento de Bolívar ${ }^{7}$, ha sido un escenario donde la violencia sociopolítica, la concentración de la tierra y la criminalización de los sectores rurales, han configurado una estructura socioterritorial desigual y excluyente, la cual ha sido reforzada en los últimos 10 años con la práctica sistemática del desplazamiento forzado, dejando como saldo desde 1999 hasta el año 2011 el número de $459.231^{8}$ personas desarraigadas. Una de las múltiples consecuencias de este desarraigo para la subregión en cuestión, ha sido la reconfiguración, no solamente de los vínculos de propiedad, sino también de aquellos lazos subjetivos de identidad y de afecto existentes entre el sujeto, la comunidad y el espacio.

Actualmente, este proceso de reconfiguración de las diferentes esferas que conforman la vida de los que han sido desplazados, no ha cesado. El «retorno», el volver a los

\footnotetext{
${ }^{6}$ Municipio de Morroa, Los Palmitos, San Antonio de Palmito, Chalán, Ovejas, San Onofre, Colosó y Toluviejo

${ }^{7}$ Municipio de El Carmen de Bolívar, Zambrano, El Guamo, María La Baja, Córdoba Tetón, San Jacinto y San Juan Nepomuceno

${ }^{8}$ Cifras procesadas por CODHES para los departamentos de Sucre y Bolívar, período 1999-2011, en VerdadAbierta.com recuperadas el 23 de julio de 2013.
} 
territorios, el buscar reterritorializarse a partir de acciones individuales, familiares $u$ organizativas, no significó "des pausar" una vida interrumpida años atrás. El continuar o el intentar continuar después del desplazamiento forzado, parte del hecho, que tanto los sujetos como sus relaciones sociales y por ende, sus relaciones espaciales ya no son las mismas. Entonces, el modificar o adaptarse a las nuevas circunstancias y dinámicas se constituye en una premisa, pero a la vez en una consecuencia del ejercicio violento de la desterritorialización.

Justamente, este es el caso de un grupo de 30 familias de las Veredas de Borracheras y VillaColombia en el departamento de Sucre (mapa 2, 3), que después de ser desplazadas en el año 2000 y 2001 -respectivamente- deciden regresar el 5 de marzo del 2004 a los lugares que originalmente fueron expulsadas, tratando de reacomodarse a los contextos y a las dinámicas presentes ${ }^{9}$.

Es así que en el momento de volver o retornar, y después de ocho años (2004-2012), estas familias se han visto en la necesidad de ajustar sus modos de producción y de reproducción social, reconfigurando en medio de ello, los sentidos que sitúan los sistemas de representaciones, apreciaciones y acciones que constituyeron y constituyen sus prácticas espaciales y por ende, su modo de vida campesino en relación con las formas en que apropian y controlan su espacio. De ahí que el interrogante que guio el presente trabajo girará en torno al análisis de dicha reconfiguración, intentando explicar los factores, actores y relaciones que intervienen en dicho proceso.

\footnotetext{
${ }^{9}$ Es importante señalar que el proceso de retorno no fue el resultado de un programa institucional sino que fue el resultado de un proceso organizativo liderado por los propios campesinos.
} 
Mapa 2. Municipio de Ovejas en el Departamento de Sucre

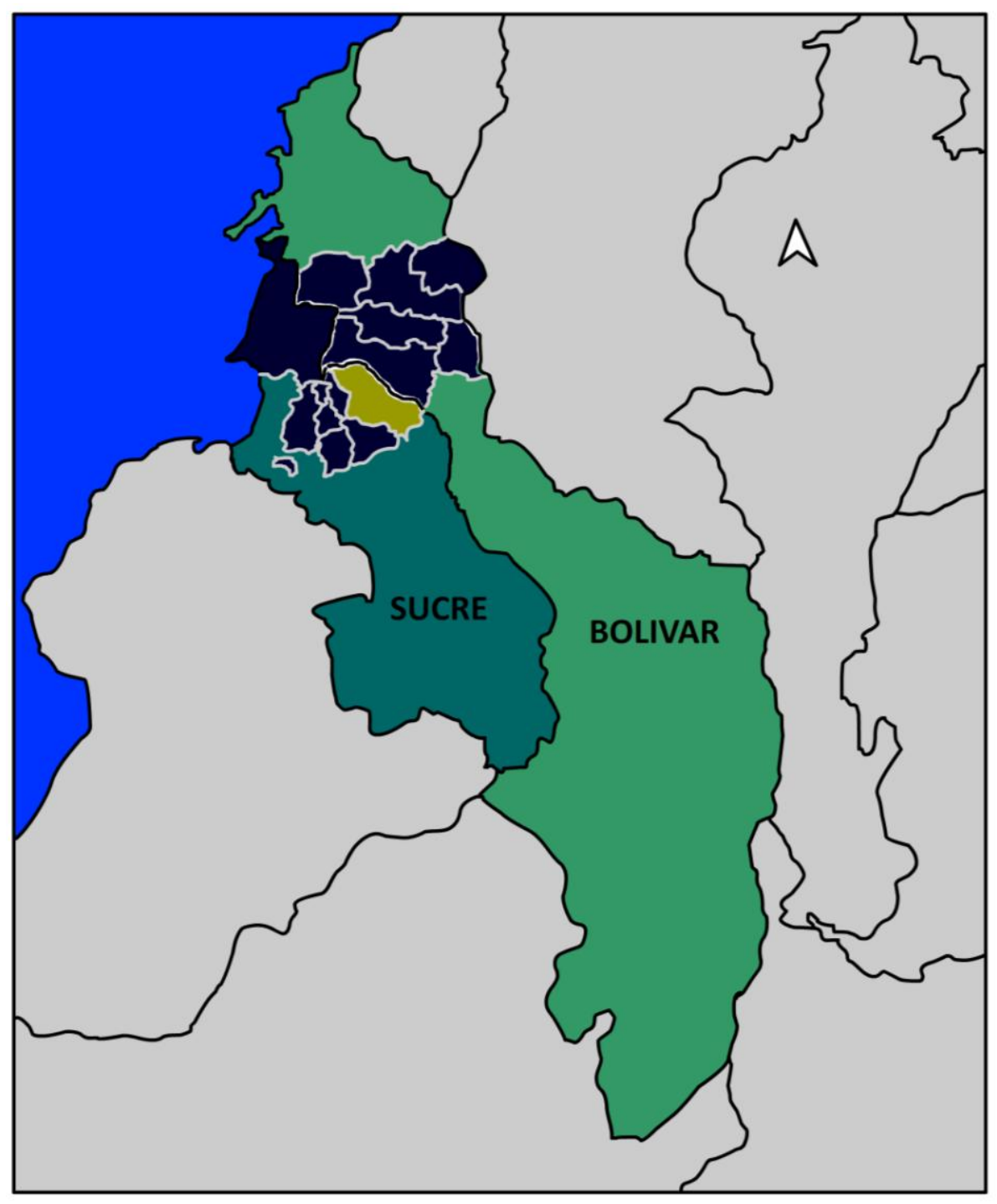

Fuente. Elaboración propia con base en datos IGAC 


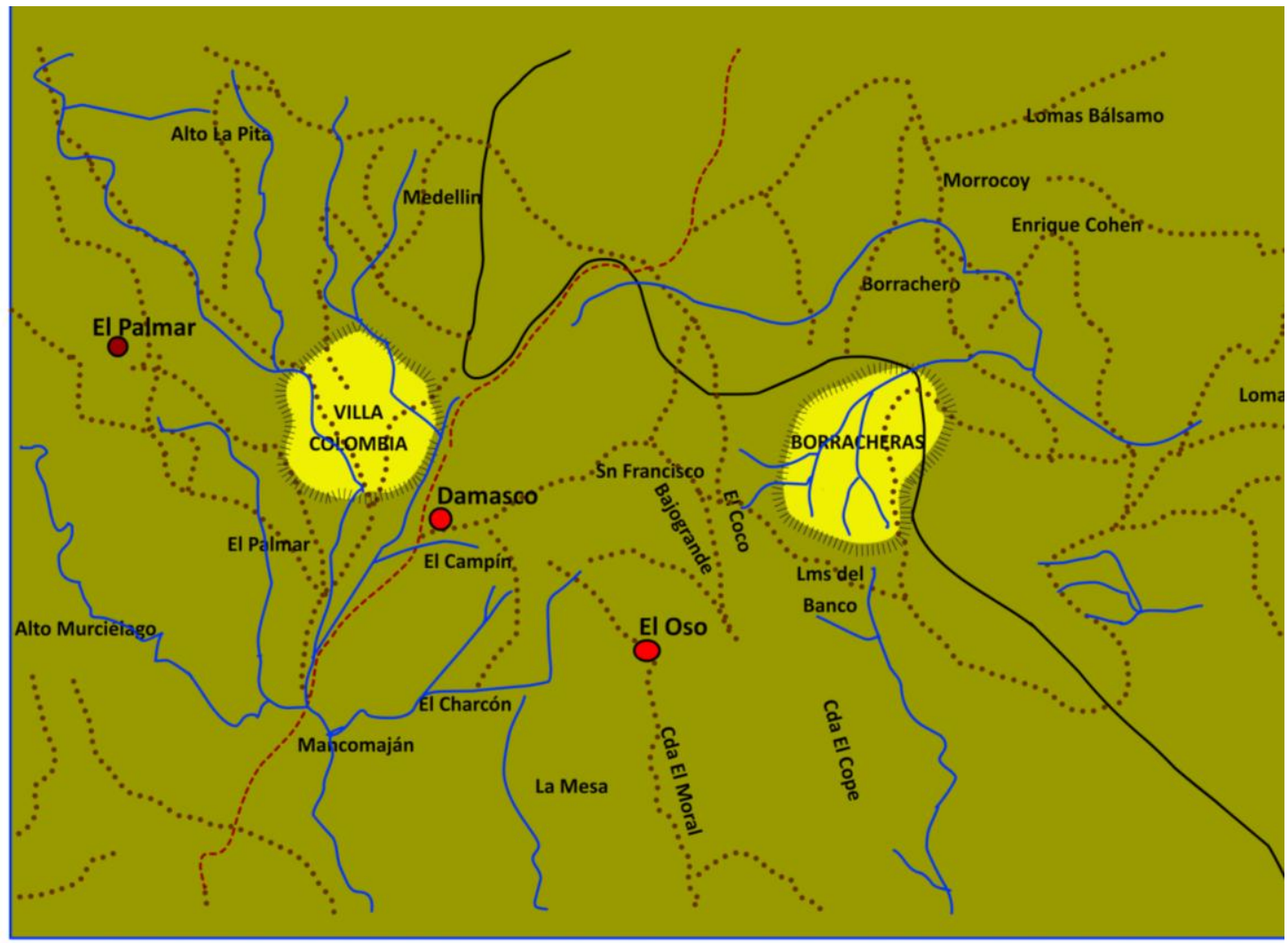

Fuente. Elaboración propia con base datos IGAC

Desplazamiento y retorno: el devenir del campesinado

Los resultados arrojados en la II ENV ${ }^{10}-2008$ muestran como la tenencia de la tierra es una constante para la gran mayoría de los hogares desplazados, el 55\% de los grupos familiares tenían tierra y el $94 \%$ de ellos tuvieron que abandonarla, de acuerdo con la III ENV-2010, como producto del desplazamiento se produjo un abandono de tierras aproximado de 6,65 millones de hectáreas es un área que equivale aproximadamente al 12,9 por ciento de la superficie agropecuaria de Colombia (CID-UN, 2008, 2010) bajo estos datos, el problema del desarraigo podría pensarse dentro de un proceso más general, a saber: la reestructuración y reconfiguración violenta de los territorios y las prácticas espaciales en los escenarios rurales. Entendido de esta manera, tanto el desplazamiento como las diferentes iniciativas que han buscado mitigar el abandono forzado de tierras y territorios, tales como el retorno y la reubicación, deben ser comprendidos dentro de marcos y dinámicas complejas en donde la interacción de

\footnotetext{
${ }^{10}$ La Encuesta Nacional de Verificación ENV es una herramienta utilizada por parte de la Comisión de Seguimiento a la Política Pública sobre Desplazamiento Forzado para verificar el grado de realización de un conjunto de derechos por medio de indicadores de goce efectivo adoptados por la Corte Constitucional (Autos 109 y 233 de 2007 y 116 de 2008).
} 
múltiples actores, intereses y relaciones de poder, determinan los nuevos escenarios en donde las poblaciones desarraigadas pretenden continuar con una vida "suspendida" por la violencia.

Hoy, pese a los múltiples esfuerzos por vislumbrar los factores, las circunstancias y los contextos que constituyen este fenómeno, poco se sabe de las actuales condiciones de los hogares retornados, de los procesos por los que han y siguen pasando, de las tensiones y conflictualidades entre éstos y los otros actores (armados, económicos, políticos e institucionales). Más aún, poco se sabe de los predios y de las relaciones de propiedad de los hogares después de los procesos retorno, poco se sabe del éxito o fracaso de estos procesos en relación con la permanencia y sostenibilidad socioeconómica de los hogares en los territorios.

Pero sobre todo, poco se sabe de los sujetos campesinos y como sus prácticas socioespaciales han tenido que ser reajustadas en el proceso del desplazamiento y el retorno. Dentro de la limitada literatura que aborda el fenómeno del retorno campesino, se encuentra una marcada tendencia por estudiar tal fenómeno casi que exclusivamente desde su componente sociojurídico, es decir, desde el marco de derecho. Aunque necesario para los procesos de exigibilidad frente al goce efectivo de los derechos y las actuales discusiones en relación a la reparación integral y la restitución de tierras, la orientación hacia este enfoque ha reproducido un alejamiento hacia otros tipos de análisis, que a nuestro modo de ver podrían aportar otras miradas y enriquecer la propia política pública.

Justamente, el valor del presente trabajo está dado por la apertura de una nueva -o por lo menos poco abordada perspectiva- desde la cual hemos pretendido abordar la problemática del retorno desde la caracterización y el análisis de las relaciones sociales, culturales, familiares y tradicionales de los campesinos retornados así como de los sentidos que orientan las prácticas que reproducen su espacialidad.

En pocas palabras, lo que se ha buscado a lo largo de la investigación, ha sido la introducción de una propuesta teórica-metodológica, desde la cual se desplace la categoría de «retorno» y «retornado» a una esfera de análisis que permita entender esta problemática como un proceso complejo, saturado de múltiples relaciones, con fuertes vínculos entre lo vivido, lo percibido y lo concebido, pero sobre todo con una impronta en los sentidos que constituyen al sujeto y al modo de vida campesino. 
Así el trabajo que el lector tiene en sus manos se incorpora a las diferentes expresiones que apuestan por redimensionar el saber espacial como una posibilidad para abordar los fenómenos sociales.

Estructura de los capítulos.

Con el objetivo de presentar la información y el análisis sin perder el sentido de proceso que constituyó la investigación y el mismo caso estudiado, el trabajo está organizado en seis capítulos.

En el capítulo I se presenta de manera general la revisión bibliográfica de la literatura que ha abordado el tema del retorno en Colombia, a la vez que se expone los criterios metodológicos con los cuales se estudió este fenómeno en la presente investigación; en el capítulo II "Espacio y prácticas espaciales como marcos interpretativos de los retornos campesinos", el lector encontrará las aproximaciones teóricas y las definiciones conceptuales que nos acompañaron a lo largo del trasegar investigativo. A partir de las perspectivas teóricas de Henry Lefebvre (1974,1976); David Harvey (2008); Edward Soja (1985); Milton Santos (2000); Claude Raffestin (1984) y Bernardo Mançano Fernandes (2008) entrecruzamos las categorías de espacio y prácticas espaciales como herramientas teóricas que nos permiten identificar las transformaciones socioespaciales de las comunidades campesinas desplazadas en procesos de retorno. En el Capítulo III "Espacios, pobladores e historias de la montaña de María", exponemos el marco espaciotemporal desde el cual se desenvolvió el campesinado montemariano. Es una descripción del devenir del campesinado en cuanto a la conformación de su espacialidad y al reconocimiento sociohistórico del mismo. Los capítulos IV y V presentan las especificidades del caso estudiado en relación a los factores, los actores, las relaciones y los contextos que determinaron y constituyeron el proceso de desplazamiento y retorno. En el capítulo IV "Entre el irse y el volver: el desplazamiento" se expone el contexto social e identitario así como el ciclo de violencia que envolvió el proceso de desplazamiento de las familias campesinas de las veredas de VillaColombia y Borracheras. Por otro lado el capítulo V "Entre el irse y el volver: el retorno" el lector encontrará los antecedentes del retorno, así como los factores determinantes para que este retorno se llevará a cabo, en seguida se presenta las reconfiguraciones espaciales a la luz de las categorías de familia, trabajo y comunidad. Finalmente en el capítulo VI, alejándonos de unas certeras conclusiones, presentamos las consideraciones finales, las proyecciones y los interrogantes derivados del proceso de investigación. 


\section{CAPITULO I}

\section{EI RETORNO COMO OBJETO DE ESTUDIO}

\section{Estado de la Cuestión.}

El retorno como categoría de análisis y objeto de estudio, ha estado durante mucho tiempo relegado a un nivel secundario en las agendas de las investigaciones que abordan -dentro del contexto del conflicto sociopolítico colombiano- las múltiples y dinámicas consecuencias del fenómeno del desplazamiento forzado. Si nos centramos en la subregión de los Montes de María, es evidente la ausencia de trabajos sistemáticos y consolidados que den cuenta de las implicaciones y las actuales condiciones de los procesos de retorno en relación a las dinámicas territoriales y a los procesos de desplazamiento en una de las subregiones con las cifras más altas de expulsión y recepción de hogares campesinos desplazados (Ruiz, 2006; CODHES, 2006; Ibáñez, 2004)

Un rastreo preliminar de la literatura, nos permite afirmar que los escasos trabajos que abordan la problemática de los retornos en la subregión de Los Montes de María (departamentos de Bolívar y Sucre) giran en torno a estudios de casos (Hernández, 2010; Esquivia, 2006; Econometría S.A; 2008; Puello, 2005 ) Dichos estudios pueden ser clasificados en dos grandes grupos: el primero de reciente aparición (Hernández, 2010), aborda experiencias de retorno y reubicación desde el análisis de las relaciones existentes entre los actores sociales, sus respectivas territorialidades y sus proyectos políticos. Es un abordaje, que orientado desde la filosofía y la ecología política, y la antropología cultural busca comprender los procesos de estabilización de los hogares desarraigados en los lugares de expulsión o de reubicación después de experimentar periodos de desplazamiento, no obstante, hay que señalar que en este trabajo Hernández, no diferencia la reubicación del retorno en cuanto a los elementos espaciales que los constituyen, lo cual - a nuestro modo de ver- puede ser un limitante en el análisis de los procesos que la autora aborda. Por otro lado, es preciso señalar que a diferencia de otros estudios orientados desde la acción racional (Ibáñez, 2010; 2008; Ibáñez \& Querubín, 2003, 2004) este proceso de estabilización es comprendido desde la articulación y la puesta en tensión de múltiples factores constituidos por la historicidad de los actores y de los mismos procesos de desplazamiento.

El segundo grupo, está formado por sistematizaciones o informes de experiencias de retorno y reubicación de poblaciones campesinas (Esquivia, 2006; Puello, 2005) 
elaboradas por organizaciones no gubernamentales -ONG's- y/o instituciones eclesiales que acompañan los procesos de retorno de las poblaciones desplazadas, como el Secretariado de Pastoral Social o la Fundación Red de Desarrollo y Paz de los Montes de María; también se encuentran trabajos de consultoría que analizan y evalúan el diseño y la ejecución de políticas públicas para la atención de la población retornada (Econometría S.A, 2008 citado en Hernández, 2010), por último encontramos los estudios que han abordado el tema del retorno como elemento vinculante a los procesos de reconstrucción de la memoria histórica de las víctimas del conflicto armado en la Región Caribe y la subregión de los Montes de María, entre los cuales destacamos, los informes entregados por la línea de Memoria Histórica de la Comisión Nacional de Reconciliación y Reparación -CNRR- La masacre del Salado. Esa guerra no es nuestra (2009) La Tierra en Disputa. Memorias del despojo y la resistencia campesina en la Costa Caribe (2010). Si bien este grupo de trabajos evidencian un progreso en el abordaje de estudios de caso sobre procesos de retorno y reubicación en la subregión de los Montes de María, es indiscutible que éstos son apenas las primeras exploraciones que se dan frente a un tema que merece ser tratado independientemente y bajo miradas teórico-metodológicas acordes con los actuales escenarios, actores y dinámicas económicas y culturales que condicionan la sostenibilidad de los procesos de retorno en la subregión.

Otras indagaciones que abordan el tema del retorno, ya no, desde el escenario subregional de los Montes de María, nos permiten descifrar el desarrollo de esta temática dentro de la literatura académica nacional. Preliminarmente se puede encontrar tres grandes enfoques que abarcan nuestro tema:

En el primero se encuentran documentos que analizan y evalúan las políticas públicas de retorno y restablecimiento a través de tres enfoques: desde la sistematización de experiencias -estudios de caso- (ILSA, 2006a; 2006b; MOVICE, et al 2009; PCS, 2003); desde la revisión general del diseño y ejecución de la política pública sobre retornos y reubicación por parte de entidades no gubernamentales (Forero, 2010; COMISIÓN DE SEGUIMIENTO SOBRE DESPLAZAMIENTO FORZADO-CODHES, 2006,2008; ACNUR, 2002, 2004, 2007; PNUD, 2011; Centro de Monitoreo del Desplazamiento Interno -IDMC-, 2010); y desde las propuestas de políticas públicas diseñadas por las instituciones estatales para la atención y la ejecución de programas de retorno (SNAIPD, 2009; ACCIÓN SOCIAL, 2006; ACNUR-ACCIÓN SOCIAL, 2010)

En general, los trabajos que han abordado tanto la presentación como la evaluación del diseño e implementación de la política pública de retorno y reubicación de población 
desplazada han girado alrededor de tres factores: i) el marco político y normativo, nacional e internacional dado por los Principios Rectores de los Desplazamientos Internos (ONU, 1998); ii) el contexto político de la llamada Seguridad Democrática y los planes de desarrollo y, iii) el despojo de tierras y territorios como medio y fin último del desplazamiento forzado (MOVICE et al, 2009)

En el segundo enfoque, encontramos las investigaciones que han desarrollado la temática del retorno de forma dependiente, en relación a marcos más generales que abordan las causas; los actores; los factores y las consecuencias económicas (Ibáñez, et al, 2006, 2004), sociales, institucionales o psicosociales (Mesa de trabajo de Bogotá sobre desplazamiento Interno, 2006; Corporación Región, 2004) del desplazamiento forzado. A diferencia del anterior grupo de trabajos, el abordaje de la problemática del retorno se hace de forma secundaría, pues el eje de las observaciones están dadas por la comprensión del fenómeno del desplazamiento forzado través de múltiples componentes, entre ellos, la relación entre las implicaciones económicas y sociales.

En el rastreo preliminar de este creciente número de trabajos se puede encontrar un evidente interés por analizar los retornos desde un enfoque econométrico. De estas indagaciones destacan aquellas elaboradas por la Universidad de los Andes, a través del Centro de Estudios sobre Desarrollo Económico $(2004,2008)$ y el Centro de Investigaciones Sociojurídicas (2010). Estas investigaciones se han preguntado por los factores sociales, económicos y de orden público que determinan el «deseo de retorno» de los hogares desplazados a través de un modelo de utilidad aleatoria que considera tanto variables tradicionales de la literatura de migración, como variables propias del conflicto armado (Ibáñez; Querubín; 2003, 2004). Este tipo de estudios fuertemente influenciados por perspectivas cuantitativas y de la acción racional, han ubicado al actor «desplazado» en un proceso de elección, donde los beneficios y los costos de la decisión de retornar son sopesados a partir del contexto socioeconómico: como la extrema pobreza (Chávez; Romero, 2010); la violencia o la presencia institucional del Estado en los lugares de recepción y de expulsión (Ibáñez, 2008; 2010, Ibáñez \& Querubín, 2003, 2004)

Estas indagaciones basadas en líneas de análisis econométricas han aportado nuevas fuentes de referencia en el campo del desplazamiento forzado, necesarias para el diseño de propuestas de políticas públicas acordes a los contextos, necesidades y prioridades de las poblaciones retornadas o en proceso de retorno (Ibáñez \& Querubín, 2004). No obstante, por la metodología y naturaleza de estas investigaciones, se evidencia una tendencia a la generalización de los resultados, lo cual reduce el análisis 
a un modelo de utilidad asociado a factores determinísticos que desconocen las dinámicas de las variables dentro de contextos locales y regionales.

Tanto los estudios econométricos como, los trabajos que analizan la política pública de retorno y reubicación, coinciden en establecer una fuerte relación entre el desplazamiento forzado y los procesos de retorno con el problema de la tierra y las configuraciones territoriales en las zonas de expulsión.

Este reconocimiento aunado al análisis crítico de las políticas públicas de reparación y restitución, (Becerra, 2010; 2011a; 2011b, Observatorio de Desplazamiento Interno, 2010) específicamente de la más recientemente ley de víctimas y restitución de tierra (Ley 1448 de 2011) ha suscitado un creciente número de trabajos que abordan -directa o indirectamente- el tema de los retornos desde el análisis de la cuestión agraria, el marco jurídico y los futuros escenarios de restitución y las implicaciones de lo territorial dentro de procesos de desplazamiento, retorno y reubicación.

El énfasis de este tercer enfoque, se centra en el análisis de la cuestión agraria, en el carácter vinculante de ésta, con el conflicto armado, la concentración de la tierra y las dinámicas de desplazamiento, abandono y despojo de tierras ${ }^{11}$ (Reyes, 2009, 1987; Fajardo, 2002, 2011; Machado 2002, 1994; Ibáñez \& Muñoz, 2010; Pérez, 2004; PNUD, 2011). A pesar que estas investigaciones no abordan el tema del retorno directamente 0 como categoría medular de análisis, éstos si ofrecen una valiosa perspectiva para poder comprender como la estructura agraria, la organización, distribución y evolución de la propiedad rural se consolida en un factor estructurante en la reorganización territorial de las zonas de expulsión o recepción y, en un determinante para los cambios y/o permanencias de las prácticas y representaciones espaciales (Garzón, 2011; Chaves \& Romero, 2010; Bolaños \& Pérez, 2011; Hernández, 2010) de los hogares desplazados en proceso de retorno o reasentamiento.

Justamente, el tema de lo territorial cobra relevancia si se considera que la tenencia de tierras es una constante para la gran mayoría de los hogares desplazados. Un poco más del 60 por ciento de los hogares desplazados [...] reportan algún tipo de tenencia

\footnotetext{
${ }^{11}$ Con el fin de establecer una diferenciación entre las categorías de despojo y abandono de tierras, la presente investigación a clara que se identifica con la categoría de tierras despojadas aquellas que fueron usurpadas a la población desplazada (identificando éste último término con la venta o cesión bajo presión del dominio de la propiedad); la categoría abandono forzado se refiere aquellas tierras que la población desplazada se vio obligada a dejar sin que ello implique necesariamente una pérdida del dominio. Fuente: II ENV 2010
} 
de tierra (Ibáñez \& Querubín, 2004:62) De este modo el abandono forzado de tierras y territorios, representaría un fuerte impacto en las relaciones de propiedad y consecuentemente en las prácticas y modos de producción-reproducción de los hogares desarraigados. A pesar de la preponderancia de estas implicaciones, el referente espacial ha estado, un poco más que desatendido por los recientes trabajos sobre retorno; solamente se cuenta con estudios que han abordado la relación desplazamiento-retorno-territorio desde la cuestión de la memoria (Garzón, 2011, CNRR-Área de Memoria Histórica, 2009, 2010; Ospina, 2011; Sastoque et al, 2010) y el mundo de las representaciones sociales y políticas (Chaves \& Romero, 2010; Bolaño, 2011; Hernández, 2010). Es preocupante observar que áreas que tienen como centro de reflexión el territorio y el espacio no hayan abordado esta problemática, tan sólo se encuentra unos reducidos intentos por analizar el fenómeno y las consecuencias del desarraigo desde un marco conceptual vinculado a la geografía humana (Cubides \& Domínguez, 2004; Oslender, 2008a, 2008b, 2004, 1999); entre estos investigaciones, sobresalen los trabajos elaborados por Ulrich Oslender frente a la relación desplazamiento, territorio, lugar e identidad en el pacífico colombiano, en lo que se ha denominado: el giro geográfico de los estudios de movimientos sociales (2008a) y la geografía del terror (2004, 2008b).

Bajo las anteriores consideraciones, y sin negar las múltiples interacciones del retorno con las demás categorías que conforman el entramado del desplazamiento forzado, es necesario pensar el retorno como objeto de estudio delimitado, que permita dar cuenta de las implicaciones del abandono forzado, de los movimientos espaciales que constituyen procesos de desterritorialización y desarraigo, así como de procesos de readaptación y reconfiguración de prácticas y representaciones espaciales en hogares ya retornados.

\subsection{Consideraciones Metodológicas.}

Este trabajo se propuso -a partir de un estudio explicativo- analizar las reconfiguraciones de las prácticas espaciales de familias campesinas en el marco de procesos de retorno. Se pretendió de este modo, superar un nivel descriptivo, para poder así, comprender y explicar las variables y las múltiples relaciones de dichos cambios. 
De esta manera el marco epistemológico y ontológico que guio esta premisa, estuvo orientado por el enfoque cualitativo, el cual, respondiendo a los objetivos de la investigación se apoyo en el uso de fuentes primarias y secundarias ${ }^{12}$.

Adviértase que la elección de este enfoque respondió a los propios desafíos que nos ofreció nuestro objeto de estudio, ya que el considerar a las prácticas espaciales, y específicamente, las prácticas de apropiación y dominio espacial como resultado de producciones y reproducciones sociales y materiales (Lefebvre, 1974, 1976; Harvey, 2008) nos exhortó a diseñar una investigación que nos permitiera aprehender dichas prácticas, distinguiendo dentro del proceso de retorno a los sujetos campesinos productores de prácticas, así como a unas relaciones sociales que eran a la vez, producto y productoras de dichos sujetos y dichas prácticas. Así, el reto fue comprender la complejidad que atravesaba la realidad social de los procesos de retorno, sin perder de vista las especificidades de los fenómenos, pero a la vez sin descuidar su multiplicidad y relacionalidad en pro de una comprensión más holística ${ }^{13}$.

Bajo esta premisa, el diseño de investigación giró en torno al método de los estudios de caso. Es necesario señalar en este punto, que particularmente nos interesó estudiar las experiencias de las familias retornadas de las veredas de VillaColombia y Borracheras, en el municipio de Ovejas departamento de Sucre, no tanto por su posible carácter excepcional o por la inquietud de comprender dicha experiencia en particular -lo que denominaremos valor intrínseco de la experiencia - sino por la posibilidad que dicha experiencia nos brindó para comprender aspectos generales del proceso de reconfiguración de prácticas espaciales de familias campesinas retornadas ${ }^{14}$. En este

\footnotetext{
${ }^{12}$ Las fuentes utilizadas respondieron a la premisa de reconstruir el contexto del caso estudiado a nivel local y regional. Particularmente nos concentraremos en aquellas fuentes historiográficas y geográficas que nos permitían cruzar las categorías de «desplazamiento», «retorno», «espacio», «territorio» y "campesino».

${ }^{13}$ Es importante aclarar que con el fin de dar cuenta de la multiplicidad de relaciones que atraviesan los procesos de retorno, el trabajo también considero algunas referencias relacionadas con el propio proceso de desplazamiento, pues la naturaleza y las características del desplazamiento como antecedente, determinan hasta cierto punto las condiciones y las decisiones de retorno.

${ }^{14}$ Ahora, el porqué entendemos el retorno de VillaColombia y Borracheras como un solo caso, no radica en la naturaleza de sus desplazamiento pues como notará el lector estos se dieron en tiempos diferentes (Capítulos III), lo que lo constituye en un solo caso es la manera y el proceso de retorno, es decir, el compartir la decisión de volver y el constituir frente a ese volver unos criterios compartidos, que hasta el día de hoy mantienen estas comunidades. Tal vez lo que se puede decir frente a este caso es que la posibilidad de comprender el retorno desde dos perspectivas que aunque compartidas guardan sus especificidades, nos permitió encontrar unos puntos de referencia y a partir de ellos proyectar de manera holística una generalidad frente a la realidad de los retornos y a las implicaciones socioespaciales del volver en la subregión de los Montes de María.
} 
sentido, nuestra propuesta no se orientó a la realización de un estudio de caso intrínseco, es decir, fundamentado en la singularidad o excepcionalidad del caso de retorno en sí mismos. El enfoque que proponemos se orientó a desarrollar un estudio de caso en el cual, el estudio de una experiencia singular tiene sentido porque nos permite responder a una inquietud, pregunta o problemática que excede la experiencia en cuestión (Stake, 1995: 3), que para el objeto de esta investigación, son las reconfiguraciones en las prácticas espaciales de poblaciones campesinas después de procesos de retorno. Esta decisión metodológica respondió a la necesidad de generar, a partir de la comprensión del valor intrínseco de la experiencia y a la particularidad del caso, un conocimiento y aprendizaje que permitieran desarrollar un cuerpo sistemático de saber, que a la vez posibilitara enriquecer los estudios sobre desplazamiento y retorno campesino desde un enfoque socioespacial - un campo de por sí, desatendido por la investigación social en Colombia- (ver estado de la cuestión)

Con el fin de producir la información necesaria y para lograr los objetivos plantados para este estudio, se realizó durante el periodo 2011-2013 un trabajo de campo constituido por cuatro estadías prolongadas en el municipio de El Carmen de Bolívar ${ }^{15}$, municipio desde el cual tuvimos contacto directo tanto con los campesinos retornados en las veredas de VillaColombia y Borracheras como de aquellos que se encontraban en los cascos urbanos más cercanos. Además de las cuatro estadías en la subregión, se realizaron múltiples acercamientos con algunas organizaciones e investigadores que habían o actualmente estaban acompañado el proceso de retorno ${ }^{16}$.

Las técnicas e instrumentos implementados durante el trabajo de campo fueron variados y su uso dependió del objetivo buscado, así se aplicaron en un primer momento 20 encuestas $^{17}$, las cuales nos permitieron acercarnos a las generalidades

\footnotetext{
${ }^{15}$ El Carmen de Bolívar es el municipio más importante que cuenta el departamento de Bolívar dentro de la subregión de los Montes de María. Por ser uno de los principales centros de recepción de población desplazada y por estar localizada a pocos kilómetros de las veredas estudiadas, este municipio nos permitió estar en contacto con aquellas familias de VillaColombia y Borracheras que se encontraban en el casco urbano de dicho municipio, así como permitirnos movilizarnos hacia las veredas en cuestión. Por otro lado la elección de quedarse en el Carmen, a demás de brindar las condiciones de seguridad y de logística para el trabajo en terreno, nos facilitó el contacto con otros informantes como ONG's que habían acompañado el proceso de retorno de estas comunidades.

${ }^{16}$ Estos acercamientos consistieron en algunas jornadas de trabajo y discusión -principalmente en la ciudad de Bogotá- alrededor del caso de VillaColombia y Borracheras, así como del contexto y la problemática del desplazamiento y despojo de tierras en la subregión de los Montes de María. Es importante resaltar los aportes que tuvimos por parte de los investigadores del campo Territorio, Migraciones y Desplazamiento Forzado del Instituto Latinoamericano por un Derecho y una Sociedad Alternativa ILSA.

${ }^{17}$ Las encuestas se aplicaron por veredas, 19 en VillaColombia y 10 en Borracheras.
} 
socioespaciales del proceso de desplazamiento y retorno, específicamente a lo referido a la historia de los predios y el tipo de relacionamiento sociojurídico que tenían estas comunidades con la tierra. Hay que anotar que la encuesta que se aplicó fue diseñada para ampliar los datos relacionados con la descripción del proceso de desplazamiento y retorno, a la vez que nos posibilitó abordar un primer nivel de explicación, es decir, de encontrar las relaciones de causa y efecto entre los elementos que componían dichos fenómenos. Las variables que orientaron estas premisas giraron en torno a siete aspectos del dominio y la apropiación del espacio en relación con el proceso de desplazamiento y retorno: uso de la tierra; formalidad con la tierra; prácticas familiares, comunitarias $y$ organizativas; bienes muebles $e$ inmuebles; actividades socioeconómicas; motivos y responsables del desplazamiento, proceso de retorno. El procedimiento de administración del cuestionario fue aplicado a través de entrevistas personales ${ }^{18}$ y la dimensión temporal de los fenómenos analizados estuvo determinado por el antes y el después de los desplazamientos y retornos.

Por otro lado y con el fin de profundizar en las trayectorias individuales, familiares y comunitarias en relación a las prácticas de apropiación y dominio espacial antes y después del proceso de retorno, se realizaron 16 entrevistas individuale ${ }^{19}$ y cuatro grupos focales. Las entrevistas estuvieron orientadas por preguntas semiestructuradas, lo cual nos permitió orientar la producción de la información hacia los criterios y objetivos del estudio, pero a la vez nos permitió obtener otra serie de datos pertinentes para el análisis de las reconfiguraciones espaciales, en especial los componentes socioculturales de las prácticas espaciales. A su vez, los grupos focales, integrados en su mayoría por líderes campesinos de las dos veredas estudiadas, generaron un espacio de diálogo donde a la vez que se validaba la información resultante de las entrevistas, se lograba construir colectivamente los antecedentes, el desarrollo y las implicaciones comunitarias del proceso de desplazamiento y retorno.

Con el interés de identificar y graficar las representaciones más tangibles del espacio, en cuanto a las transformaciones del paisaje y al modo de vida campesino, así como a las dinámicas socioespaciales, se implementaron tres talleres de cartografía social. ${ }^{20} \mathrm{La}$

\footnotetext{
${ }^{18}$ Por la naturaleza de la administración del cuestionario, la aplicación de la encuesta estuvo apoyada por los miembros del equipo de ILSA (entidad que apoyó la financiación del trabajo de campo en la subregión de Los Montes de María)

${ }^{19}$ Las muestras para las entrevistas se seleccionaran a través de criterios de representatividad cualitativa en relación con los propósitos del estudio

${ }^{20}$ Esta técnica se implementó en tres grupos focales, compuesto por seis representantes de familias campesinas retornadas de las veredas de VillaColombia y Borracheras desarrolladas en el mes de abril del 2011, noviembre del 2012.
} 
cartografía social, se constituyó en una herramienta de suma importancia en cuanto a la identificación de los cambios en la organización y la producción de los objetos-formas que constituían el paisaje campesino antes y después de los desplazamientos del 2000 y el 2001. Recordemos que la cartografía social es una metodología nueva y alternativa que permite a las comunidades conocer y construir un conocimiento integral de su territorio para que puedan elegir una mejor manera de vivirlo. Es una forma de investigación humanista y humanizadora. Es una propuesta conceptual y metodológica novedosa que hace uso de instrumentos técnicos y vivenciales. Este tipo de mapas (en oposición con los mapas tradicionales que se elaboraban únicamente por los técnicos) se elaboran por la comunidad en un proceso de planificación participativa poniendo en común el saber colectivo (horizontal) y de esta forma legitimarlo. Es un proceso democrático de construcción de conocimiento a través de la trascripción de la experiencia de los lugares no nombrados (Herrera, sf:6), de ahí su importancia en la reconstrucción de los sentidos y en la representación de los mismos en la conformación del espacio y el territorio.

Ahora, la información resultante de las técnicas anteriormente descritas fue categorizada y analizada a partir del relacionamiento con datos estadísticos ${ }^{21}$ y con una serie de categorías específicas, las cuales surgieron de las entrevistas y las notas de campo, a saber: familia-trabajo-comunidad (Ver gráfico 1). A partir de dichas categorías se identificaron las variables con las cuales se construyó el modelo de análisis que nos permitió observar las reconfiguraciones de las prácticas espaciales desde un ejercicio interpretativo. Lo anterior nos llevó a replantear desde el plano de la reproducción social y material del espacio (Lefebvre, 1974, 1976; Harvey, 2008), que las prácticas espaciales que nosotros buscamos develar en cuanto a sus reconfiguraciones, no solo podían ser observadas en los cambios o reajustes de las diferentes formas jurídicas de relacionamiento que estas familias tenían y tienen con la tierra y el territorio (propiedad, posesión, arriendo, tenencia), sino también en las transformaciones de ciertas prácticas de apropiación y dominio -que podrían considerarse- menos formalizadas y cuya

\footnotetext{
${ }^{21}$ Para la construcción del contexto de violencia, en cuanto a los impactos del desplazamiento y de la criminalización de los campesinos en la subregión de los Montes de María, esta investigación retomó y cruzó dos diferentes fuentes de trabajo estadístico: el primero corresponde al Sipod y al Registro Único de Víctimas (RUV) el cual es procesado por Observatorio del Programa Presidencial de DDHH (fuente oficial alimentada por el registro que hacen las víctimas antes las instituciones del Estado), la otra fuente corresponde a la Encuesta Nacional de Verificación de los derechos de la población desplazada, la cual es elaborada por la Universidad Nacional en el marco de los trabajos de la Comisión de vigilancia de la política pública de población desplazada.
} 
materialización, corresponde más a las actividades y formas de organización socioespacial del modo de vida campesino, en el cual sobresale por su importante aporte en la constitución de los sujetos, la correlación familia-trabajo-comunidad.

\section{Gráfico 1. Modelo de análisis. Variables analíticas}

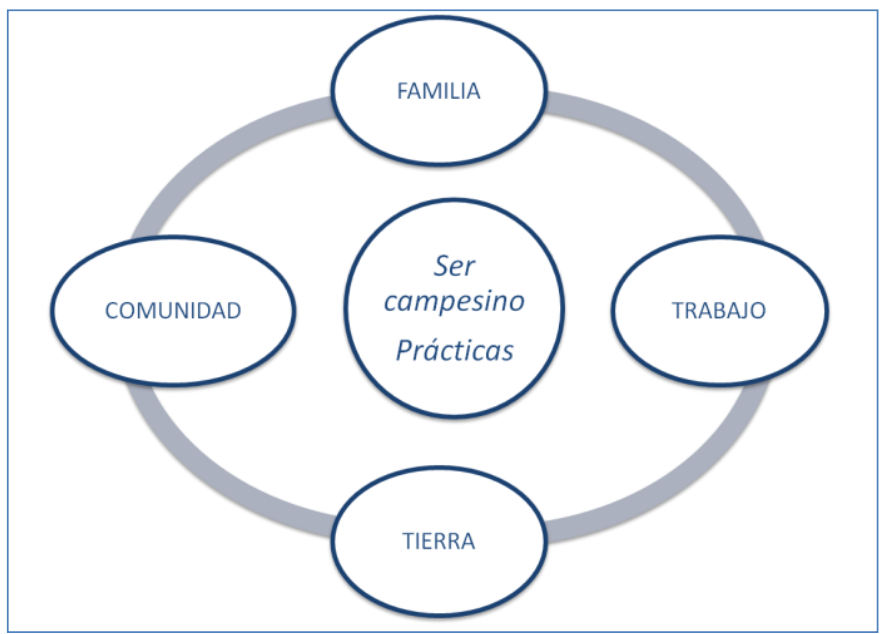

Fuente. Elaboración propia

Justamente es a partir de esta modelo de análisis que buscando expresar aquellas relaciones que articulaban el plano social con el plano espacial. En este sentido en el centro del análisis se ubicó al ser campesino y junto a él las prácticas espaciales, que para nosotros son la expresión y el modo de reproducir a ese ser campesino. Po otro lado, encontramos que la posibilidad de aprehender la estructura de lo campesino y de sus prácticas, pasa por el análisis del espacio familiar, comunitario y del trabajo no solo como unidades que dan sentido y soporte al centro sino como totalidades que hacen parte de los sujetos y por ende de sus prácticas. (capítulo III y IV) Hay que señalar que a pesar que no se desarrolló de manera independiente, la tierra como categoría relevante del modelo de análisis, se abordó como el medio o el marco a partir del cual se desarrollaron las anteriores relaciones, es decir que su tratamiento es implícito en el análisis que se presenta en los capítulos siguientes. 


\section{CAPÍTULO II}

\section{ESPACIO Y PRÁCTICAS ESPACIALES COMO MARCOS INTERPRETATIVOS DE LOS RETORNOS CAMPESINOS.}

Las aproximaciones teóricas que me han permitido acercarme a la naturaleza de las reconfiguraciones de las prácticas espaciales de familias campesinas retornadas en la subregión de los Montes de María, provienen de los trabajos de seis autores que plantean la relación entre el espacio, el territorio y las relaciones sociales: específicamente, frente a las categorías de espacio, espacialidad y prácticas espaciales, retomé los trabajos de Henry Lefebvre, The production of space (1994 [1974]); David Harvey, La condición de la modernidad (2008); Edward Soja, La espacialidad de la vida social (1985); Milton Santos, La naturaleza del espacio (2000); y frente a la categoría de territorio he abordado las perspectivas de Claude Raffestin, Por uma geografía do poder (1994) [1984]; y algunas apreciaciones recientes de la geografía brasilera, principalmente las elaboradas por Bernardo Mançano Fernandes 2008).

Siguiendo estas orientaciones, está investigación se plantea que las prácticas espaciales tienen su origen en las relaciones sociales, bajo esta interpretación, las prácticas espaciales son consideradas como el producto de las condiciones materiales e inmateriales que los actores configuran en procesos geohistoricamente dinámicos. La base de este principio es que el espacio no es un contenedor de experiencias sino que, por el contrario, es -a la vez- el objeto y el sujeto de dichas experiencias.

El develar dicha preposición obliga a preguntar sobre la naturaleza del espacio en relación a la teoría social y a las prácticas agenciadas por las familias campesinas retornadas. Siguiendo esta línea, un primer esfuerzo radica en pensar lo espacial como una categoría con potencial explicativo de lo social y en especial de los procesos generados por el retorno de población desplazada.

Como punto de partida es importante examinar el debate que hay en el seno de las ciencias sociales frente a las categorías de espacio y tiempo: 
El esfuerzo de una parte de las ciencias sociales por comprender la realidad como un conjunto contradictorio, lleno de interrelaciones, interdependencias y complejidades ha suscitado el acercamiento de diversas ciencias y/o campos del saber en lo que podría denominarse como una complementariedad epistemológica. Resultado de ello, el tiempo y el espacio tradicionalmente delimitados en disciplinas como la historia y la geografía, han estrechado caminos teórico-metodológicos, renovando la naturaleza de lo social en una interpretación de lo histórico y lo geográfico como una sola unidad de indagación.

A pesar de las tentativas epistemológicas que han propuesto la articulación de las viejas fronteras del conocimiento, todavía es frecuente encontrar estudios donde claramente persiste la vieja oposición entre la temporalidad y la espacialidad. El ambiente antagónico - y artificial- en el cual se inserta esta oposición, alimenta la ya normalizada separación de la «unidad» (espaciotiempo) en pequeñas unidades o fracciones (espacios-tiempos), donde cada una de las partes es reproducida junto a su correspondiente apariencia absoluta. De tal operación se deriva un enunciado cuyo orden analítico está guiado por una especie de aporía que antepone -generalmente- la mirada histórica por sobre la espacial. Esta enunciación tal como ha sido descrita, restringe las propiedades del espacio asumiéndolas como simples prolongaciones del paisaje natural o como referentes de localización. El espacio y todo lo que lo constituye es reducido a mero contenedor.

Pero, ¿qué repercusiones genera la contracción del concepto espacio en la construcción del conocimiento social? Considerando lo hasta acá expuesto, podríamos afirmar que la anterior operación (la fragmentación de la unidad espacio-tiempo y la posterior reducción de una de sus partes - el espacio-) insta a la configuración de un modelo epistemológico de expresión metafórica: esquema de pensamiento en el que se encarna un orden sustentado en alegorías, donde el significado, el sentido recto de los conceptos, se somete a la ambigüedad contenida en el uso y abuso del sentido figurado. Se utiliza por ejemplo, lo espacial o lo temporal como meros referentes ilustrativos, que soportados en una sobrevaloración figurativa desconocen el potencial explicativo de éstos. Justamente, Peña (2011) sostiene para el caso del territorio que: 
"El territorio puede ser todo o nada a la vez. Hablamos del cuerpo como territorio, el territorio como algo físico, algo imaginado, como naturaleza, como segunda naturaleza, como paisaje, como utopía, como posibilidad de acción, como lo fijo y simbólico (...) Y al final estamos confundidos. Incluso muchas veces se habla de espacio o territorio y ni siquiera se está hablando en términos de despliegue, de localización, de distribución, de implantación en la superficie terrestre, es decir, no se está pensando en términos de la diferenciación de un fenómeno en el espacio y, concomitantemente, no se está pensando en la importancia que la diferencia -o más bien la diferencia espacial- tiene para comprender la dinámica social" ( $p$ 17)

En medio de este encuadramiento metafórico no sólo se reduce el sentido recto de los conceptos sino que además los enmarca en simuladas relaciones. Se dice que el tiempo y el espacio son relacionales, pero esa relacionalidad -vista desde esta perspectiva- no es más que una figuración. Se fingen relaciones porque es imposible interpretar la realidad social como el resultado dialéctico de procesos históricos y geográficos.

Al afirmar que la relacionalidad manifestada en esta metaforización del conocimiento no es completa, entonces, lo que se podría afirmar por deducción lógica, es que las partes de la unidad no se encuentran en un mismo nivel de despliegue y elaboración, por el contrario, lo que se observa - casi como el proceso de subducción que ocurre entre las placas de la tierra- es la dilatación de una de las partes, mientras que la otra, es intencionalmente cubierta bajo una vestidura alegórica. De ahí que se constituya una «relacionalidad aparente» donde lo "uno" se diluye en lo "otro" -casi- hasta el punto de desvanecerse sin más pretensiones que la simple enunciación de una relación. Así, lo espacial o lo temporal terminan siendo meras expresiones disociadas.

Si relacionamos esta exigua manera de observar la unidad (espacio-tiempo) con los estudios que se han elaborado entorno al retorno de población desplazada, podríamos señalar que la base explicativa de la mayoría estos trabajos está constituida por el esquema metafórico anteriormente descrito; es decir, un análisis orientado por hiatos que fragmentan en unidades inconexas, lo que en sí mismo se entendería como unidad infragmentable (el espacio y el tiempo). Así los estudios sobre retorno han sido asumidos desde perspectivas descriptivas, 
narraciones lineales de acontecimientos o experiencias traumáticas derivadas del desplazamiento forzado (Esquivia, 2006; Puello, 2005) en este sentido se encuentran innumerables informes (ILSA, 2006a; 2006b; MOVICE, et al 2009; PCS, 2003) que intentan periodizar dichas experiencias a través de la reconstrucción -paso a paso- de los hechos, actores y dinámicas que motivaron el desplazamiento y el posterior retorno (determinantes del deseo de retorno). No obstante frente a la categoría espacial -y esto es casi una mandato- no se encuentra más que una descripción de los entornos físicos donde se dieron tales hechos, resaltando en ello los lugares de expulsión, las rutas de desplazamiento y los lugares de recepción; es en otras palabras, la localización del proceso de desplazamiento y retorno a través de cartografías estáticas.

Lo que de entrada desconoce esta postura, es que tanto los hechos como los actores y dinámicas que motivaron el desplazamiento forzado tienen un componente espacial, no solo por el hecho de estar localizados en un espacio determinado (un pueblo, un municipio, una región,...) sino porque éstos han sido producto y resultado de procesos geográficos dados históricamente.

$\mathrm{Si}$ aceptamos esto último, es incuestionable la necesidad de pensar la espacialidad "como un producto social y una parte integral de la construcción material y la estructuración de la vida social. Esto significa, por encima de cualquier otra cosa, que la espacialidad no puede ser comprendida y teorizada de manera apropiada, separadamente de la sociedad y de las relaciones sociales (...)" (Soja 1985:2), por consiguiente, es perentorio introducir epistemológica y teóricamente otros marcos de pensamiento que nos permitan vindicar el lugar de la espacialidad como eje de análisis en el estudio del retorno de población desplazada, sin olvidar en ello, la historicidad implícita de todo producto social, pues contrario a una interpretación determinista, lo que acá se procura es establecer el contenido espacial de los retornos sin desconocer la propia historicidad del caso estudiado. Siguiendo esta proposición, en este capítulo presentamos los lineamientos teóricos que orientaron la presente investigación y que permitieron comprender el contenido espacial del retorno campesino. En este sentido, exponemos -en primer lugar- las definiciones de espacio y espacialidad desde la premisa de que el espacio es un constructo 
social y material, cuyo proceso de conformación puede darse por procesos geográficos y prácticas espaciales.

En un segundo apartado, mostramos como estas prácticas espaciales están insertas e instituidas por diversas fuerzas que en determinados momentos y dinámicas pueden reconfigurar el sentido de las mismas. Siguiendo los trabajos de Mançano (2008) explicitamos la naturaleza de dichos cambios, a la vez que definimos nuestras categorías de análisis.

\section{Un recorrido teórico}

\subsubsection{El espacio y lo espacial.}

Tal como se ha afirmado, el estudio de la sociedad y de sus múltiples manifestaciones ha sido enmarcado -generalmente- dentro de un esquema donde prevalece la historicidad de los hechos, sobre la espacialidad de los mismos, eliminando así la potencialidad (relacional) de las propiedades que constituyen y son constituyentes de la realidad. De acuerdo con Foucault la obsesión modernista por la historia produjo una ciencia social en la que "el espacio fue tratado como lo muerto, lo fijo, lo no dialéctico, lo inmóvil. El tiempo, al contrario, era la riqueza, la fecundidad, la vida y la dialéctica" (Foucault 1980, citado en Delgado 2001:39)

Incorporar lo temporal como único rasgo, o como rasgo preferente de lo social, introduce una discontinuidad analítica, que en palabras de Bachelard (1984) genera, una especie de obstáculo epistémico que no permite hacer consciente las relaciones y el movimiento que subyace a toda acción humana. De ahí que la negación de la relación «espacio-tiempo» como una relación interdependiente, acentúe las expresiones morfológicas de lo social, conformando un tiempo vacio de espacio y un espacio vacío de tiempo.

Como respuesta a estas vacilaciones epistemológicas, algunos pensadores desde el campo de la geografía, el urbanismo, la arquitectura, la filosofía, la sociología -entre otras orillas disciplinares- (Lefebvre 1994 [1974], Ledrut 1977, Bachelard 1957, Foucault 1984, Raffestin 1980, Harvey 2008, Soja 1985, Santos 2000, Mançano 2008) han impulsado una revisión de lo espacial, concentrando 
sus observaciones en los elementos y las configuraciones espaciales (...) que dan expresión y forma material a la sociedad (Soja 1985:2).

Esta reteorización transformativa como la denominó Soja (1985), ha instituido una lectura geográfica en función de explicaciones y marcos interpretativos de la espacialización como producto y productora de vida social.

De las múltiples perspectivas que se han desarrollado entorno a lo espacial y a su relación con la sociedad, es necesario destacar las contribuciones derivadas del marxismo francés, y de la geografía marxista anglófona de los años 70's, así como algunas elaboraciones propias de la geografía latinoamericana, en su versión brasilera.

Estas aportaciones han dado forma a un cuerpo teórico cuyo principio ha alimentado -entre otros- la revolución de la geografía radical. Un movimiento cuyo discurso -contrario a la geografía cuantitativa- privilegia la dimensión social y dialéctica del espacio, pues asume que el espacio geográfico no es un ente natural, sino un producto social (Lefebvre 1994 [1974], Raffestin 1980, Harvey 2008, Soja 1985, Santos 2000, Mançano 2008). Aquí, el espacio y el territorio son asumidos como los resultados de las relaciones sociales, las contradicciones y las manifestaciones de poder entre los actores y estructuras productoras de espacio.

Bajo estas orientaciones, se rescata el principio de la espacialidad como el lugar (material e inmaterial) donde se entabla un conjunto de relaciones en el marco de procesos que fluyen permanentemente y que se modifican con la temporalidad de los fenómenos (Rogan, 2007:21) Desde esta premisa, se busca aprehender el movimiento, el emplazamiento de la realidad en una continua y reflexiva abstracción de lo morfológico, que para el caso del desplazamiento forzado y los procesos de retorno campesino en la subregión de los Montes de María permite -justamente- pensar el contenido espacial de éstos como el resultado de dinámicas producidas en medio de procesos geográficos, prácticas espaciales y relaciones socioterritoriales. La proposición que permite encuadrar esta última afirmación está dada por la afirmación de que "el espacio (social) es un producto (social)" (Lefebvre 1994: 17) de ahí que el espacio dentro de la geografía radical sea comprendido como una producción social. 


\subsubsection{La producción social del espacio social}

En contravía con aquellas manifestaciones que han banalizado el espacio y su potencial explicativo, es inexcusable señalar -siguiendo a Lefebvre (1994 [1974]) que "el espacio no es un objeto científico ajeno a la ideología o a la política; siempre ha sido político y estratégico. Si el espacio tiene un aura de neutralidad e indiferencia en relación con sus contenidos y de esta forma parece ser 'puramente' formal, el epitome de la abstracción racional, es precisamente porque ya ha sido ocupado y usado, y ya ha sido el centro de procesos pasados cuyas huellas no son siempre evidentes en el paisaje. El espacio ha sido moldeado y determinado a partir de elementos históricos y naturales, pero esto ha sido un proceso político. El espacio es político e ideológico. Es un producto literalmente lleno de ideologías" (Lefebvre, 1976:36).

Aquí Lefebvre no solo nos muestra el carácter y el contenido del espacio en términos políticos e ideológicos, más allá de ésto, lo que manifiesta es la relación de la producción del espacio con la cotidianidad y la materialidad de la vida misma (lo político, lo económico, lo cultural, lo tradicional,... son entendidos como expresiones espaciales). Las contradicciones, la resistencia, la experiencia, las instituciones, el poder, etc., son las unidades de un proceso histórico que otorga sentido y permite que los hombres en sus múltiples interacciones produzcan socialmente el espacio.

Desde esta óptica, el espacio (social) es entendido como el resultado de un proceso relacional que se interpone a la vieja noción de espacio absoluto (espacio contenedor). Para Lefebvre el espacio es entonces, una manifestación dinámica y muchas veces contradictoria del espacio real y el espacio mental; (...) En este sentido, si el espacio es a la vez real y mental, puede entonces abrirse a tres dimensiones, que [Lefebvre] denomina la triada (...)" (Ramírez, 2004: 65)

La triada, es la manera en que Lefebvre abstrae los momentos de la producción del espacio. Solo a partir de estos momentos se logra adentrar en el estudio de los procesos que genera la construcción del espacio en el contexto social. 
Es así que la producción del espacio debe ser aprehendido a partir de tres momentos -interconectados y/o complementarios-: las prácticas espaciales, las representaciones del espacio y los espacios de representación.

Veamos las principales características de estos momentos:

Figura 2. Momentos de la producción del espacio, según Henry Lefebvre

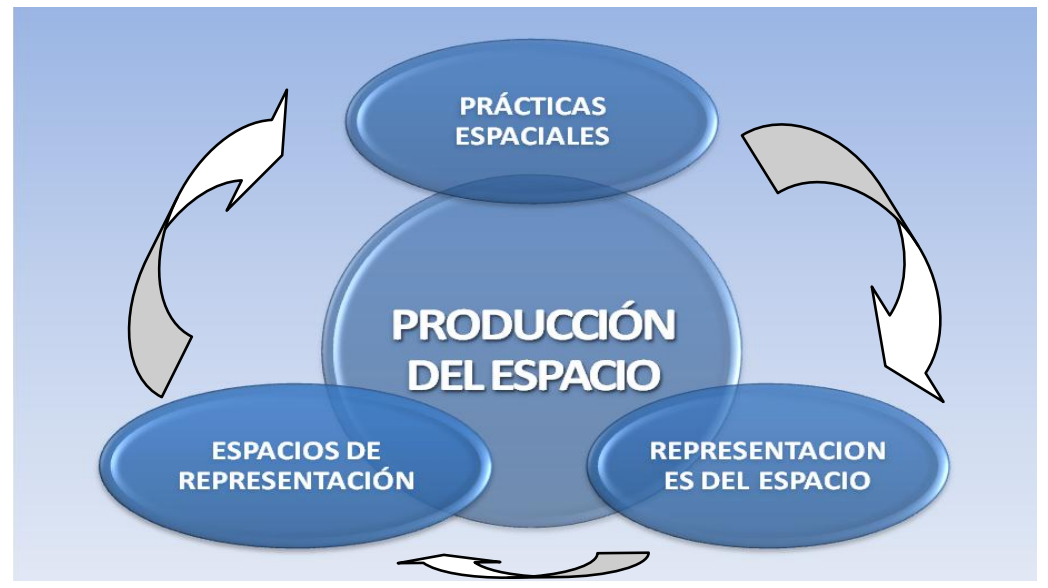

Fuente. Lefebvre 1991 [1974].

i) Las prácticas espaciales corresponden a una intersubjetividad de la experiencia que, para el caso de algunas comunidades campesinas de los Montes de María, son reflejadas en la conformación de un forma de vida, donde la vinculación con la tierra ha generado un particular modelo de producción no sólo económico (minifundio, autoabastecimiento) sino social, político y cultural. Las prácticas espaciales expresan la forma de vida atravesada por una apropiación y una identidad demarcada por el imaginario históricamente construido, vivido y heredado, que para nuestra investigación podrían ser resumidas en lo que se entendería como "ser un campesino montemariano";

ii) Por su parte, las representaciones espaciales se refieren a los saberes que se producen y reproducen en una conceptualización funcional y racionalizada del espacio, devienen de las instituciones y de los centros hegemónicos de poder. Lo que se representa es un ideal de espacio constituido y derivado de la lógica del desarrollo y del progreso. 
Justamente, la carga racionalizada que posee estas representaciones ha producido un proceso de comodificación y burocratización de la vida cotidiana, que en palabras de Habermas (2008) reproduce la colonización del mundo vida. Parte de esta representación espacial podemos verla en la subregión de los Montes de María en los Planes de Ordenamiento Territorial -POT' $S^{22}$ y a partir de las instituciones estatales ${ }^{23}$ que por medio de programas sociales ${ }^{24}$ pretenden orientar el "desarrollo" local de las comunidades retornadas sin tener en cuenta la situación de retorno sin acompañamiento estatal y sin garantías, a estas comunidades.

No obstante, esta pretendida cuantificación del espacio-tiempo lleva consigo un alto grado de resistencia, ya que, por su acumulado experiencial y relacional, las prácticas espaciales contienen un potencial para resistir la colonización de los espacios concretos.

iii) De ahí que en el tercer momento, los espacios de representación complejicen las prácticas espaciales, dando lugar a una apropiación más íntima de espaciotiempo, apropiación espacial que no "necesita obedecer a reglas de consistencia o cohesión; llenos de elementos imaginarios y simbólicos, tienen su origen en la historia, en la historia del pueblo y en la historia de cada individuo que pertenece a este pueblo" (Lefebvre 1991 [1974]: 41). De tal forma, los espacios de representación son a la vez sujeto de dominación y fuente de resistencia. (Oslender, 2001:83)

\footnotetext{
22 Planes de Ordenamiento Territorial o POT por su sigla son es en el ámbito del urbanismo, una herramienta técnica que poseen los municipios, los departamento y la nación para planificar y ordenar el territorio. Esta herramienta, fue institucionalizada en la Ley 388 de 1997.

${ }^{23}$ Entre las principales instituciones encargadas de orientar a la población en condición de desplazamiento encontramos a La Agencia Presidencial para la Acción Social y la Cooperación Internacional, -ACCIÓN SOCIAL, la cual desarrolla el Programa de Atención a la Población Desplazada, de acuerdo con lo contemplado en la Ley 387 de 1.997, reglamentada por el decreto 2569 del 12 de diciembre de 2.000. El programa se desarrolla bajo los parámetros operativos, procedimentales, y jurídicos planteados por el Plan Nacional de Atención Integral a la Población Desplazada.

${ }^{24}$ Entre dichos programas encontramos la estrategia denominada "Retornar es Vivir", a través del cual el Gobierno busca que miles de desplazados regresen a 206 poblaciones que abandonara por causa de la violencia. Cabe señalar como otros, casi siempre provienen del gobierno de turno, con lo cual se tienen a impor una determinada manera de poblar y de manejar el espacio.
} 
En medio de esta tensión (dominación-resistencia) subyacen manifestaciones conflictivas entretejidas y constituidas en el poder; éste es entendido no como una manifestación unidireccional de dominador sobre dominado, pues al contrario, se pone en juego un doble sentido de poder con diferentes niveles de exclusión, imposición y resistencia.

Tanto dominación como resistencia contienen entramados de poder con distintos estadios de proyección y práctica, dados por la naturaleza de los conflictos (historicidad y espacialidad).

Frente a este entramado (poder, resistencia y dominación) Sharp (2000, citado en Oslender, 2008) afirma que la resistencia implica poder, lo requiere, lo libera y genera efectos de poder tanto como lo hace la dominación, con lo cual se genera un poder resistente como catalizador constructivo y positivo de un contraespacio.

Estos contraespacios son entendidos como la concreción de espacios alternativos; son la respuesta a la colonización del mundo vida. A pesar que los contraespacios como contenidos de resistencia son construidos en el tercer momento de la producción social del espacio, es necesario leerlos simultáneamente a los otros dos momentos, ya que lo vivido, lo percibido y lo concebido están imbricados de tal forma que sus límites se desbordan entre sí, conduciendo a una interdependencia y complementariedad que en la práctica son imposibles de separar.

Ahora, si entendemos que las relaciones de poder o los entramados de poder son el resultado de procesos dialécticos dados histórica y geográficamente, entonces, estas relaciones podrían ser leídas junto a otras manifestaciones y/o condiciones de mayor envergadura en la producción y representación espacial, a saber: los sistemas sociopolíticos-económicos. Bajo esta óptica, los sistemas sociales producidos y reproducidos en un tiempo y espacio determinado, influirían en las representaciones de mundo y -claro está- en las representaciones espaciales de los sujetos de ese tiempo y espacio determinado. Esta idea puede ser entendida si ubicamos los sistemas sociales dentro de una continua tensión entre posibilidad y limitación (Giddens 1984), es 
decir, entre sistemas que posibilitan y limitan -muchas veces de forma contradictoria- reproducciones y representaciones de vida.

De ahí que la producción social del espacio -también- esté atravesada por relaciones más amplias (estructurales) que limitan o posibilitan discursos, procesos y prácticas tanto en escenario locales como en escalas regionales, nacionales y globales. Entre estas estructuras, se destaca por su capacidad de producir espacios y representaciones espaciales, el sistema económico capitalista.

Fijarnos en este sistema y en su necesidad de producir espacios, nos impone la necesidad de retomar la estructura material como punto de partida en la construcción y develación de lo espacial.

\subsubsection{La estructura material en las prácticas espaciales}

Con la aceleración de los procesos de producción después de la segunda fase de la revolución industrial y hoy bajo nuevos modelos de acumulación de capital; el tiempo y el espacio han sido objeto de una serie de transformaciones (de tipo ontológica, epistemológica y material) que ha alterado las cualidades objetivas con las cuales no sólo comprendíamos este binomio sino también nuestra propia lectura de mundo.

Justamente, las contradicciones manifiestas por el sistema capitalista son la base para la reelaboración teórica que elabora Harvey (2008) sobre los tres momentos propuestos por Lefebvre.

Básicamente, lo que observa Harvey en los tres niveles (lo vivido (experiencia), lo percibido (percepciones) y lo concebido (imaginación) es que a pesar del anuncio de Lefebvre (1991 [1974]), éste no presta mayor atención a las relaciones sociales de producción y a los conflictos generados por éstos, con lo cual se desdibuja -según Harvey- el epicentro dialéctico de la producción espacial. Dicho de otra manera, "Harvey considera que Lefebvre va demasiado lejos y le atribuye una independencia exagerada a cada uno de estos elementos del espacio, olvidando que la contradicción fundamental en las sociedades son, las contradicciones de clase" (Peña, 2011:37) Bajo este presupuesto, Harvey adjunta cuatro aspectos a la matriz ya propuesta por Lefebvre, centrando su 
análisis en las prácticas espaciales a partir de: i) Accesibilidad y distanciamiento;

ii) Apropiación y uso del Espacio; ii) Dominación y control del espacio y; iii)

\section{Producción del espacio. (Ver cuadro 1)}

\section{Cuadro1. Matriz de Prácticas espaciales según Harvey.}

\begin{tabular}{|c|c|c|c|c|}
\hline & $\begin{array}{l}\text { Accesibilidad } \\
\text { distanciamiento }\end{array}$ & $\begin{array}{l}\text { Apropiación y uso } \\
\text { del espacio }\end{array}$ & $\begin{array}{l}\text { Dominio y control } \\
\text { del espacio }\end{array}$ & $\begin{array}{l}\text { Producción del } \\
\text { espacio }\end{array}$ \\
\hline $\begin{array}{l}\text { Prácticas } \\
\text { materiales } \\
\text { espaciales } \\
\text { (experiencia) }\end{array}$ & $\begin{array}{l}\text { Flujos de bienes, } \\
\text { dinero, personas, } \\
\text { fuerza de trabajo, } \\
\text { información.; sistemas } \\
\text { de transporte y } \\
\text { comunicaciones; } \\
\text { jerarquías urbanas y } \\
\text { de mercado; } \\
\text { aglomeración }\end{array}$ & $\begin{array}{l}\text { Usos de la tierra y } \\
\text { ambientes } \\
\text { construidos; } \\
\text { espacios sociales y } \\
\text { otras designaciones } \\
\text { de «territorios»; } \\
\text { redes sociales de } \\
\text { comunicación y } \\
\text { ayuda mutua }\end{array}$ & $\begin{array}{l}\text { Propiedad privada } \\
\text { de la tierra; } \\
\text { divisiones estatales } \\
\text { y administrativas del } \\
\text { espacio; } \\
\text { comunidades y } \\
\text { vecindarios } \\
\text { exclusivos; } \\
\text { zonificación } \\
\text { excluyente y formas } \\
\text { de control social } \\
\text { (control policial y } \\
\text { vigilancia) }\end{array}$ & $\begin{array}{l}\text { Producción de } \\
\text { infraestructuras } \\
\text { físicas (transporte } \\
\text { y comunicaciones; } \\
\text { ambientes } \\
\text { construidos; } \\
\text { renovación } \\
\text { urbana, } \\
\text { organización } \\
\text { territorial } \\
\text { infraestructuras } \\
\text { sociales (formales } \\
\text { e informales) }\end{array}$ \\
\hline $\begin{array}{l}\text { Representaciones } \\
\text { del espacio } \\
\text { (percepciones) }\end{array}$ & $\begin{array}{l}\text { Medidas de distancia } \\
\text { social, sicológica y } \\
\text { física; trazado de } \\
\text { mapas; teoría de la } \\
\text { «fricción por } \\
\text { distancia» (principio } \\
\text { del menos esfuerzo, } \\
\text { física social, } \\
\text { clasificación de un } \\
\text { lugar central bueno y } \\
\text { otras formas de teoría } \\
\text { de la localización) }\end{array}$ & $\begin{array}{l}\text { Espacio personal; } \\
\text { mapas mentales de } \\
\text { un espacio } \\
\text { ocupado; jerarquías } \\
\text { espaciales; } \\
\text { representación de } \\
\text { simbólicas } \\
\text { espacios; } \\
\text { «discursos } \\
\text { espaciales» }\end{array}$ & $\begin{array}{l}\text { Espacios } \\
\text { prohibidos; } \\
\text { «imperativos } \\
\text { territoriales»; } \\
\text { comunidad; cultura } \\
\text { regional; } \\
\text { nacionalismo; } \\
\text { geopolítica; } \\
\text { jerarquías. }\end{array}$ & $\begin{array}{l}\text { Sistemas nuevos } \\
\text { de trazados de } \\
\text { mapas, } \\
\text { representación } \\
\text { visual, } \\
\text { comunicación, } \\
\text { etc.; nuevos } \\
\text { «discursos» } \\
\text { artísticos y } \\
\text { arquitectónicos; } \\
\text { semiótica }\end{array}$ \\
\hline $\begin{array}{l}\text { Espacio de } \\
\text { representación } \\
\text { (imaginación) }\end{array}$ & $\begin{array}{l}\text { Atracción/repulsión; } \\
\text { distancia/deseo; } \\
\text { acceso/rechazo; } \\
\text { trascendencia: «el } \\
\text { medio es el mensaje» }\end{array}$ & $\begin{array}{lr}\text { Familiaridad; } & \text { el } \\
\text { hogar y la } & \text { casa; } \\
\text { lugares } & \text { abiertos; } \\
\text { lugares } & \text { de } \\
\text { espectáculo } & \text { popular } \\
\text { (calles, } & \text { plazas, } \\
\text { mercados); } & \\
\text { iconografía y } & \text { graffiti; } \\
\text { publicidad }\end{array}$ & $\begin{array}{l}\text { No familiaridad; } \\
\text { espacios temidos; } \\
\text { propiedad } \\
\text { posesión; } \\
\text { monumentalismo y } \\
\text { espacios de ritual } \\
\text { construidos; } \\
\text { barreras simbólicas } \\
\text { y capital simbólico; } \\
\text { construcción de una } \\
\text { «tradición» espacios } \\
\text { de represión. }\end{array}$ & $\begin{array}{l}\text { Proyectos } \\
\text { utópicos; paisajes } \\
\text { imaginarios; } \\
\text { ontologías y } \\
\text { espacio de la } \\
\text { ciencia ficción; } \\
\text { dibujos de } \\
\text { artistas; } \\
\text { mitologías } \\
\text { espacio y el lugar; } \\
\text { poética del } \\
\text { espacio, espacios }\end{array}$ \\
\hline
\end{tabular}




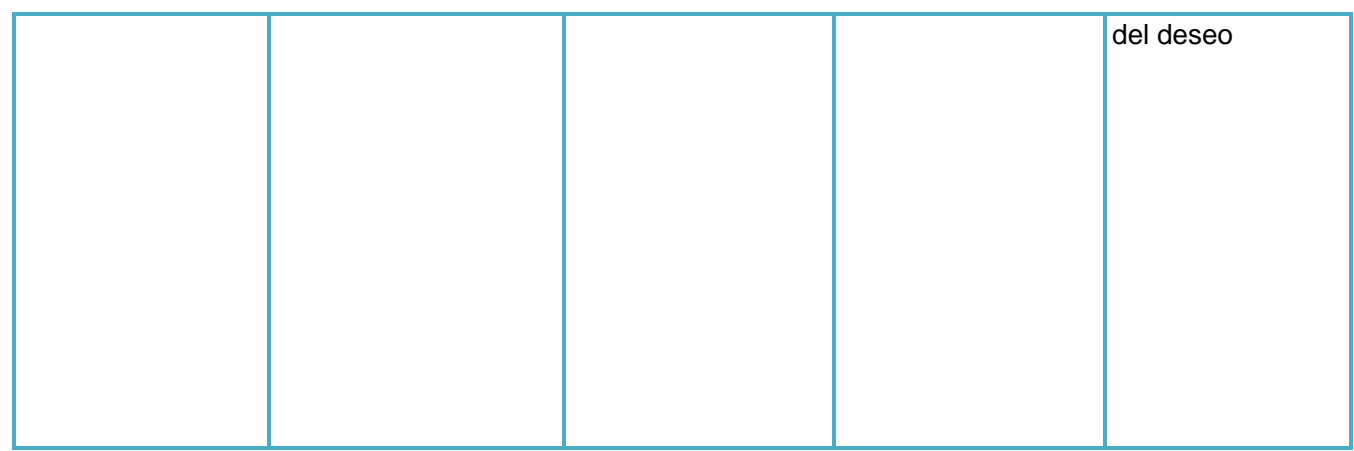

Fuente. Harvey 2008: 244-245

Con esta propuesta, Harvey ofrece una ilustración mucho más precisa de los elementos con los que se relaciona la espacialidad con el sistema económico, estableciendo una matriz donde enfatiza las expresiones espaciales de las relaciones sociales de producción. De acuerdo con Peña (2011), a "Harvey le interesa enfatizar en el carácter contradictorio y político de la producción del espacio [...] por lo que sus ideas ofrecen, sobre todo, argumentos para abordar las conflictualidades sociales desde una perspectiva materialista" ( $p 38$ )

Bajo esta perspectiva materialista, Harvey concibe el espacio social casi como un subproducto de los modos de producción, es decir "el espacio es lo que la economía hace de él, y el paisaje económico es el producto de la estructura total del sistema económico en el cual actúan los individuos que toman decisiones económicas. [...] Por tanto, las explicaciones sobre la localización y el cambio espacial toman como base las condiciones estructurales que subyacen en la sociedad capitalista en que se generan las estructuras espaciales, y hacen más énfasis en el análisis de los procesos de producción que en la localización como hecho particular" (Delgado, 2003: 81)

Al considerar esta base analítica, es necesario subrayar que a pesar que Harvey es uno de los referentes que nos permite pensar el espacio como producto social, rescatando en ello, la materialidad y las contradicciones inherentes de dicha producción, el énfasis que él da al espacio no es del todo reproducida en este trabajo, pues la propia naturaleza de nuestro objeto de estudio no nos permite centrar -exclusivamente- nuestro análisis a los modos de producción, categoría clave para Harvey. No obstante la contribución que el mismo Harvey hace de la triada de Lefebvre, si nos permite incorporar dos de sus referentes: la 
apropiación y el dominio del espacio; pues estos son, justamente, los ejes que nos permiten aprehender los cambios y/o reconfiguraciones en las prácticas espaciales de las familias retornas en relación a las maneras en que ellas ocupan, usan, controlan y dominan su espacio después de los procesos de retorno.

Por ende, la investigación prestó un mayor interés en las unidades relacionadas con la apropiación y el dominio del espacio, pues tal como encontramos, analizar los procesos de retornos a través de estas prácticas, permite acercarse a los elementos socioespaciales que intervienen y alimentan las dinámicas de retorno de la población desplazada. La primera de estas prácticas -la apropiación del espacio-, examina la forma en que el espacio es ocupado por objetos (parcelas, carreteras, fuentes de agua, caminos, paisaje campesino,...); actividades (usos de la tierra, especialmente los relacionados con los cultivos y otros usos familiares y comunitarios del espacio); e individuos, clases u otras agrupaciones sociales. Según Harvey, esta apropiación [vista] de manera sistematizada e institucionalizada puede entrañar la producción de formas territoriales de solidaridad social (2008:246), con lo cual, dicha apropiación carga consigo fuertes impresiones en lo comunitario y lo tradicional.

Por su parte, el dominio del espacio refleja la forma en que individuos o grupos dominan la organización y producción del espacio, por medio legales o extralegales, a fin de ejercer un mayor grado de control sobre la fricción por distancia o sobre la manera en que el espacio es apropiado por ellos o por otros (Harvey, 2008:246). El pensar las prácticas de dominio espacial, tal como se verá en las siguientes líneas, nos ha impuesto la necesidad de establecer una fuerte relación con otras categorías claves en el análisis de los cambios espaciales, tal como lo es el territorio y los procesos derivados de éste, como la territorialización, la reterritorialización y la desterritorialización. Relaciones que a continuación describimos.

2.2. Una lectura de los retornos campesinos desde las prácticas espaciales.

2.2.1. Acerca de las configuraciones y las reconfiguraciones 
Hasta el momento hemos abordado la una lectura geográfica del espacio desde un marco referencial, claramente interdisciplinario, en donde las categorías de tiempo-espacio y espacio se encuentran en un constante diálogo con los presupuestos de la teoría social. De hecho, la construcción teórico descrita anteriormente, nos muestra la intensión de redimensionar el abordaje académico del estudio de la realidad social y especialmente del estudio de los retornos campesinos, por medio de una lectura social y material de las prácticas espaciales, donde la relación entre el espacio percibido, concebido y vivido con la producción y la reproducción material de la sociedad son la base de la estructura espacial de la sociedad.

No obstante, en lo expuesto, no se ha aclarado el por qué hablamos de reconfiguración cuando nos referimos a las actuales prácticas espaciales de las familias campesinas retornadas. Para aclarar este vacío, hay que recordar que las prácticas espaciales las entendemos como la articulación y la expresión interdependiente de tres dimensiones de la producción espacial (lo percibido, lo concebido y lo vivido), cuya naturaleza posee un importante sentido, tanto a nivel simbólico como en las manifestaciones más materiales de la vida social.

Como el marco en el cual se insertan estas prácticas es eminentemente social, éstas deben ser entendidas como producto socio-histórico-espacial; ésto es, como producto y productor que en medio de sistemas de acciones y sistemas de objetos (Santos, 2000), configuran determinadas maneras de asumir y producir el espacio. En este sentido, sería pretencioso considerarlas como adjetivos fijos e inmutables que expresan estabilidades en sus propiedades constitutivas ${ }^{25}$. Contario a ello, dichas prácticas están en constante construcción, por lo que no pueden ser imaginadas como unidades acabadas. Por ende en toda práctica espacial subyace una continua modificación de las relaciones simbólicas y

\footnotetext{
${ }^{25}$ A pesar de que las prácticas espaciales son el resultado de una continua interacción histórica y espacial, hay que señalar que los cambios que se dan en estás, por ser parte de un proceso, que por lo general son de largo aliento, no son percibidos fácilmente por los sujetos y las comunidades que los producen, por lo que en muchas ocasiones podrían parecer estables o contar con cierta estabilidad; tal vez, estos cambios o modificaciones podrían ser más fácilmente identificados en los ajustes propios que las generaciones hacen de sus propia representación espacial.
} 
materiales que determinan la producción que los sujetos hacen del espacio. Entonces, si reconocemos que las propiedades constitutivas de las prácticas espaciales están en una constante configuración sociohistórica (un constante movimiento), ¿por qué insistimos en referirnos a una reconfiguración para explicar los cambios en las prácticas espaciales de las familias retornadas en los Montes de María?

La respuesta está asociada al sentido que le damos al prefijo «re» dentro de la continua configuración de las propiedades espaciales. Para nosotros la reconfiguración consiste en una intensificación del acto de configurar, es decir, la magnitud de la configuración sobrepasa el ritmo social e histórico que alimenta los cambios que puedan darse dentro de una comunidad en relación a sus prácticas en y por el espacio y el tiempo; en esta reconfiguración el desplazamiento forzado se constituye en la fuerza aceleradora de cambios, pues éste irrumpe el continuo espaciotemporal de las comunidades campesinas, instaurando un nuevo régimen de relacionamiento entre los sujetos (individuales y colectivos) y su posición en el espacio.

De tal manera, las modificaciones en los sentidos, en las apreciaciones y en las acciones de las familias retornadas frente a su espacio y a su producción, contiene un alto grado de transformación que instaura en muy corto tiempo (siete años para el caso de las comunidades de Borracheras y VillaColombia), nuevas formas de disponer los elementos y/o las propiedades «sociales y naturales» que componen un determinado espacio.

Estas «configuraciones intensificadas» que mediadas por fuerzas externas a las mismas dinámicas y relaciones sociales de las comunidades campesinas (escenarios de terror por causa del conflicto armado, principalmente generados por masacres y el desplazamiento forzado; nuevas relaciones de trabajo y dinámicas económicas; etc.,) generan fuertes modificaciones en las maneras en las que ellas habían producido y reproducido el espacio, y claro está su propia existencia vital. De esta manera, observamos como los campesinos retornados en su relacionamiento familiar, comunitario, tradicional y de trabajo (en la tierra) han apropiado otras formas de reproducirse en la subregión. Por ende, la reconfiguración a la que nosotros hacemos alusión, responde - si se quiere- a la 
recomposición acelerada de las relaciones constitutivas entre el sujeto y su producción espacial.

Dicha reconfiguración se encuentra establecida por una serie de relaciones, yuxtaposiciones y contradicciones cuya naturaleza puede observarse más nítidamente en los procesos y movimientos geográficos (Mançano, 2008) que los sujetos y sus dinámicas sociales recrean constantemente.

2.2.2. El movimiento en el espacio: espacializando y territorializando el retorno campesino

Para entender los procesos que han atravesado la reconfiguración de las prácticas espaciales de las familias campesinas de Los Montes de María, hemos articulado al marco teórico descrito anteriormente, otros presupuestos y categorías provenientes del geógrafo Bernardo Mançano Fernandes (2005, 2008). Esta elección nos ha conducido a la introducción de una serie de elementos que en un principio no estaban contemplados, pero que en el trasegar investigativo, se fueron constituyendo en valiosas ayudas para el análisis de la realidad espacial de los retornos, a saber: la multidimensionalidad del espacio y la comprensión del movimiento espacial como un proceso geográfico.

Estos dos elementos permiten una relectura de las intrincadas relaciones que reconfiguran las prácticas espaciales de las familias campesinas. Veamos algunas consideraciones:

La multidimensionalidad del espacio solo puede ser aprendida, si reconocemos la complejidad que enmarca las múltiples variantes que producen y reproducen el espacio. Diferentes relaciones, contradicciones e intencionalidades constituyen diferentes espacios, pero éstos, solo son una parte, una cara de un gran complejo espacial, por lo que la multidimensionalidad es entendida como un proceso de intensa yuxtaposición de espacios creados y recreados por las múltiples manifestaciones de la realidad social. Así, la multidimensionalidad toma forma en el amalgamamiento de planos materiales e inmateriales creados y transformados por las relaciones sociales (y sus manifestaciones) en el espacio. 
No obstante se asume el espacio como un cuerpo único y terminado en sí mismo, que reproduce análisis parciales, unidimensionales, sectoriales, lineares, uniescalares, incompletos y en consecuencia limitados (Mançano, 2005:275) que abstraen -anulando casi por completo- el intenso proceso de completividad, conflictividad e interacción del espacio.

Ahora, si entendemos que el espacio es una manifestación multidimensional de otros espacios, entonces, las prácticas espaciales que los producen y los reproducen, también guardarían esa relación de multidimensionalidad. De esta manera, las prácticas espaciales son el resultado de diferentes construcciones e interacciones de los sujetos (individuales y colectivos) con su espacio. Estas construcciones responden de cierto modo a las diferentes dimensiones y condiciones que determinan algunos roles y por ende ciertas perspectivas de observar, producir y ajustar espacios. Así el espacio familiar, el espacio comunitario, el espacio cultural, el espacio político, el espacio económico... dan sentido y coherencia a mi posición y a la posición de los demás en el espaciotiempo. En consecuencia, estas prácticas no obedecen a manifestaciones rígidas sino que por el contrario solo pueden ser comprendidas desde las diferentes dimensiones que configuran dichos espacios.

Para el caso de las familias retornadas en las veredas de Borracheras y VillaColombia en los Montes de María, hemos enfocado nuestra atención en las prácticas espaciales de apropiación y domino, no obstante estas -respondiendo a la cualidad de la multidimensionalidad- no podrían ser apropiadas desde una mirada fragmentaria, es decir, desde una sola concepción de lo espacial, por el contario, lo que hemos tratado de observar son los elementos transversales que alimentan o hacen parte de dichas prácticas. De este modo encontramos que analizar las prácticas de apropiación y dominio espacial de las familias retornadas es un ejercicio que no puede desvincular los diferentes entramados individuales y colectivos que dan sentido a la producción espacial, por lo que -tal como se verá en el capítulo 4- mostraremos como la dimensión familiar, del trabajo, de lo cultural, lo tradicional y lo comunitario son componentes y reflejos de las actuales reconfiguraciones de las prácticas espaciales de estas comunidades. 
Otra categoría que precisa de explicación es la de proceso geográfico. Para esta investigación la noción de proceso geográfico elaborada por Mançano, nos ha permitido vislumbrar cómo la naturaleza del desplazamiento y el retorno están íntimamente relacionados con movimientos en el espacio. El que el movimiento sea una característica del desplazamiento forzado y del retorno parecería una deducción lógica, no obstante la importancia analítica que esto supone no ha sido abordada lo suficiente por los diferentes trabajos que se han preguntado sobre esta temática, lo cual ha reproducido una idea simplista -en cuanto a lo espacial se refiere- del proceso y de sus implicaciones en las personas y sus relaciones sociales, así como en los lugares de recepción y de expulsión de campesinos.

De acuerdo con Mançano (2005), los procesos geográficos son definidos como las configuraciones iniciales y finales que se encuentran en medio de las producciones y representaciones del espacio; en este sentido, los procesos geográficos se pueden entender como los centros dinamizadores de la perenne locomoción y transformación de las propiedades de los espacios y por ende, de los territorios. Esta locomoción, constantemente redimensiona las cualidades y propiedades de lo espacial, lo cual se refleja en acciones, contradicciones, relaciones y expresiones materiales e inmateriales. Por otro lado, estos procesos no obedecen a reglas fijas, por el contrario, son resultado de la interacción de los hombres y sus relaciones sociales, al igual que el espacio, los procesos geográficos y los movimientos contenidos en ellos, son socialmente producidos.

Ahora, frente a esta idea de movimiento es preciso señalar que éste no solamente atraviesa o es constitutivo del espacio en sí, sino que también está significando y resignificando constantemente el dominio espacial más próximo: el territorio. En este sentido, abría que aclarar que a pesar que nuestra categoría central es la «práctica espacial», la naturaleza de la investigación nos obliga a leer estas prácticas -sobre todo, la práctica de dominio espacial- junto al componente territorial, pues es en este último, donde se observan los modos en los que se han dado las reconfiguraciones acá estudiadas.

Bajo esta premisa, considero importante, antes de proseguir con la presentación conceptual del proceso geográfico, dar un espacio para exponer la implicación 
territorial en las prácticas espaciales de las familias campesinas retornadas. En primer lugar, hay que especificar que el territorio es concebido como el espacio apropiado por una determinada relación social que lo produce y lo mantiene a partir de una forma de poder (Mançano, 2005:75) que en medio de una constante tensión entre dominación y resistencia, es cargado de sentido. (Raffestin, [1984]).

Bajo esta enunciación, los límites que conceptualmente separarían el espacio y el territorio no son clara y fácilmente diferenciables; como ejemplo de ello, Mançano afirma que,

[...] "todo territorio es un espacio (no siempre geográfico, puede ser social, político, cultural, cibernético, etc.). Por otro lado, es evidente que no siempre y no todo espacio es un territorio". (Mançano, 2005:277)

Frente a este postulado es importante recordar que [...] "Son las relaciones sociales las que transforman el espacio en territorio y viceversa. Siendo el espacio un a priori y el territorio un a posteriori". (Fernandes, 2005:276) Lo anterior nos lleva a sostener que son las relaciones sociales las que movilizan continuamente la línea que delimita tanto el espacio como el territorio, en este punto, se observa un entrecruzamiento, casi intangible, entre uno y otro concepto. El grado de complejidad en este ejercicio de diferenciación conceptual, es contenido bajo la idea misma de la multidimensionalidad. De ahí que al observar las prácticas espaciales debamos prestar atención a su representación territorial, especialmente al referirnos a las prácticas de dominio. Pues como fue descrito anteriormente, éstas guardan especial relación con las formas particulares y colectivas en la que se ejerce control y dominio de un determinado espacio (territorio).

Así, las prácticas espaciales abordadas desde su componente social, se inscriben en un manifiesto y dinámico contexto de contradicciones, solidaridades y conflictualidades que producen dentro de un mismo espacio, diferentes tipos de territorios y territorialidades, así -a través de en un entramado de relaciones: sociales, de poder, económicas,...etc., -se amplía el sentido y el significado que las personas otorgan a su espacio más próximo «territorio». 
Lo anterior reafirma el postulado de la multidimensionalidad, en el sentido de proponer un espacio constituido por múltiples manifestaciones y producciones de la realidad social (la configuración espacial en los Montes de María da cuenta de este proceso).

Retomando nuestro hilo argumental en torno a los procesos geográficos, pero sin olvidar en ello, estas últimas anotaciones, es importante aludir que estas múltiples manifestaciones, producciones, representaciones e intencionalidades configuradas en y por la relacionalidad social, llevan consigo una dinamicidad, que connaturalmente se traduce en movimiento. De tal manera, podríamos caracterizar dichos movimientos o procesos geográficos como: expansión, flujo, multidimensionamiento, creación y destrucción (Mançano, 2005:276)

La expresión más conocida de estos movimientos en el territorio pueden ser resumidos como la TDR (territorialización, desterritorialización y reterritorialización), en este sentido Mançano (2005) sostiene que del mismo modo que algunas [relaciones sociales] transformaron espacios en territorios, éstos también se territorializan y son desterritorializados y se reterritorializan y cargan consigo sus territorialidades, sus identidades territoriales, construyendo una pluriterritorialidad. [...] (Mançano, 2005: 277.)

En su conjunto estos movimientos representan la complejidad y la conflictualidad de la multidimensionalidad, tanto del espacio como del territorio. Por esta razón, estos movimientos no son ni pueden realizarse de forma independiente, ya que uno puede ser condición para que se pueda realizar el otro y viceversa. Por ejemplo, expansión y destrucción; creación y reflujo ocurren paralelamente en un proceso de constante yuxtaposición.

Es así, que desde una perspectiva espacial abordamos el análisis de los retornos campesinos y de las reconfiguraciones en las prácticas espaciales desde dos rutas teóricas: i) las prácticas espaciales (inspirada por la producción social y material del espacio de Henry Lefebvre y David Harvey) y, ii) el reconocimiento de que las prácticas espaciales y los retornos campesinos están constituidos - a la par que el espacio- por una multidimensionalidad y por una serie de elementos fundados en y por los procesos geográficos. 


\section{3 ¿Desplazado, retornados o campesinos? La pregunta por el sujeto.}

Además de las anteriores aproximaciones teóricas conceptuales, aún precisamos definir la población con la cual se va a trabajar. Hasta el momento y de forma expositiva hemos enunciado sin ninguna diferenciación: población, campesinos, comunidad y familia en relación con el desplazamiento. En este sentido es preciso señalar que nuestro estudio se va a centrar en la categoría de «Campesino desplazado retornado» cuyo abordaje va a considerar tanto su relacionamiento con el ámbito familiar (familia campesina) como con el ámbito comunitario (vecindad y sentido comunitario). El centrar nuestro análisis entorno a esta categoría, nos obliga a precisar los lugares desde los cuales estamos comprendiendo dicha categoría.

En primer lugar, esta decisión responde a la necesidad de revisar y de redefinir a los sujetos que viven o vivieron el desarraigo (desplazados) así como a los que por diferentes razones decidieron retornan a sus hogares (retornados). Al respecto, es común encontrar en la literatura que aborda el tema del desplazamiento y el retorno definiciones entorno a estos sujetos desde acepciones jurídicas, por ejemplo, un desplazado es toda persona que se ha visto forzada a migrar dentro del territorio nacional abandonando su localidad de residencia o actividades económicas habituales, porque su vida, su integridad física, su seguridad o libertad personales han sido vulneradas o se encuentran directamente amenazadas, con ocasión de cualquiera de las siguientes ocasiones: conflicto armado interno, violencia generalizada,(...) (Artículo 1 de la Ley 387 de 1997) El problema de este tipo de definición no radica en lo que define sino en la interpretación que se le ha dado, no solamente en el escenario investigativo sino en el escenario social. El desplazado, entonces, tiende a ser un sujeto homogenizado, una designación dada por el desarraigo que minimiza el sistema de autoreconocimiento y heteroreconocimiento (Giménez,1997), es decir el cómo me leo y el cómo me leen los demás es mediado necesaria y casi que exclusivamente, por la situación del desplazamiento: el niño desplazado, la mujer desplazada, el indígena desplazado son tan solo algunas de las formulaciones a partir de las cuales se expresa una imposición o una marcación 
identitaria (Giménez 1997; Restrepo, 2007) alrededor del desplazamiento. Así mismo, el «retornado» entendido como el «desplazado» que decide "regresar" o "volver" a su tierra, es leído como una continuación de esa representación homogenizada del desplazado.

Alejándonos de dichas interpretaciones, nuestro interés radica no en el desplazado o el retornado como expresiones totalizantes de unos sujetos en unas circunstancias particulares, sino en los sujetos y las prácticas que éstos crean y recrean en condiciones sociohistóricas particulares el "desplazamiento" y el "retorno". Entendido así, es el sujeto campesino en condición de desplazamiento y de retorno el que produce y reproduce las prácticas que nosotros estudiamos. En síntesis el campesino se sitúa en el centro de las experiencias que otorgan sentido y producen las prácticas espaciales y el desplazamiento y el retorno son las circunstancias sociohistóricas que determinan o influyen en dicho proceso de producción.

Ahora, el ubicar al campesino en el centro del proceso de producción de prácticas espaciales nos lleva a precisar otro aspecto fundamental para la presente investigación: la idea sobre el campesino que se desarrolla en este trabajo tiende a separarse de la clásica perspectiva economicista de algunos autores como Chayanov (1974) y Shanin (1979) donde el campesino y lo campesino son limitados a su función o relación productiva ${ }^{26}$. Bajo este enfoque economicista, las demás relaciones que se encuentran enmarcados en torno al campesinado tienden a reproducir esta misma racionalidad, por lo que la familia campesina es comprendida solamente como unidad de producción ${ }^{27}$.

\footnotetext{
26 Para Shanin (1979) "El campesino es una entidad social preindustrial que lleva a la sociedad contemporánea elementos específicos de una estructura social, una economía y una cultura, diferentes, más antiguas" (Shanin 1979, 218), (...) "El campesinado se compone de pequeños productores agrícolas que, con la ayuda de equipo sencillo y el trabajo de sus familias, producen sobre todo para su propio consumo y para el cumplimiento de sus obligaciones con los detentadores del poder político y económico. Tal definición implica una relación específica con la tierra, con la granja familiar campesina y con la comunidad aldeana campesina como las unidades básicas de la interacción social; una estructura ocupacional específica, e influencias de la historia pasada y patrones específicos de desarrollo (Shanin 1979, 215).

${ }^{27}$ Tal como lo expuso Chayanov, "la actividad económica de la familia campesina se rige por el equilibrio existente entre el consumo de los miembros de la misma y la auto explotación del trabajo. El agrónomo ruso elabora la ecuación de trabajo y consumo, diseñando una matriz donde se combinan el tamaño de la
} 
Lejos de esta apreciación, pero consientes del componente material y de las particularidades propias de las relaciones sociales que constituyen la economía campesina, hemos querido recuperar al campesino no solamente como homo economicus sino como sujeto social.

Pensar al campesino como sujeto social, es un esfuerzo por comprender la red de relacionamiento y la complejidad sociohistórica que ha constituido a unos sujetos y aun modo de vida particular en un contexto espacial particular (Los Montes de María).

La recuperación del sujeto, por consiguiente, significa recuperar el sentido de que la historia continúa siendo el gran e inevitable designio del hombre, lo que le confiere su identidad como actor concreto, porque constituye el contenido de su propia vida. La historia en el sujeto es el momento como parte de la necesidad de futuro, necesidad que no es sino el momento vivido conforme a la apetencia de valores que trascienden el momento". (Zemelman:1995:12)

Entendido así, la importancia del tema de los sujetos estriba en que constituyen un esfuerzo significativo para alcanzar una mejor captación de la realidad histórica, en tanto conforma un horizonte que articula diferentes planos de lo social (Zemelman, 1996: 97). En tal sentido, el plano económico es tan solo uno de los múltiples escenarios que han configurado al campesinado, por lo que en relación a las prácticas espaciales intentamos identificar aquellos otros planos muchos más informales- creados alrededor de diversas mediaciones y expresiones culturales simbólicas, no discursivas como los imaginarios colectivos, las representaciones sociales, las creencias, los mitos (...); aclarando que estas dinámicas no son sólo resultado del proceso de conformación de los sujetos sino componentes permanentes del mismo. (Torres \& Torres, sf:8). Estas expresiones más inmateriales de la conformación de los sujetos, están en el caso de los campesinos de VillaColombia y Borracheras ligadas con los espacios sociales de reproducción individual y social; el lugar de la familia, el del trabajo y el de la comunidad se funden en una relación que reproducen los sentidos de un modo de vida campesino, donde el campesino genera unos

familia y la relación entre miembros que realizan actividades (trabajadores) y miembros que no lo hacen (consumidores)" (Posada,1997:76) 
modos particulares de ser y estar tanto en el entorno como en las relaciones sociales que lo atraviesan. 


\section{CAPITULO III}

\section{ESPACIOS, POBLADORES E HISTORIAS DE LA MONTAÑA DE MARIA}

En este acápite el lector encontrará una exposición del proceso de conformación socioespacial e histórico de la subregión y de sus pobladores. En un primer momento presentamos a partir de un recorrido geohistórico, la estructuración espacial de Los Montes de María. En un segundo momento relacionamos dicha estructuración con los procesos poblaciones y la formación del campesinado montemariano.

\section{En las entrañas de la montaña: aproximación geohistórica}

La subregión de los de Montes de María se encuentra ubicada en la prolongación de la Serranía de San Jacinto y tiene una extensión total de 6.466 $\mathrm{km}^{2}$, está localizada en la parte central de los departamentos de Bolívar y Sucre en la macroregión de la Costa Caribe Colombiana (mapa 1)

Los Montes de María son integrados por 15 municipios, 7 del departamento de Bolívar (Córdoba, El Carmen de Bolívar, El Guamo, María La Baja, San Jacinto, San Juan Nepomuceno y Zambrano) y 8 del departamento de Sucre (Chalán, Colosó, Los Palmitos, Morroa, Ovejas, San Antonio de Palmito, San Onofre y Tolúviejo).

De acuerdo a su conformación natural, esta subregión está dividida en tres zonas (mapa 4), a saber:

Zona montaña. Localizada en el departamento de Sucre entre la Transversal del Caribe y la Troncal de Occidente. Son parte de ella los municipios de Chalán, Colosó, Morroa, Ovejas y Los Palmitos. Esta zona está propiamente en los Montes de María o Serranía de San Jacinto, prolongación de la Serranía de San Jerónimo en la Cordillera Occidental. Su área alcanza los $1.053 \mathrm{~km}^{2}$ y su población es de 64.221 habitantes, 31.166 en las cabeceras y 33.055 en las zonas rurales (DANE, Censo 2005 citado en Bocchi, 2011). 
Zona troncal del río Magdalena. Ubicada al nororiente de los Montes de María, en el departamento de Bolívar. Son parte de ella los municipios de Córdoba, El Carmen de Bolívar, El Guamo, San Jacinto, San Juan Nepomuceno y Zambrano. Su área alcanza los $3.262 \mathrm{~km}^{2}$ y su población es de 154.108 habitantes, 109.856 en las cabeceras y 44.252 en las zonas rurales (DANE, Censo 2005 citado en Bocchi, 2011).

Zona pie de monte occidental. Localizada entre la carretera Transversal de Caribe y el mar. Son parte de ella los municipios de María La Baja (Bolívar); San Antonio de Palmito, Tolúviejo y San Onofre (Sucre). Su área alcanza los 2.151 $\mathrm{km}^{2}$ y su población es de 122.094 habitantes, 45.748 en las cabeceras y 76.346 en las zonas rurales (DANE, Censo 2005 citado en Bocchi, 2011).

Mapa 4. Clasificación por zonas de Los Montes de María
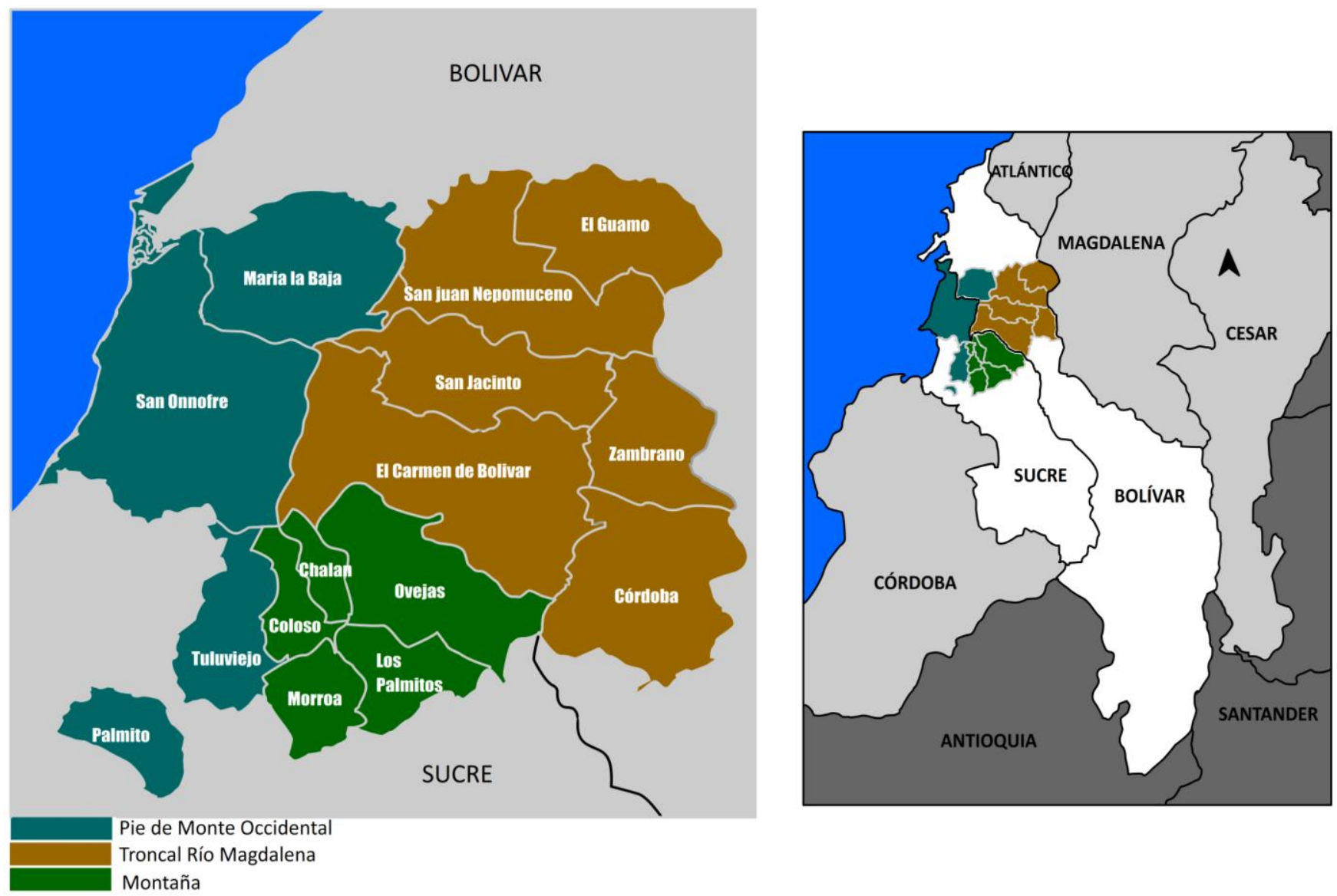

Fuente. Elaboración propia con base en datos http://www.fmontesdemaria.org 
La [sub]región de Montes de María se desarrolló tradicionalmente en la ribera occidental del río Magdalena y por tal hecho sus principales urbes eran las poblaciones que se encontraban a lo largo de ríos, como Zambrano. A mediados del siglo pasado la dinámica de la región cambió con la construcción de la Troncal de Occidente (carretera nacional que comunica los departamentos de Nariño y de Atlántico), la cual atravesó la Serranía de sur a norte por su costado oriental y convirtió a la población de El Carmen de Bolívar en el centro de la región. A principios de la década de 1970 se inauguró la Transversal del Caribe, conectando María La Baja con Sincelejo pasando por San Onofre y Tolúviejo. Dentro de los principales cambios también se destaca el establecimiento en la década de 1980 del paso del oleoducto que viene de Caño Limón (Arauca) y termina en Coveñas (Sucre), donde cuenta con un terminal de embarque de petróleo en el golfo de Morrosquillo. (Bocchi, 2011)

Es a partir de la construcción de la Troncal de Occidente y la Transversal del Caribe, que la subregión afianza su posición como paso de interconexión comercial, pues se encuentra entre los centros económicos de ValleduparBucaramanga (al oriente) y el mar Caribe (al occidente) y entre el corredor urbano-regional de Cartagena-Barranquilla-Santa Marta (al norte) y la carretera transversal de la depresión momposina que comunica a los departamentos de Sucre, Córdoba y Antioquia (Expopaz, 2010).

Esta situación ha convertido a Los Montes de María en una zona geoestratégica, de gran valor no solo por la movilización de mercancías de los principales puertos de Colombia (Barranquilla, Cartagena y Sata Marta) hacia y desde el interior de los polos de desarrollo como Bogotá y Medellín, sino que además, sus corredores principales son objeto de disputa por parte de actores armados y el narcotráfico, quienes ven en el control territorial de éstos, opciones para la consolidación militar o el tráfico de estupefacientes y armas.

Es justamente la disputa territorial entre grupos armados lo que forjó y consolidó el fenómeno del desplazamiento forzado en la subregión y en general, en todo el caribe colombiano, a pesar de que el proceso de desplazamiento y retorno serán analizado en el capítulo IV y $\mathrm{V}$, en este momento es importante resaltar la incidencia de los actores armados en la región como elementos explicativos del proceso de despojo y desterritorialización de las poblaciones acá estudiadas. En síntesis, el aspecto geopolítico se constituye en pieza fundamental para 
comprender las condiciones que han alimentado el conflicto sociopolítico y armado en la subregión en los últimos 20 años.

Además de estos elementos, debe sumarse al potencial geoestratégico de la subregión, la diversidad agrológica de los suelos ${ }^{28}$ y su capacidad productiva, la que, por más de 50 años, ha sustentado un modelo de producción agrícola y ganadero de importancia para la economía ${ }^{29}$ de toda la región Caribe.

Frente al uso de los suelos en la subregión, conviene recalcar que "las tierras de Montes de María tradicionalmente han sido aptas para la agricultura y la ganadería. Dadas las condiciones de relieve, se identifican dos tipos de paisajes que evidencian una apropiación y un uso diferenciado del suelo. Uno de ellos comprende las partes propiamente altas de los montes, en donde el uso de la tierra ha sido especialmente agrícola. El otro tipo de paisaje son los valles (o pie de monte) en donde tradicionalmente se establecieron la ganadería y el cultivo intensivo del tabaco" (Observatorio del Programa Presidencial para los DDHH y el DIH, 2003: 3, citado en Hernández, 2010).

Estos tipos de paisajes reflejan el proceso histórico y a veces conflictivo, de los modos en los que los hombres se han relacionado entre sí y con la naturaleza, en esta parte del Caribe colombiano. Empero, la observación del anterior proceso tiende a centrarse casi exclusivamente en el componente físico o natural de tal fenómeno, es decir, en «el paisaje como paisaje natural». En un ejercicio que amplíe esta mirada desde una perspectiva espaciotemporal, hemos entendido al paisaje como una parte de las dinámicas organizativas que dotan de orden a las formas-objetos del espacio. En palabras de Santos (2000:64) el paisaje es un aspecto o una fracción de la configuración territorial [...] es el conjunto de formas que, en un momento dado, expresa las herencias que representan las sucesivas relaciones localizadas entre hombre y naturaleza (86).

\footnotetext{
${ }^{28}$ En la subregión sucreña de los Montes de María encontramos suelos clases II, III, IV, VI y VII, de acuerdo con la clasificación agrológica realizada por el Instituto Geográfico Agustín Codazzi -IGAC-. Ver, PNUDUniversidad de Cartagena, 2003: 15-16.

${ }^{29}$ Este sistema económico ha ido transformándose por causa de los diferentes proyectos agroindustriales y forestales que se han acentuado en la macroregión desde los últimos 10 años.
} 
La palabra paisaje se utiliza frecuentemente en lugar de la expresión configuración territorial [o espacial] ${ }^{30}$. (...) Así, cuando se habla de paisaje también se hace referencia a la configuración territorial $y$, en muchos idiomas, el uso de las dos expresiones es indiferente (Santos, 2000: 86)

Entonces, el paisaje como [parte de la] configuración territorial expresa uno de los acápites del ordenamiento espacial, más no podría explicar por sí mismo la totalidad del contenido y el sentido del espacio. El paisaje es parte de la configuración espacial, pero una parte incompleta si/no se articula con la acción social, esta última imprescindible para la producción del espacio. Al respecto Santos (2000:90) nos recuerda que el paisaje es solo una abstracción, a pesar de su concreción como cosa material. Su realidad es histórica y le viene de su asociación con el espacio social.

Es justamente la acción social la que otorga contenido y sentido al espacio a través de prácticas concretas. Así, históricamente a cada organización espacial le corresponde una manera particular de producir espacio y estas producciones solo son explicadas por la acción social de hombres concretos. De esta manera, organizar o configurar el espacio no solo tiene una base física o natural, es la interacción entre los objetos-formas y los contenidos sociales otorgados a éstos, los que configuran la espacialización del mundo; en este proceso interviene, entre otros, la acción de actores y proyectos de espacio con territorios y territorialidades -muchas veces en tensión-. Hoy en día esta tensión puede ser ejemplificada en Los Montes de María a través de las disputas establecidas entre tierras de menor extensión (relacionadas con la economía campesina) y los nuevos proyectos agroindustriales, cada uno de ellos con sus propias representaciones de espacio y claro está, con sus propias maneras de organizar y ejercer territorialidades.

30 En la obra de Santos "la naturaleza del espacio" no se diferencian las categorías de configuración espacial, configuración territorial y configuración geográfica: "La configuración territorial, o configuración geográfica, tiene pues una existencia material propia, pero su existencia social, es decir, su existencia real, solamente le viene dada por el hecho de las relacione sociales" (54) "En nuestros días, estaría mejor representada por el conjunto de objetos culturales que, al lado o en lugar de los objetos «naturales», cuya significación modifican, forman lo que podemos denominar configuración espacial, configuración territorial o configuración geográfica" (64) Ver Santos, 2000: 54 y 64. 
A propósito Mançano (2010) a firma que:

Los territorios del campesinado y los territorios del agronegócio son organizados de diferentes formas, a partir de diferentes relaciones sociales. Un ejemplo importante es cuando el agronegócio organiza su territorio para la producción de mercancías, mientras que los grupos de campesinos organizan su territorio, primeramente, para su existencia, precisando desarrollar las dimensiones de la vida. Esta diferencia se expresa en el paisaje, donde pueden ser observadas las distintas formas de organización de los dos territorios. El paisaje del territorio del agronegócio es homogéneo, en cuanto al territorio campesino es heterogéneo. La composición uniforme y geométrica del monocultivo se caracteriza por la poca presencia de población en el territorio, porque su área está ocupada por las mercancías que predomina en el paisaje. La mercancía es la expresión del territorio del agronegócio. La diversidad de elementos que componen el paisaje del territorio campesino se caracteriza por la gran presencia de población, porque en éste es donde construyen sus existencias produciendo alimentos (...) (Mançano, 2010:10)

Entonces el paisaje como parte de la organización espacial no solo refleja el ordenamiento de ciertos objetos-formas del espacio, sino que constituye una parte fundamental del proceso de configuración de sentido que diferentes actores le otorgan al espacio. Por lo cual, las formas particulares de organizar, dar sentido y producir la materialidad del espacio y el territorio tienen que ser leídas históricamente.

\subsection{Espacios y pobladores}

Bajo la premisa de la historicidad, la temporalidad introduce la idea de una construcción, de un proceso que lejos de ser un a priori naturalmente dado, es síntesis de una consecución social; lo que nos permite reconocer la historicidad de los espacios y de su conformación social. Bajo esta perspectiva y retomando las características geohistóricas de la subregión de los Montes de María, se pueden diferenciar cinco maneras de organizar el espacio, cada una con su correspondiente manera de producir territorio y territorialidad. Insistimos en exponer que toda organización espacial es resultado de relaciones sociales en contextos históricos particulares, por lo cual, las maneras de organización 
espacial en la subregión de los Montes de María solo son evidentes en la medida en que reconozcamos la naturaleza de dichas relaciones sociales ${ }^{31}$ :

\subsubsection{Organización espacial indígena.}

Al llegar lo españoles a la parte de sur de Costa Atlántica se encontraron con un importante número de comunidades indígenas (mapa 4) pertenecientes a la familia de los Caribes $^{32}$ : Caonaos, Buredes, Bubures, Tupes, Pemeos, Xiriguanos, Motilones, Dubey, Upar, Orejones, Malibúes, Calamares, Turbacos, Mahates, Zenúes, Urabaes y, posiblemente, Chimilas (Zambrano, 2000:18) todos con una organización socioespacial sustentada por diversos patrones de vida (semi-nómadas, semi-sedentarias, prácticas anfibias o prácticas totalmente sedentarias). Estos patrones y maneras de reproducción social, parecen estar asociado a los ecosistemas caribeños y a las formaciones naturales del territorio, principalmente el ambiente marino, ribereño, lacustre, sabanero y selvático (Zambrano, 2000)

Justamente estos diversos ecosistemas fueron configurando una ventaja ecológica que proveía mayores posibilidades de acceder a los más diversos recursos, lo que con el paso del tiempo, más el crecimiento del número de miembros de una comunidad, orientó los patrones de vida semi-nómadas a una total reproducción social basada en el sedentarismo y la consecuente especialización en la agricultura y la horticultura.

La pauta de asentamiento típica de estas formaciones sociales es la de grandes aldeas nucleadas y pequeños poblados satélites, donde los grupos locales renuncian parcialmente a su antigua autarquía, en favor de una relativa especialización ecológica que aumenta la productividad de la agricultura. (Zambrano, 2000; 15)

\footnotetext{
${ }^{31}$ Advertimos al lector que solo abordaremos la generalidad de estas cinco formas de organizar el espacio, ya que la duración temporal y sus implicaciones en la historia social de Colombia, exigiría una mayor precisión; un reto que por la naturaleza de nuestro objeto de estudio no podremos asumir. Para un abordaje más cuidadoso, ver: Fals Borda, 1973, 1986; Zambrano, 2000; Herrera, 2002; Kalmanovitz, 2003.

32 Mencionamos solo el caso de la familia Caribe porque su localización tiene mayor aproximación territorial a la subregión estudiada, no obstante hay que señalar que -según Zambrano (2000) en una lectura de Burcher (1984)- durante el periodo prehispánico en la región Caribe se encontraban tres grandes familias: Arawak, Chibchas y Caribes.
} 
Mapa 5. El Caribe colombiano prehispánico. Grupos aborígenes caribeños

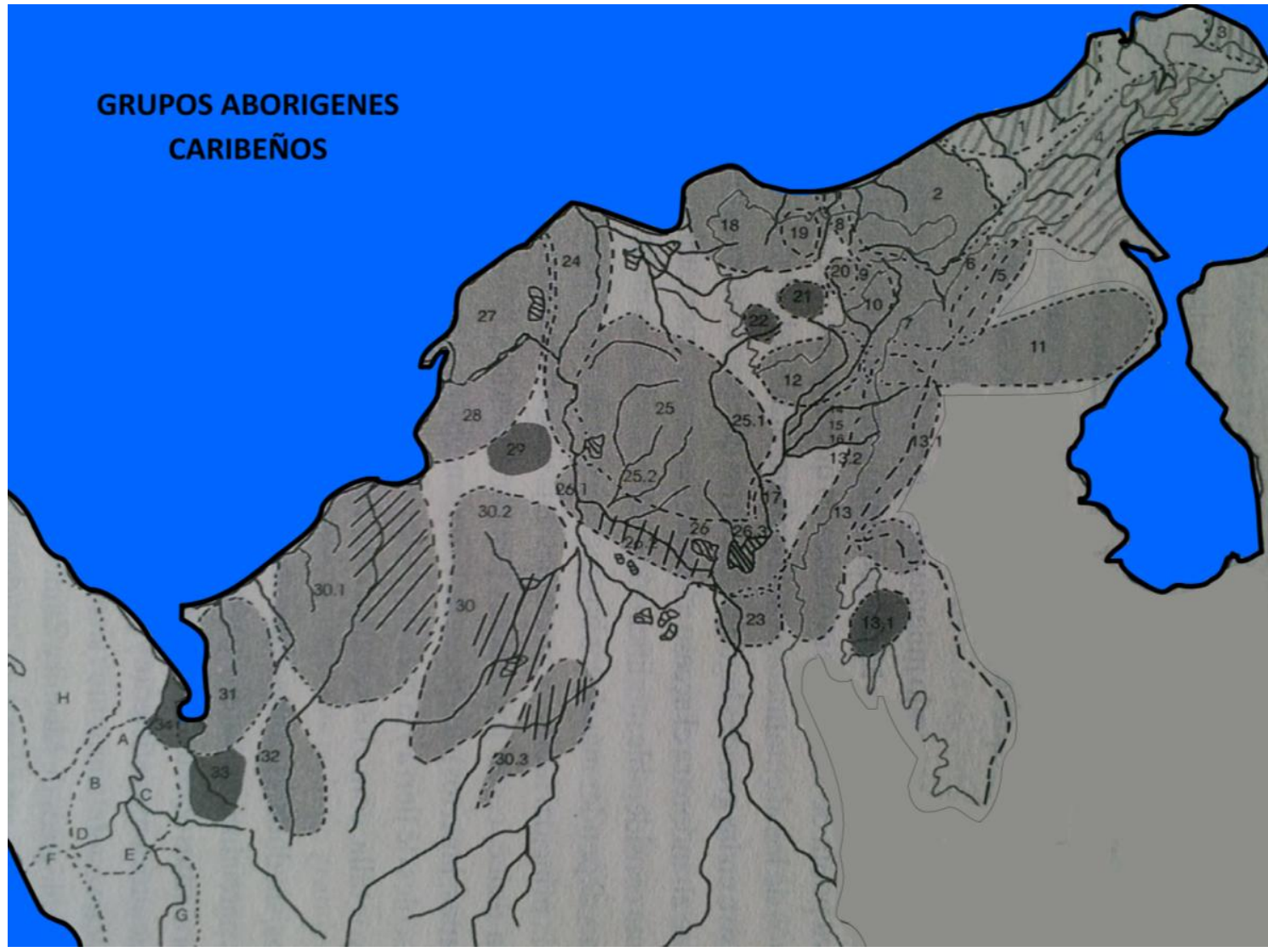

PENINSULA DE LA GUAJIRA: 1. KAKETIOS/ 2. WANEBUCAN/3. KUSINA WUAYUU/ 4. KUSINA WUAYUU Y GUAJIRO WUAYUU

EL GRAN VALLE DEL RÍO CESAR Y NORTE SEPTENTRIONAL DE LA CORDILLERA ORIENTAL: 5. BUREDE/ 6 ITOTOS/ 7 DUBEY/8CANOAO/ 9SOWIGA/ 10 UPAR/ 11 BUBURE/ 12 TUPES/ 13 MOTILONES/ 13.1 KANAGUASAYA/ 13.2 YUCOS/ 14 SOCOMBA/ 15SICARARE/ 16 SACARARE/ 17 XIRIGUANO/ 23. PEMEOS

SIERRA NECAVA DE SANTA MARTA: 18. TAIRONAS/ 19. KOGUIS/ 20. SANKAS/ 21, CÁGABA/ 22 IKÁ

LINEA LITORAL CARIBEÑA Y COMPLEJOS DEPRESIONALES: 24 MOCANA/ 25. CHIMILA (25.1 ALCOHOLADOS/ 25.2. PINTADOS) 26. MALIBÚ (26.1. SOMPALLON/ 26.2 KIMBAY. 26.3 POCABURY)/ 27 CALAMARES/ 28. TURBACO/ 29 MAHATES/ 30 ZENÚES (30.1 FINZENÚ/ 30.2 PANZENÚ/ 30.3 ZENUFANA)

GOLFO DE URABA Y AL REDEDORES: 31. URABES/ 19. GUAZUCES/ 20. CARAUTAS/ 21. COROBARI BEA

Fuente. Zambrano 2000:13.

Como ejemplo de ello, los Zenúes desarrollaron formas de producciones tributarias, basadas en la agricultura sedentaria (Fals Borda, 1976) y que basadas en fuertes relaciones materiales e inmateriales con la tierra; configuraron una organización social que supo articular el parentesco con la propiedad colectiva y la producción social comunitaria. 
El instrumento de trabajo esencial -la tierra- era propiedad colectiva para ser usada según reglas particulares, y según el grado de sedentarismo agrícola (Borda, 1976:15)

La tierra y el control territorial empiezan a tornarse en piezas fundamentales para la producción y reproducción de estas comunidades, lo cual reconfiguró gran parte de sus prácticas espaciales, adoptando nuevas maneras de relacionamiento social reflejadas en prácticas concretas de apropiación, uso y dominio del espacio. Al respecto, Zambrano (2000; 23) a firma que los Zenúes desarrollaron un extenso control territorial; la población se encontraba dispersa por las llanuras, en aldeas y pequeñas poblaciones. Existían algunos centros internos de intercambio comercial, en los cuales diferentes productos, ya fueran alimentos $\mathrm{o}$ bien elementos técnicos y herramientas de trabajo, eran intercambiados entre los indígenas de la región. Igualmente, es evidente que para mantener un control territorial estable, se hizo necesaria la presencia de controles jerárquicos que determinaran las condiciones, tanto políticas como sociales, de la comunidad.

En síntesis, Las comunidades indígenas que poblaron esta zona del país, hicieron gran uso de las condiciones del territorio, del cual aprovecharon los recursos naturales y también desarrollaron importantes capacidades técnicas para utilizar, de la mejor manera, las riquezas de la tierra. Ante la diversidad de posibilidades de producción, tanto agrícola como técnica, la especialización del trabajo se constituye en un elemento fundamental y característico de estas comunidades. Las poblaciones no sólo se preocupaban por subsistir. Más allá de ésto, eran conscientes de la importancia de fortalecer sus fuentes productivas para obtener el beneficio necesario en los intercambios comerciales que se realizaban dentro de la comunidad. (Zambrano, 2000:23)

Ahora, tanto las particulares maneras de aprovechar y organizar el espacio como las relaciones sociales que las sustentaban fueron -en su mayoríadrásticamente transformadas durante la colonización y la implantación del modelo de organización socioespacial español. De este modo, la encomienda, como institución socio-económica basada en el pago de tributos y el trabajo servil; las reducciones y los resguardos, como formas de desterritorialización 
originaria y de emplazamiento indígena, deben ser analizadas como sistemas de reordenamiento y de control social, político y cultural que intentaron -y en la mayoría de los casos- lograron, insertar a territorios y poblaciones a las lógicas de producción espacial español.

\subsubsection{Palenques o espacios de libertad.}

Desde el momento mismo del arribo de los españoles al continente y en contravía de la política dirigida por las autoridades coloniales, se desarrollaron diversas formas de poblamiento alterno del territorio continental, tales como el cimarronaje indígena, el amancebamiento de españoles con indígenas y negros gracias a la temprana introducción de esclavos negros, así como su cimarronismo. Se conformaban así diferentes grupos sociales que se caracterizaban por su oposición al régimen español y porque buscaban a lo ancho del territorio desarrollar sus propias condiciones de vida, distantes de la opresión y del control de los europeos. (Conde Calderón, 1999, citado en Zambrano, 2000:39)

Estas diversas formas de poblamiento, como las denomina Calderón, son resultado de las estrategias que ejecutaron las comunidades indígenas y negras para pervivir al régimen colonial. Para lograr tal fin, rehuir al control espacial era una premisa que muchas veces se pagaba con la vida misma.

Si nos concentramos en el devenir de los negros esclavos traídos al Caribe colombiano entre los años 1595-1640 y 1695-1735, y nos detenemos a desentrañar sus formas de resistencia en relación a lo espacial y territorial, es indispensable abordar la naturaleza y la institución de los palenques:

Los llamados palenques eran fortificaciones que encerraban un terreno o rancherío, en donde se ocultaban los esclavos negros fugitivos para utilizarlas como protección. Los palenques se ubicaron generalmente en zonas inhóspitas y de difícil acceso, en territorios boscosos y pantanosos de las sabanas, en llanuras y ciénagas que, precisamente, por tales características constituían lugares de difícil manutención. Los palenques 
existieron a lo largo del siglo XVII y, desde principios del XVIII, proliferaron en el territorio de la provincia de Cartagena. (Zambrano, 2000:40-41)

Es indudable que la constitución de los espacios palanqueros, son la respuesta al sistema de explotación servil y esclavista que intentó revertir -a través de la fuerza de trabajo negro- la crisis del sistema económico colonial basado en la encomienda y la fuerza de trabajo indígena ${ }^{33}$. De ahí que la organización socioespacial de los palenques, deba ser leída como la consecución de un proceso histórico de construcción y consolidación de contraespacios de resistencias y de identidad (Oslender, 2008).

Nuestros ancestros africanos lucharon heroicamente contra la esclavitud y por su libertad, su lucha de resistencia iniciaba en los propios suelos africanos y se hizo inquebrantable tan pronto pisaron territorio americano, protagonizando una gesta libertadora por todos los caminos y los ríos colombianos, que posibilitó la recreación de la africanidad en América y la supervivencia de las personas africanas en las montañas y selvas de Colombia. La gran guerra cimarrona se desarrolló durante todo el periodo de la esclavización; donde hubo esclavitud hubo cimarronaje y los palenques se convirtieron en faros que iluminaban los caminos de la libertad en América. (Mosquera, 2001)

Los palenques se erigen en espacios de libertad y de identidad (la africanidad) con acciones específicas orientadas hacia la reproducción sociocultural; por ejemplo, la organización espacial y social de los palenques obedeció -en un primer momento- a la estructura africana; según Fals Borda (1976: 22) los negros cimarrones fundaron aldeas como las de su cultura original en el sudoeste africano y organizaron una explotación sedentaria y colectiva de la tierra, o en pequeños fundos. Escogieron jefes o "reyes" (...) lo cual es índice de una diferenciación rudimentaria de clases. (...) estos grupos se organizaron según formas de producción comunitaria, sujeta a su origen negro o palenquero.

\footnotetext{
33 “Ante la inocultable catástrofe indígena, los españoles se vieron en la necesidad de sustituir la mano de obra para mantener la infraestructura económica que garantizaba la manutención de la colonia. Fue así como los indígenas fueron reemplazados por negros traídos de las Antillas y del África, con lo cual se incidía en la modificación de la encomienda como sistema de producción, ante la impresionante desaparición de los indígenas" Ver Zambrano, 2000: 40
} 
Entonces, la organización espacial de los negros cimarrones no solo está asociada con ciertas características físicas, como el de localizarse en zonas altas, inaccesibles y generalmente cercanas a las riveras de ríos, sino que su propia estructura social y de producción refleja la intensión por restablecer la estructura identitaria africana desmembrada con la llegada a las Américas.

\subsubsection{El Estado colonial y el control espacial.}

Los territorios que hoy hacen parte de la subregión de los Montes de María, al igual que la mayoría de los territorios ubicados en el interior de la macroregión Caribe, no fueron parte del dominio espacial español sino hasta mediados del siglo $\mathrm{XVI}$, en un proceso de reordenamiento territorial que tardaría casi hasta finales del siglo XVIII.

Frente a este proceso, hay que recordar que los primeros años de la tercera década del siglo XVI, los españoles, a excepción de lo realizado en México, que fue el primer país en ser penetrado casi en su totalidad, se habían limitado a explorar y a reconocer sin mayor profundidad los miles de kilómetros de litoral del continente americano, así como las cuencas de los grandes ríos Amazonas y de La Plata. Es entonces, cuando la Corona decide dar un viraje en su política colonizadora y por medio del Consejo de Indias órgano administrativo erigido en España para coordinar los asuntos americanos, determinó, específicamente para el caso del territorio neogranadino, favorecer la apertura del continente, por medio de la colonización interna del terreno, empresa que hasta ese momento se había limitado a la exploración costera (Zambrano, 2000:30)

Esta colonización estuvo orientada por una estrategia donde la penetración en el territorio se consolidaba a través de la fundación de pueblos, villas y parroquias; al respecto, Zambrano (2000: 35) sostiene que España dominó los espacios conquistados, mediante el establecimiento de núcleos urbanos, que se constituyeron no sólo en enclaves económicos y militares, sino fundamentalmente, en centros del poder político, pues el Estado toma lugar precisamente sobre la ciudad y es en ella donde se organiza la explotación de las tierras conquistadas y la sujeción de los pueblos que las habitan. 
De esta manera, los centros urbanos son la base de un proceso de organización espacial que buscó encuadrar las poblaciones y los territorios indígenas al modo de producción y reproducción socioespacial de la corona; de ahí que el Estado colonial orientará una nueva espacialidad centrada en la reducción de los territorios indígenas y el control poblacional de éstos, originando una especie de «desterritorialización primaria» que reprodujo el proceso de expropiación y/o usurpación de tierras en la región.

Martha Herrera (2002), describe una de las fases de ese proceso de "desterritorialización primaria":

(...) la transformación de un pueblo de indios en parroquia de "blancos" básicamente consistía en sacar a los indios del caserío y de las tierras comunales que usufructuaban en su pueblo de indios y trasladarlos a otro pueblo. Al sacar a los indígenas solo quedaban pobladores no indios o "blancos" dentro del territorio del pueblo transformado en parroquia. (...) Las autoridades indias se mudaban junto con sus comunidades. Como resultado de tal medida se daba fin a la dualidad territorial, ética y administrativa de los pueblos de indios" (Herrera, 2002:96)

La continúa alteración en las relaciones territoriales de los pobladores indígenas no solo los alejaba de las prácticas de apropiación, uso y dominio espacial establecidas histórica y culturalmente por sus antepasados- sino que también los adentraba a nuevas formas de relacionamiento y reconocimiento social, todo dentro de una estructura jerárquica y rígida, donde los valores étnicos y raciales eran parte del proceso de organización espacial español.

En la sociedad colonial las divisiones raciales establecidas por el Estado, se veían complementadas y reforzadas con las normas relativas al ordenamiento espacial de la población, al cual iba aparejado un tipo de organización administrativa. La parte central de una ciudad o de una villa era ocupada por los "españoles", mientras que en la periferia, en los llamados arrabales, se asentaban los indios que prestaban sus servicios a los "españoles" allí radicados. Fuera de esas poblaciones para "españoles", en las áreas "rurales" se erigieron los pueblos de indios para la población nativa, donde los "españoles" no debían residir, salvo excepciones, como en el caso de sus respectivos curas. 
Para la población procedente de África no se definía una tipología de asentamientos, ya que se la incorporaba dentro del ámbito de lo "español", en su calidad de esclavos (...) de esta forma, la pertenencia a uno u otro tipo de asentamiento y el lugar que se ocupaba dentro de él, indicaban y reforzaban el lugar del individuo dentro de la sociedad" (Herrera, 2002: 82-83)

En suma, la urbanización y la geometrización de los espacios, la distribución étnica y el control social dentro de los mismos, fueron las bases para la reducción de las "tierras salvajes" y la consolidación de la colonización interna. Junto con las parroquias y las villas, la hacienda se implantó como una de las formas preeminentes de organización socioespacial en las zonas no urbanas. Su incidencia desbordó la época de la colonia, logrando instalarse en la historia social y en la actual estructura agraria de los Montes de María.

\subsubsection{La Hacienda, un modelo que pervive.}

Entre los elementos propios que distinguen las formas americanas de producción pre-capitalista del modo feudal europeo, se encuentra el conjunto de relaciones de producción construidas alrededor de la hacienda. Esta es una estructura económica y social particular, (...) cuya expresión concreta ha ido variado de una época a otra según el desarrollo de las fuerzas productivas. Iniciada en la colonia como una relación de explotación y subordinación, la hacienda ha pasado por diversas etapas para llegar hasta hoy cobijadas por relaciones de producción capitalista (Fals Borda, 1976:31)

En la Costa Caribe como en casi toda zona de colonización, la hacienda, a través de la apropiación de tierras y la implantación de formas serviles de trabajo, se impone sobre las anteriores formas de organización social y espacial, principalmente la indígena.

De ahí que la hacienda como sistema de organización social y productivo fundará nuevas territorialidades, $y$, en consecuencia, nuevas prácticas espaciales. Estas nuevas territorialidades fueron antecedidas durante los primeros años de la colonia, por dos acciones principales: i) la violencia directa; 
y, ii) la legalización de despojos a través de las reducciones, los resguardos o la promulgación de mercedes reales.

La merced de tierras fue uno de los primeros mecanismos que utilizaron las autoridades coloniales españolas para recompensar -con bienes indígenasa los conquistadores por los servicios prestados a la corona durante la invasión y posterior sometimiento de los indígenas y colonización de estas tierras. Se trataba de una cesión graciosa de una "regalía" de la corona ("bienes realengos") destinada a aquellos que se avecindaran en alguna ciudad, que sólo podía ser vendida luego de mantener la ocupación y la explotación por varios años, y que requería de una posterior confirmación real (Ots Capdequi 1946, citado en Albecks \& Palomeque, 2009)

Al respecto Fals Borda, señala que:

La hacienda costeña se inicia en los intersticios del territorio indio -aquellos dejados, en teoría, por los resguardos- mediante la adjudicación de "mercedes" en tierras vacas. Estas mercedes, que eran muy distintas de las adjudicaciones de encomiendas que no daban derecho a la tierra sino al tributo de los indios, sólo eran potestativas del Estado, es decir, el rey y sus representantes y de los cabildos españoles de primeros pobladores (Fals Borda, 1976:31)

Como las mercedes solo se adjudicaban en territorios cercanos a las ciudades, las primeras haciendas en la Costa Caribe, aparecen en cercanías de Cartagena, Tolú y Mompós (Borda, 1976: 31).

El devenir de estas primeras haciendas y el desenvolvimiento de las mismas en la historia social de la Costa puede rastrearse a través de dos de sus expresiones históricas, la «hacienda ganadera» y la «hacienda tabacalera», ambas descendientes de la hacienda del periodo de la Colonia.

En los primeros años, las haciendas costeñas se constituyeron en centros de producción agrícola, ésto, en virtud del relativo auge de la economía colonial a partir de 1730 (Kalmanovitz, 2003), no obstante, este potencial agrícola sería reemplazado rápidamente -no sin mantener reductos agrícolas- por una especialización pecuaria, la cual se constituiría, con el paso de los años en la base de la producción del sistema de hacienda en esta macroregión. 
A partir del siglo XIX, el ganado se convirtió en un elemento fundamental de la economía de la costa Caribe. Extensos territorios, hasta entonces desprovistos de cultivos o de algún tipo de elemento productivo, fueron inundados de reses. Diferentes tierras en el Cesar, Sucre, Córdoba, Bolívar $y$, en general, en toda la costa Caribe, fueron testigos de este nuevo elemento fundamental de la economía regional (Zambrano, 2000:61)

De este modo, la hacienda, sinónimo de «gran propiedad» y de «concentración de la tierra», sería el motor que desde mediados del siglo XIX integraría la región Caribe al mercado interno y posteriormente al mercado internacional; apropósito Zambrano (2000) recuerda que uno de los factores que hicieron parte del tránsito del sistema económico de la región, de un sistema pre-capitalista a uno capitalista, es justamente la hacienda y en especial la hacienda tabacalera

El desarrollo económico de la costa Caribe, se vio favorecido por una formidable expansión de la economía mundial, sobre todo en el período comprendido entre 1870 y 1930 y por una creciente integración de la región con los mercados andinos, bien como proveedora de ganado vacuno para sus centros de consumo, o bien como puerta de salida de los productos de las zonas agrícolas andinas y de entrada de las importaciones que éstas requerían. (Zambrano, 2000:54)

Como mencionamos anteriormente, la hacienda centrada en la producción agrícola no desapareció del todo, algunos reductos lograron sostener su producción desde finales del siglo XVII hasta mediados del siglo XIX, por medio de inestables periodos de crecimiento -menos dinámicos que los experimentados por la hacienda ganadera- pero que en términos generales proporcionó el tiempo suficiente para adaptarse al nuevo sistema económico que empezó a dominar las relaciones comerciales de la región y el mundo desde mediados del siglo XIX. Justamente el reacomodamiento del sistema económico de toda la región, permitió transformar los modos de producción que hasta ese momento se había instaurado, por lo que la agricultura en la costa Caribe pasó de ser una actividad aislada y casi que destinada exclusivamente al autoabastecimiento, a arrojar un excedente para la exportación, tanto en el mercado nacional como internacional (Zambrano, 2000:55)

De tal manera: 
Con el transcurrir del siglo $[X I X]$, se consolida la hacienda como estructuradora del espacio regional, a la vez que va transformándose, paulatinamente, en una verdadera empresa agrícola, sobre todo en aquellas zonas dedicadas al cultivo para la exportación y también va diferenciándose, cada vez más, de las pequeñas propiedades dedicadas a la agricultura de subsistencia. La expansión de la hacienda costeña se debió, en cierta medida, a la necesidad de producción de arroz, azúcar, algodón y ganado vacuno para el mercado interno, y de tabaco y banano para el externo.(Zambrano, 2000:56)

De los diferentes productos que sostuvieron la expansión de la hacienda agrícola en el siglo XIX, el tabaco se constituyó en un referente, que poco a poco se instaló en las prácticas productivas tanto de los pequeños campesinos como de los terratenientes de la región. Recordemos que "el cultivo del tabaco, se vio estimulado por el mercado internacional, particularmente durante el auge que siguió a la abolición de su monopolio, a mediados del siglo XIX. Si bien esta bonanza duró, apenas, veinte años (1850-1870), su influencia fue definitiva en la consolidación de la hacienda como empresa agrícola en ciertas zonas así como en la reactivación portuaria, tras las convulsiones de la primera mitad del siglo XIX. En esta época, ya existían dos factorías de tabaco en María la Alta y en El Carmen, en Bolívar, esta última instalada en 1848, en un área de cultivos clandestinos" (Pardo Pardo, 1972: 295, citado en Zambrano, 2000:59) Hoy, se podría decir que el cultivo de tabaco más que un mero producto susceptible de intercambio comercial es una forma particular de identificación del campesino de la región.

Tanto la hacienda tabacalera como la hacienda ganadera establecieron, en consecuencia, nuevas formas de composición de la estructura laboral y geográfica de la región. Este cambio, significaba aglutinar a un gran número de trabajadores alrededor de las extensas plantaciones de los productos referidos. Así, las poblaciones que se encontraban en las fronteras de las grandes plantaciones eran absorbidas por la dinámica de estas últimas (Zambrano, 2000:56), de igual forma, la necesidad de atraer y mantener peones en las haciendas ganaderas, reprodujo una estructura regional donde poblaciones y 
tierras, pasaban por un sistema de sujeción, secundado por instituciones del orden local y regional.

Este sistema de sujeción trasformó las relaciones sociales agrarias de la región, pues incidió directamente en la configuración socioterritorial del Caribe, sobre todo a lo que se refiere a la propiedad:

La introducción del alambre de púas fue un nuevo elemento en el paisaje rural de la región Caribe colombiana. Esta manera de delimitar la propiedad, no determinó forma alguna de poblamiento, pero sí simbolizó una nueva manera de concebir la tierra, o sea, el cercamiento gradual de los terrenos que anteriormente se encontraban libres (Zambrano, 2000:62)

Así la gran propiedad determinó y en gran parte aún lo hace, la posibilidad de que colonos y pequeños campesinos obtuvieran pleno dominio sobre la tierra; a propósito Kalmanovitz asegura que:

(...) si algún pobre se introduce en tierras que considera baldías y hace en ellas una plantación, pronto surge un poderoso exigiéndole un arriendo excesivo (Kalmanovitz, 2003: 70)

En síntesis, la hacienda en la costa Caribe configuró una estructura de poder, un sistema social agrario mediado por relaciones de servidumbre; una concentración de la tierra y un sistema político regional monolítico (el gamonalismo y/o el cacicazgo) conducente al sostenimiento de dicha estructura. Así, la hacienda se cimenta como centro del proceso de organización espacial de la región durante el Siglo XIX y gran parte del Siglo XX.

Muchos de los elementos derivados de los procesos de organización y dominio espacial reproducidos durante este periodo, se lograron empotrar en la estructura agraria de la región, ahondando las tensiones entre los pequeños campesinos y los terratenientes, lo que posteriormente explicaría el movimiento social campesino y la lucha por la tierra en la segunda mitad del siglo XX. 


\subsubsection{El campesino costeño.}

El surgimiento del campesinado costeño así como de las prácticas espaciales que definieron su posición entre las relaciones sociales y territoriales de la subregión, están atadas al devenir de las dinámicas poblaciones y de producción instauradas durante y posterior al periodo de la colonia.

Como fue expuesto anteriormente, la corona española baso el proceso de colonización a través de la fundación de núcleos urbanos, éstos a su vez, reorganizaron el entorno socioespacial -incluyendo a los indígenas y a sus tierras- a través de las encomiendas. Con la crisis demográfica indígena que alcanzó su nivel más agudo en la tercera década del siglo XVII y su consecuente impacto en el desenvolvimiento de la encomienda, los españoles optaron por reorganizar el espacio de producción, concentrando a la mano de obra indígena en las denominadas «reducciones». A través de la política de "reducciones", se concentraban los supervivientes en áreas cada vez más restringidas y al alcance de los hacendados y estancieros que los requirieran como trabajadores "concentrados" en sus tierras (Fajardo, 1988:19)

Este proceso de reducción (...) fue dando lugar entonces a la aparición de aldeas colindantes con las tierras apropiadas por las haciendas y estancias medias; en éstas se concentraba la mano de obra ocupada dentro de aquellas en la producción que había que abastecer los núcleos pobladores mayores y las minas, al tiempo que afianzaba la pequeña producción parcelaria (Fajardo, 1988: 20)

Así, la descomposición de las comunidades indígenas fue el principal venero para la generación de núcleos campesinos (Fajardo, 1988: 20), no obstante, la conformación campesina de los Montes de María estuvo atravesada por otros factores de tipo étnico y mestizo, a saber, los cimarrones o palanqueros y los pueblos de blancos libres.

En cuanto a los primeros, hay que mencionar que la crisis del sistema de producción basado en la fuerza de trabajo esclavo ${ }^{34}$, dio como resultado una

\footnotetext{
34 “La minería del oro en Colombia (...) se caracterizó por su marcado atraso tecnológico, lo cual hizo depender los aumentos en la producción simplemente de los nuevos hallazgos del metal; en esta forma se llegaba a un rápido agotamiento de las minas, lo que hacía de esta actividad una actividad prácticamente
} 
"liberación" de una buena parte de los esclavos negros de las haciendas y las minas, lo que generó la conformación de pequeños grupos de "libres" y el comienzo -por parte de éstos- de un proceso de colonización en las regiones aledañas a las áreas en las que anteriormente trabajaban como esclavos. De acuerdo con Fajardo (1988) estos núcleos engrosaron probablemente los frentes ya abiertos por numerosos palenques de esclavos fugitivos, modalidad de poblamiento que se presentó en la Costa Caribe, especialmente en territorios cercanos a Cartagena y a los territorios que hoy conforman los Montes de María como San Basilio, Tolú y San Onofre; pero también en el interior de las llanuras costeras, como Mompós.

No obstante, esta liberación tan solo significaría un cambio en las maneras de explotación, pues tal como afirma Fajardo, se tendió a "liberar" a los esclavos, fijándolos sin embargo a las haciendas mediante la entrega de lotes y creando un campesinado atado por relaciones de aparcería (1988: 21)

Los esclavos se convirtieron entonces en jornaleros, trabajadores a destajo o concertados. En las haciendas y empresas se les contrató como agricultores, vaqueros, artesanos, aserradores, bogas, etc. Para la realización de los trabajos duraderos o temporales. A estos sitios de labores debían presentarse con sus respectivos animales, instrumentos de trabajo y la sarapa o comida. (Negrete, 1981:29 citado en Escobar 1982:9)

Frente a los pueblos de blancos pobres, es relevante destacar su influjo en la constitución de pequeños poblados y en la producción de la agricultura de subsistencia. Estos vecindarios o pueblos deben entenderse como una notable vertiente en la formación del campesinado (Fajardo, 1988) y del sistema de aparcería de la región.

Durante la mayor parte del siglo XIX y XX, la aparcería sirvió como modo de sujeción del naciente campesinado. Fue, entonces, en estas circunstancias, como se empezaron a forjar los mecanismos de explotación de la nueva mano

itinerante, con las limitaciones que esto imponía al encarecer la producción por causa de las dificultades para la obtención de alimentos y vituallas. En estas circunstancias la minería de oro realizada con trabajadores esclavos no fue una actividad de prolongada duración, ya que los elevados costos de esta mano de obra no podrían ser sostenidos con las inconstantes retribuciones obtenidas por los empresarios" (Fajardo, 1988:21) 
de obra y que habrían de dejar una impronta definitiva en la forma del poblamiento de la costa Caribe. Se trataba de arreglos no institucionales, destinados a subordinar a la población mestiza, sobre la base del peonaje y del colonato, es decir, de formas de prestación de servicios dentro de un sistema de clientelas no remuneradas por un salario, sino por la concesión de tierras (Colmenares, 1989: 118 citado en Zambrano 2000:38)

Así, la sujeción de los trabajadores residentes impedía la conformación de un mercado de trabajadores libres. Su necesidad se comprende aún mejor por la existencia de mucha tierra no abierta todavía, a la cual hubieran podido dirigirse los campesinos de no haber estado atados a las haciendas (Kalmanovitz, 2003: 59). De este modo, la aparcería no solo mantenía la mano de obra necesaria para los terratenientes sino que se convertía en un mecanismo que impedía la apertura de nuevas tierras por fuera del control del hacendado o terrateniente. Toda tierra por fuera de la jurisdicción del terrateniente se vería como una perturbación masiva de las estructuras de poder, susceptible de eliminación o cooptación. Justamente el aprovechamiento de la movilización campesina, representado por la colonización y la apertura de la frontera agrícola en la región Caribe fue aprovechado por los terratenientes en un ejercicio que Fals Borda denomina, la ley de tres pasos:

El colono marginal tumba el monte y ejecuta todas las actividades económicas de habilitación de la tierra, permaneciendo en ella por un tiempo relativamente corto o hasta que ésta "se cansa", para ir a tumbar en otra parte (primer paso). Malvende luego o cede sus mejoras a un finquero, contratista o intermediario que semi-explota el fundo y aun intenta alguna consolidación o unificación de las explotaciones o lotes (segundo paso). Este finquero o contratista cede a su vez ante presiones de un latifundista empeñado en ampliar sus propiedades o en crear una nueva hacienda (tercer paso). (1976:41)

Apropósito Escobar afirma que:

Grupos de Colonos costeños migraban a las regiones de montaña [como la actual subregión de los Montes de María], baldíos de la nación, creando formas de autosubsistencia (Fals Borda, 1976). (...) No obstante la presión 
hacendil lograba muchas veces para sí estas nuevas tierras con su "ley de tres pasos". (Negrete, 1981:28 citado en Escobar 1982:12)

Por consiguiente, los núcleos campesinos y la relación que éstos fueron construyendo alrededor de la tierra y su tenencia, estuvo de marcada por las dinámicas que impuso la expansión de las grandes propiedades en la región, que, de acuerdo con Alejandro Reyes, esta situación puede ser comprobada a través de dos mecanismos fundamentales: por la introducción del alambre de puas, que permitieron enlazar los procesos de apropiación de tierras y su ocupación con ganado: y, la apropiación de tierras comunales que servían al pequeño propietario para mantener un poco de ganado y algunos cultivos [por fuera del control del terrateniente] (Reyes, 1978:63 citado en Escobar, 1982:7)

Es indudable que la suerte del campesinado estaba atada a la de la hacienda, los primeros núcleos campesinos estuvieron supeditados a residir en pequeñas extensiones de tierra bajo la figura de la aparcería o el arriendo, ubicando al campesino y a su trabajo en dos frentes: el trabajo familiar de subsistencia y, el trabajo dependiente del jornaleo en las haciendas.

Para esta época existía ya en la región, además del sistema de avance, el concierto, a destajo y el jornaleo. En sucre se uso también el arriendo con pago en productos (maíz principalmente) y siembra de pastos. El valor del arriendo era una fanegada de maíz por hectárea, más la siembra de pastos. Se acostumbró finalmente al arriendo combinado con siembra de pastos y pago en dinero, cuando las áreas de desmontar estaban llegando a su fin. También se usaban los avances de dinero y mercancía para vincular a los campesinos a la hacienda ${ }^{35}$ (Reyes, 1978:63 citado en Escobar, 1982:8)

La reproducción de estas condiciones y las consecuentes tensiones que generó a lo largo del siglo XIX y sobre todo el siglo XX, motivaron el levantamiento continuo del campesinado en contra de las relaciones sociales y de producción impuestas por los grandes propietarios (Escobar, 1982). Estas expresiones de inconformidad empezaron a tener resonancia primero a nivel local y regional, y luego a nivel nacional, alcanzando su máxima expresión en los años 70's del

\footnotetext{
${ }^{35}$ Sobre la conformación de la hacienda ganadera, ver también; Fals Borda (1976) y Alejandro Reyes (1976)
} 
siglo pasado. Así, las primeras manifestaciones campesinas en contra del sistema de aparcería y de arriendo se pueden localizar en los años 20's y 30's, sobre todo en la región central de Colombia, en donde es evidente un proceso de formación política por parte del campesinado.

(...) en algunas de estas regiones, durante los años veinte, el Partido Socialista revolucionario adelantó labores de organización sindical y política entre campesinos, jornaleros e indígenas, las cuales habrían de demostrar un especial arraigo en las décadas posteriores. (Fajardo, 1988:42)

No obstante, no es sino hasta después de la segunda mitad del siglo $X X$, que el movimiento campesino logra trascender la incidencia local y regional. La batuta de este proceso estuvo en la cabeza de la Asociación Nacional de Usuarios Campesinos -ANUC-.

Como una manera de encauzar los descontentos frente a las relaciones sociales $y$ de propiedad enraizadas en el campo colombiano la ANUC es creada por decreto en 1967 por parte del presidente Carlos Lleras Restrepo, empero es formalmente constituida en el Primer Congreso Nacional de Usuarios Campesinos celebrado el 7 de julio de 1970. A partir de esa fecha y en un rápido movimiento hacia un posicionamiento más crítico y alejado del influjo del Estado, se constituyó en el más importante proceso organizativo campesino de todo el siglo XX en Colombia.

Para mí la ANUC fue importante no solamente en Sucre sino en toda Colombia porque transformó la mentalidad de muchos campesinos; se convirtió en un instrumento de lucha que de sirvientes de los ricos pasamos a ser propietarios de las tierras. La Asociación de Usuarios nos unió en base de unos lineamientos políticos "tierra pal" que la trabaja" [...] La ANUC nos ofreció la oportunidad primero de organizarnos y de capacitarnos. Pero lo más importante es que nos dimos cuenta que la ANUC somos cada uno de nosotros (Hombre, Adulto, dirigente campesino, Los Palmitos, Sucre, julio de 2009 tomado de $\mathrm{CMH}, 2008)$.

Con la ANUC, los campesinos de Colombia delinearon el camino para luchar por una Reforma Agraria Integral y democrática (ANUC, 1970), dicho camino tomó diversos matices, en cuanto a lo regional se refiere, pues algunos procesos 
organizativos tuvieron mayor arraigo y desarrollo. Justamente las dinámicas que adquirió la ANUC en los departamentos de Sucre y Bolívar, hicieron de la subregión de los Montes de María un bastión del campesinado en el Caribe, pues en sus tierras se libraron las más importantes luchas por la eliminación del latifundio y el establecimiento de la pequeña parcela campesina (tabla 1)

Tabla 1. Recuperaciones de tierra. Departamento de Sucre. Década del 70.

\begin{tabular}{|c|c|c|c|}
\hline Municipio & Recuperaciones de tierra & Municipio & $\begin{array}{c}\text { Recuperaciones de } \\
\text { tierra }\end{array}$ \\
\hline Chalan & Candelillas & \multirow{2}{*}{ San Benito Abad } & La Unión \\
\hline \multirow{5}{*}{ Colosó } & Columbita & & Palito \\
\hline & El Paraiso & \multirow{6}{*}{ San Juan de Betulia } & Canime \\
\hline & Estambul & & El Socorro \\
\hline & La Esmeralda & & La Estación \\
\hline & La Marcella & & Las Delicias \\
\hline \multirow{4}{*}{ Corozal } & Bélgica & & Leningrado \\
\hline & Capiro & & Villa Raquel \\
\hline & Cuba & \multirow{5}{*}{ San Onofre } & Alemania \\
\hline & Las Mercedes & & Estambul \\
\hline \multirow{2}{*}{ Chinú } & Las Flores & & Santa Helena \\
\hline & Malabrigo & & Arroyo del medio \\
\hline \multirow{7}{*}{ Los Palmitos } & Villa Luz & & Comandancia \\
\hline & Hatilo & \multirow{8}{*}{ San Pedro } & Camajones \\
\hline & La Aldea & & Admirable \\
\hline & Arenal & & Los Andes \\
\hline & El Bongo & & Juan Arias \\
\hline & Las Esperanzas & & Paraiso \\
\hline & San Jaime & & El Carmen \\
\hline \multirow{8}{*}{ Morroa } & Peñata & & El diamente \\
\hline & Tumba Vaca & & Moralitos \\
\hline & Tumba Toro & \multirow{4}{*}{ Santiago de Tulú } & Estanzuela \\
\hline & Bremen & & Las Hambrunas \\
\hline & Arenal & & Alicante \\
\hline & Asmon & & Santa Clara \\
\hline & Pichin & \multirow{7}{*}{ Toluviejo } & Macajan \\
\hline & Los linderos & & Belgica \\
\hline \multirow{5}{*}{ Ovejas } & Santa Fe & & La Candelaria \\
\hline & El Piñal & & La China \\
\hline & Mula & & San Jose \\
\hline & El Cedro & & El Prado \\
\hline & Cantaleta & & Navas \\
\hline
\end{tabular}




\begin{tabular}{|c|c|c|c|}
\hline & Flor del Monte & & Birmania \\
\hline & Las mrcedes & & Nuevo Mundo \\
\hline & Buenos Aires & & Aguas Negras \\
\hline & Pijiguay & \multirow{8}{*}{ Palmito } & Tierra Libre \\
\hline & Capitolio & & Las Pavas \\
\hline & El Cedro & & Brebaje \\
\hline \multirow{2}{*}{ Since } & Bellavista & & San Antonio \\
\hline & Moralito & & Floresta \\
\hline \multirow{6}{*}{ Sucre } & Palmarito & & El Bonguito \\
\hline & Camboya & & La Floresta \\
\hline & Chile & & Las Flores \\
\hline & Aquisí & \multirow{5}{*}{ Sincelejo } & Bremen \\
\hline & Colombia & & El Recreo \\
\hline & Lindavista & & La Quinta \\
\hline \multirow{2}{*}{ Sampués } & La Herencia & & La Unión \\
\hline & Guadalupa & & Segovia \\
\hline
\end{tabular}

Fuente. CMH 2010:204

El desarrollo del movimiento campesino de las décadas del 70 y 80 en Los Montes de María, se ha constituido en un referente doblemente importante para entender la actual coyuntura de la subregión.

En primer lugar hay que señalar que la principal incidencia de la ANUC fue el de conformar una base campesina politizada, esto es un movimiento campesino con fuertes niveles de concienciación frente a los problemas de los hombres y mujeres del campo. Esto es reflejado en las actuales organizaciones y proyectos de los líderes campesinos formados en aquellos años de lucha, de igual manera esto puede evidenciarse en la propia identificación del campesinado de la subregión, sobre todo de los campesinos que aun viven en algunos de los municipios con mayor participación durante los proceso de recuperación de tierras, como lo fue el municipio de Ovejas dentro del departamento de Sucre.

De esta manera, se ha consolidado dentro del campesinado una autoreferencia de lucha y reivindicación que puede explicar la actual acción por resistir el desplazamiento y el luchar por las tierras despojadas. En otras palabras, algunos de los campesinos de la subregión se leen como herederos de los procesos de lucha que ellos mismo u otros lideraron durante las históricas tomas de tierra, ahora, esta condición nos lleva a analizar otro referente reproducido por la 
acción de la ANUC en la subregión, este es el proceso de adjudicación de tierras que se hizo durante los años 80 y 90 por parte del desaparecido Instituto Nacional de Reforma Agraria -INCORA-.

En este sentido los campesinos de la subregión no solo lograron un importante acumulado en términos políticos y organizativos sino que también disputaron la vieja estructura de trabajo y de propiedad procedida de la hacienda y del poder terrateniente.

Este último -aunque en una escala menor- modificó la organización del espacio de la subregión, en cuanto, que miles de hectáreas improductivas o copadas con ganado, empezaron hacer pobladas por pequeñas familias campesinas, dando lugar a algunas de las actuales veredas de la subregión, entre ellas VillaColombia en el departamento de Sucre. Esta situación generalizó un paisaje diversificado, donde el cultivo del tabaco compartía el espacio con el cultivo de alimentos como la yuca, el ñame o el maíz; o la cría de animales. Constituyéndose así la parcela campesina que en la mayoría de los casos, no sobrepasaba las 10 o 22 hectáreas. Siguiendo las anotaciones de Mançano (2008), esta manera particular de organizar y producir el espacio, da vida al territorio campesino, un territorio saturado por un fuerte sentido de lugar, relaciones sociales y tradicionales con un componente comunitario importante y un trabajo basado en la familia.

Este espacio y su territorialización en la subregión han sido disputados y radicalmente transformados en los últimos 20 años, sobre todo desde finales del siglo XX y comienzos del XXI. El desplazamiento forzado y la generalización e intensificación del conflicto sociopolítico armado, por un lado y, la entrada de nuevos actores económicos como consecuencia de lo anterior, por otro, han desestabilizado la organización y la producción espacial de los campesinos montemarianos. De ahí el interés de este trabajo en vislumbrar esas prácticas espaciales que se fueron transformando durante los años 2004 al 2012. 
3.2. A propósito de la organización espacial y la construcción de espacialidad de los campesinos montemarianos.

¿Cuál es la importancia del anterior recorrido geohistórico? ¿Por qué fijarnos en la historicidad y espacialidad de la organización espacial de la subregión y la macro región Caribe?

Pues bien, el fijarnos en la historicidad y espacialidad de la organización espacial en los Montes de María se debe a dos aspectos fundamentales: el primero tiene que ver con la misma historicidad y espacialidad de la conformación campesina y de sus prácticas espaciales. Frente a este primer aspecto hay que recordar que muchas de las prácticas espaciales que analizamos en el trabajo y que fueron modificadas por el desplazamiento forzado, fueron resultado de ese recorrido histórico y del característico proceso de mixtura étnica, propio del campesino costeño.

Algunas de las prácticas espaciales de las familias campesinas de la subregión tienen que pasar por una lectura de larga duración, pues sin ésto, no se podría entender el efecto del desplazamiento forzado y del posterior retorno, en la temporalidad misma de las prácticas. Así, por ejemplo, la práctica de trabajo colectivo o comunitario en las labores propias del cultivo, la siembra, la recolección o las mejoras, denominado en la subregión como "ganar día" tiene que ser entendido como un acumulado -que se ha ido transformando y renovando con la historicidad de los sujetos-, originado en las relaciones sociales comunitarias de los primeros pobladores de la subregión, las fuentes consultadas nos permiten deducir que el "día ganado" es una manera de relacionamiento surgida en las propia maneras de organización del trabajo de los originarios Zenues. Un elemento presente en las maneras de concebir el trabajo comunitario de los campesinos. Sin entrar en mayor detalle, pues este tema es analizado con mayor detalle en el capítulo 4, lo que acá queremos demostrar es que las prácticas espaciales de las familias campesinas que fueron reconfiguradas tienen que ser leídas en términos históricos, el recorrimos que hicimos nos dan las pistas para poder comprender esa materialidad e inmaterialidad presente en la producción espacial de estas familias antes y después de los retornos. 
Ahora, el recorrido histórico no solo se justifica en razón de la comprensión de la formación de las prácticas espaciales de los campesinos montemarianos, también es clave para comprender el actual estado de cosas de la subregión.

Muchas de los aspectos que hacían parte de los ejercicios de configuración espacial que repasamos, han logado trascender su tiempo, alimentando el presente, instituyendo una estructura regional.

En concordancia las configuraciones espaciales y las prácticas concretas que producen el espacio social, pueden ser rastreadas en el presente, en la estructuración regional y en las relaciones de poder que sustentas dicha estructuración. De este modo, la organización agraria en la macroregión Caribe y en especial en los Montes de María, es el resultado o la síntesis de algunas de las acciones, propiedades y características que han logrado mantenerse, adaptado o anteponerse en un proceso histórico. Un elemento común en el recorrido geohistórico que hicimos es la continua tensión entre la gran propiedad y la posibilidad de que pequeños pobladores (sean indígenas, negros 0 campesinos) puedan desenvolver su espacialidad de manera autónoma e independiente a un poder centralizado (la hacienda y/o el terrateniente), tal vez, lo desarrollado con el movimiento campesino en el último tercio del siglo pasado, haya podido nivelar esa situación, no obstante, el accionar violento y la generalización del desplazamiento forzado de los años 2000, nos este demostrando el mantenimiento de ciertos rasgos estructurales que han hecho del desplazamiento y del despojo de tierras un aspecto connatural a la historia social de la subregión. Una particularidad que puede ser rastreada en el análisis de la propia estructura agraria de los Montes de María.

Para nosotros la estructura agraria es entendida como el proceso en el que históricamente se han establecido y se han ordenado los diferentes actores y factores de producción, que permiten describir y analizar los aspectos fundamentales de la sociedad agraria en sus diversas relaciones (Muñoz, 2007), bajo esta perspectiva, la estructura agraria en la subregión de los Montes de María es parte del análisis de la espacialidad social, de las pugnas y contradicciones que han atravesado la cuestión agraria en la subregión. Así, la estructura ha estado constituida por: i) una fuerte disputa por la tenencia de la 
propiedad, lo que ha promovido por un lado, un alto índice de concentración de la tierra y por otro, una constante lucha de los campesinos sin tierra por acceder a ésta; ii) una imposición -muchas veces violenta- de proyectos de economía regional basados en diferentes modalidades agrarias (Bimodal, Unimodal y Multimodal); una política regional soportada por un sistema constituido por el gamonalismo, la gran propiedad y la captura de las instituciones regionales (gobernaciones, alcaldías, concejos,...) y iii) unas maneras de poblar y usar el territorio consecuente con los anteriores elementos y que en determinados momentos históricos -basadas en estructuradas relaciones de poder- pueden desaparecer, se pueden imponer o se pueden modificar.

Por lo tanto, el contexto del desplazamiento y del proceso de retorno de las familias campesinas de las veredas de VillaColombia y Borracheras, puede desprenderse de su carácter más morfológico, siempre y cuando podamos vislumbrar la historicidad de su producción espacial como de las implicaciones estructurales que mantiene el despojo de tierras como una constante propia de la estructura agraria de la subregión.

De esta manera, el preguntarse por las condiciones, la naturaleza y las modificaciones espaciales de estas familias será un objetivo que en los próximos capítulos abordaremos. 


\section{CAPITULO IV}

\section{ENTRE EL IRSE Y EL VOLVER:}

EI DESPLAZAMIENTO

En el siguiente apartado, se presenta el contexto social y de violencia que envolvió el proceso de desplazamiento de las familias campesinas de las veredas de VillaColombia y Borracheras. Nos centramos en las dinámicas del desplazamiento, porque partimos de la premisa, que para comprender los cambios y las reconfiguraciones de las prácticas campesinas durante el proceso de retorno, hay que comprender primero las causas y las implicaciones que tuvo el desplazamiento forzado en los sujetos y en sus prácticas, es decir, en el ser campesino y en las maneras en que ese ser se realiza en un espacio determinado. Es ver como la relación «desplazamiento-retorno» atraviesan a los sujetos y a los sentidos de sus prácticas. Bajo esta idea, el capitulo ha sido organizado en dos momentos: en el primero se expondrá la constitución del sujeto campesino, sus representaciones sociales, sus procesos de identificación y los sentidos de sus prácticas materiales e inmateriales antes del irse, es decir antes del desplazamiento. En el segundo momento, abordamos el proceso de desplazamiento, por medio de los elementos históricos que han transcendido y articulado el actual conflicto armado en la región, resaltando los actores, los motivos y los efectos sobre la población campesina de las veredas de VillaColombia y Borracheras.

\section{Antes del irse: el ser, el estar.}

Las veredas de VillaColombia y Borracheras, así como sus pobladores, han sido el resultado de diferentes procesos de colonización y organización campesina que desde mediados del siglo XX han marcado la historia social de la subregión de los Montes de María. Dentro de este proceso -comprendido comosociohistórico y espacial, se pueden identificar una multiplicidad de relaciones que configuraron el «ser» y el «estar» de estos campesinos.

Cuando nos referimos al ser y al estar, estamos queriendo enunciar las cualidades y características materiales e inmateriales que constituyen y atraviesan el sujeto campesino así como a sus prácticas de producción y 
reproducción socioespacial. Para nosotros, los sujetos campesinos "(...) se construyen en el tiempo, [y en una espacialidad edificada alrededor del campo y el trabajo en la tierra], es ahí donde un grupo de personas se dan cuenta que comparten intereses comunes, que los hacen trabajar de manera colectiva y organizada, que conforme pasa el tiempo, reconocen la historia que los une, se reconocen (quiénes son, cómo están, por qué están), se dan cuenta de sus debilidades pero también de sus fortalezas, les permite construir como colectivo imaginarios deseados de vida buena, que los hacen caminar en el tiempo, impulsando proyectos colectivos que mejoran sus condiciones de vida, practicando el trabajo colaborativo y solidario" (López, 2010: 22)

En otras palabras, el ser y el estar del que hablamos corresponderían a la posición del sujeto y a las relaciones socioespaciales que estos establecieron alrededor de una vida rural y de unas relaciones sociales y comunitarias determinadas. Abordar ese ser y ese estar, nos permitió comprender la constitución de los sujetos y cómo estos sujetos -a partir de prácticas concretasse desenvolvieron en el espacio antes y después de los retornos.

De esta manera el ser y el estar, son ubicados en el centro de una serie de relaciones cuyas aristas envuelven y explican la naturaleza, las transformaciones y las reconfiguraciones de la vida campesina ${ }^{36}$. Identificar las dinámicas y las cualidades que estructuran estas relaciones, dependerá de la posibilidad del reconocimiento del tiempo y el espacio como soportes del proceso de identificación y constitución del sujeto campesino. Bajo esta premisa, las familias que vivieron el desarraigo y que posteriormente retornaron a las veredas de VillaColombia y Borracheras, son comprendidas no como un abstracto «familia campesina» sino como hombres y mujeres con historia, memoria y prácticas concretas, constitutivas todas ellas, de su propio proceso de autoreconocimiento.

Con base en los resultados del trabajo de campo, podemos distinguir dos niveles de ese autoreconocimiento: el primero está íntimamente relacionado con la

\footnotetext{
${ }^{36}$ De ahí que a partir del reconocimiento del ser y del estar de los sujetos campesinos, se puedan determinar los sentidos que estructuran las prácticas espaciales de dichos sujetos. Si las bases que sostienen el ser y la realización del ser en un estar, son trastocados, los sentidos prácticos que orientan la vida cotidiana de los campesinos, también se verán modificados.
} 
historicidad de los campesinos, es decir, los hechos que estructuraron y estructuran su memoria y su identidad. En el segundo nivel, encontramos los ejercicios materiales e inmateriales, a partir de los cuales, las y los campesinos apropiaron y produjeron un espacio, desenvolvieron una dominación y un sentido de pertenencia hacia y entorno al territorio. Aquí, es primordial abordar estos dos niveles desde su construcción individual como colectiva, al igual que desde el carácter interdependiente que los asocia.

En cuanto a la historicidad, es importante recordar la incidencia que tuvo la Asociación Nacional de Usuarios Campesinos -ANUC- y el movimiento campesino (en general) en la formación de un proceso de identificación ligado en gran parte- a las luchas agrarias de los años 70's.

Las recuperaciones de tierra, los paros tabacaleros, las disputas frontales en contra del sistema hacendil, la aperturas de caminos, los comités municipales y veredales de la ANUC, así como la imagen y el sacrificio de algunos líderes en pro de las reivindicaciones del campesinado, todo ello, ha sido fijado en la memoria individual y colectiva de la subregión, convirtiéndose en parte fundamental del autoreconocimiento y heteroreconocimiento (Giménez, 1997) identitario de estos campesinos.

La disposición de dichos reconocimientos (auto y hetero) permiten conformar una serie de representaciones que le otorgan sentido y estabilidad a las identidades individuales y colectivas.

Yo llegue en el 76, porque yo estaba en la lucha por la tierra en San Pedro, en el periodo de las ardientes luchas campesinas que se desarrollaron en el año de 1970, más exactamente en febrero. En ese entonces en Colombia se dieron 640 tomas de tierra (...)

Bueno, comenzamos a luchar. Comenzamos a afectar tierra en San Francisco, La Represa, El Pedregal, La Conquista, El Castillo y La Cantaleta, Sí, le caímos a La Cantaleta como en el año 78. Bueno, eso estaba teso en La Cantaleta, ahí movilizamos hasta 800 campesinos, todos a nivel departamental. En esa finca, el terrateniente nos salió bravo (era un Cachaco llamado Jaime) y estaba bien arrecho!, nos mató tres compañeros, los mató en la lucha por la tierra. (Líder campesino VillaColombia, entrevista 3 abril de 2012) 
De tal manera, las representaciones identitarias pueden ser fruto -como en el testimonio anterior- de una experiencia personal, es decir, del reconocimiento de la acción y/o las participación directa sobre el acontecimiento evocado, de igual forma, estas representaciones también pueden resultar de un proceso "heredado" o "transmitido", donde terceros actualizan un conjunto de códigos y símbolos identitarios, así como de una memoria que apropia y le otorga sentido a dichos códigos y símbolos (en este caso, nos referimos al complejo simbólico cultural construido alrededor de la ANUC y la lucha campesina).

Justamente, el carácter de lo experimentado y lo transmitido está impreso en los discursos y las prácticas de los hombres y mujeres de VillaColombia y Borracheras. En el caso de VillaColombia, el autoreconocimiento frente a la ANUC es mucho más fuerte, pues parte de la propia experiencia de sus pobladores, de ahí que la evocación de dicha experiencia esté atada a lo que podríamos definir como una memoria autobiográfica o lo que Endel Tulving (1985) ha denominado conciencia autonoética. Frente a este tipo de consciencia, Ruiz (2008: 64) afirma, que ésta le permite a los sujetos distinguir entre "estar pensando en algo" y "estar evocando o recordando algo". Lo sustancial y único de la memoria autobiográfica estaría, por tanto, en la sensación consciente de pasado, es decir, en el sentimiento subjetivo de que, en la experiencia que se revive en el momento presente, un sujeto está reviviendo algo que sucedió anteriormente en su vida; una experiencia mental única e inconfundible que no tiene nada que ver con conocer o saber algo, propio de la memoria semántica. La premisa establecida por Tulving puede ser rastreada en la memoria de los campesinos más viejos de VillaColombia, pues en ella se encuentra el pasado vivo y autoreferenciado de las luchas campesinas y el proceso organizativo de los años 70's y 80's en la subregión.

Con relación a la ANUC y al movimiento campesino, VillaColombia es -como diría Le Goff- un lugar de memoria:

En ese entonces (1974) comencé a ser parte de las organizaciones, ya me reuní con los compañeros y comencé la lucha. Por aquella época, empecé a asesorar a algunos procesos de recuperación de tierra, por ejemplo, íbamos a prestar compañía a los compañeros de la finca La Mula, íbamos a 
prestar solidaridad. [...] (Líder campesino VillaColombia, entrevista abril de 2012)

Por su parte, los pobladores de Borracheras no estuvieron íntimamente relacionados con el proceso de recuperación de tierras liderado por la ANUC, pues gran parte de los campesinos que pasaron por el drama del desplazamiento y el proceso de retorno, llegaron a la vereda tan solo a mediados de los años 90's, en una época en el que el movimiento campesino en la región Caribe, estaba atravesando serios problemas orgánicos ${ }^{37}$. No obstante, rápidamente estos campesinos han apropiado como suyo ese proceso "no vivido", esa memoria de resistencia y lucha campesina, al igual que el complejo simbólico cultural construido alrededor de ella. Hoy en día asumen los hechos del pasado como expresiones constitutivas de lo que hoy son, de lo que hoy tienen o por lo que hoy luchan, en palabras de uno de los líderes, dicha consciencia (histórica) se expresa de la siguiente manera:

Las vías, el agua, el jagüey,... todo eso le costó al campesino, porque eso costo sangre. Aquí para hacer un camino costaba sangre. Muchos de esos caminos no fueron obras del Estado - que las hizo porque quiso- sino porque fue resultado de la presión del campesinado (...) Las tierras por las que hoy peleamos, son tierras que los campesinos de los años 70's lucharon con esfuerzo, esmero, ... y que les costó sangre, muchos perdieron la vida. (...) (Líder campesino Vereda Borracheras, Entrevista 17 abril de 2012)

Así para la mayoría de los campesinos de Borracheras, el espacio producido ${ }^{38}$, es asumido como un espacio mitificado, heredado de las gestas campesinas de

\footnotetext{
${ }^{37}$ En el segundo congreso de la ANUC, celebrado en el mes de julio de 1972, se presenta una serie de divisiones de tipo ideológicas y de orientación política que terminan debilitando y fraccionando la organización campesina.

38 "El espacio producido alude a las vías de comunicación terrestres, vías de agua, los campos, espacios públicos, etc., son las transformaciones realizadas por el ser humano para hacer de la naturaleza un espacio habitable, es decir transforman su medio para poder vivir en él y poder reproducirse biológica y socialmente, por ello las familias como tal o como comunidad se han organizado para construir y/o transformar su medio para satisfacer sus necesidades. La comunidad se organiza para darle mantenimiento a sus manantiales, caminos, calles, construcción de las escuelas, capilla, por dar ejemplos" Ver López (2007: 17)
} 
las décadas pasadas. Se construye así un sentido compartido sobre el pasado, una memoria social y con ella, una identificación frente a esa memoria, frente a esa historia.

Ahora, la interiorización de esta historicidad, tanto a nivel individual como colectiva, permitió no solo la articulación de un discurso identitario (narrativa constitutiva del ser), sino que instauró además, un principio generador a partir del cual se organizó la vida cotidiana (el ser en el estar). Acá el segundo nivel del autoreconocimiento de los sujetos campesinos cobra relevancia, pues es a partir de prácticas materiales e inmateriales que los sujetos traducen las estructuras sociales objetivas construidas históricamente. Entre la historia y su interiorización se conforman esquemas -nunca determinados-, que permiten la reproducción social y espacial de los sujetos a través de maneras particulares de clasificar, apreciar, desear, sentir, valorar y actuar sobre la existencia de lo social.

Por consiguiente, tanto la historicidad (y la memoria) que los campesinos de VillaColombia y Borracheras comparten, como las prácticas que desenvuelven alrededor de un modo de vida particular, (...) terminan por constituir el pensamiento social [y espacial] que organiza la vida cotidiana, que forma parte de un marco lógico explicativo del ser y hacer de cada uno, impregnando de significado a lo tangible e intangible (...) (López, 2010:15-16)

Como vemos, este marco explicativo del ser y el hacer, le otorga sentido a las prácticas, a la vez que se conforma un escenario de mutuo reconocimiento entre aquellos que comparten dicho sentido práctico (una intersubjetividad, base de toda comunidad).

Todo lo anterior es importante si consideramos que «cada colectividad se integra alrededor de los mismos valores, creencias, símbolos, mitos y rituales, impregnando de espíritu y comportamiento religioso las relaciones sociales y consagrando espacios" (Le Bourlegat, 2001:4), todo ello es básico en la construcción del sentido de pertenencia al compartir el sistema de códigos que rigen su convivencialidad y organización que puede ser en el nivel de lo familiar, comunitario o regional (López, 2010:14) 
Así, la vida de los campesinos de VillaColombia y Borracheras, antes de los desplazamientos se caracterizaba por compartir una matriz de sentidos que les permitía actuar y orientarse de manera comunitaria en el mundo, es decir, un ser campesino, constituido en un particular y compartido estar. En este sentido, es importante señalar que en todas las entrevistas (individuales y colectivas) realizadas durante el trabajo de campo, se encontró una reiterada mención hacia la «comunidad», en todas las entrevistas se alude a un sentido de pertenencia comunitario, todos se autoreferenciaban como pertenecientes a una comunidad.

La comunidad, para el caso de estos campesinos, no es simplemente una manera de enunciarse o de enunciar un espacio de residencia (soy de tal o cual comunidad), sino que responde a la posibilidad de reconocer y organizar el mundo de manera compartida. El sentirse parte de la "comunidad de VillaColombia" o de la "comunidad de Borracheras" les permitió a estos campesinos leer, interpretar e interactuar sobre la realidad (cultural, económica, social,...) de manera colectiva. Acá, los espacios familiares y el «sentido de vecindad» se constituyeron en partes fundamentales del devenir de la misma comunidad.

Entonces, la expresión de lo comunitario puede rastrearse en las celebraciones patronales o en fiestas de cumpleaños; en el trabajo colectivo, principalmente en épocas de cosechas; en el mantenimiento de los espacios producidos (caminos, jagüeyes, cercos,...) o en la construcción de espacios públicos como la escuela o privados como un caney ${ }^{39}$. En toda esta manifestación de lo comunitario subyace una particular manera de ordenar el territorio, cuyos sentidos son elaborados continuamente por los propios procesos organizativos y políticos en una amalgama con lo simbólico.

\footnotetext{
${ }^{39}$ Los caney son las formas de vivienda tradicional de la Costa Caribe. Los Caney pueden ser sitios de vivienda o de trabajo. Cuando funciona como lugares de almacenamiento o en espacio para la preparación de alimentos o el descanso en las horas del día más calurosas, generalmente se encuentran anexas a la construcción principal de habitación. Son hechos con materiales naturales, con pilotes estructurales de madera de grandes árboles; con cubiertas protectoras a dos aguas, elaboradas con las hojas de la palmera de la región, no presentan ningún tipo de división o pared interna, sus patrones siempre siguen formas circulares o rectangulares. En términos arquitectónico y antropológicos, se podría decir que estas construcciones son resultado de una reelaboración campesina, de las originales construcciones de los indígenas Zenúes de la región.
} 
"Por ejemplo el 24 de diciembre o el 31 de diciembre, en la semana santa, u otro día... uno lo tomaba pá integrarse con la comunidad. Se hacían dulces, se hacía chicha, el bollo,...se mataba el cerdo y se hacían chicharrones" ¿y cómo se escogían los lugares para las celebraciones? "una temporada correspondía a un vecino y después en la otra, correspondía a otro, y así para que todos nos tocara parte de la participación. Para ese entonces eso era muy bonito, pues uno hacia todas esas actividades de manera colectiva,..." (Testimonio mujer campesina, Vereda Borracheras, entrevista abril del 2012)

“.....habian unas fiestas tradicionales que eran de dos santos, que velaban santos, o sea tradiciones de los más señores...había la de noviembre que era la de San Martín de Loba que era con las fiestas de Cartagena y la del niño Dios, incluso se hacían velaciones, tradiciones de la gente de por aquí, mandas...por ejemplo en este verano que tenemos ahora por aquí, uno venía y le hacía una fiesta al santo y le pedía que lloviera y llovía, uno creía en eso y decía que era milagro del santo, pero ya eso se perdió.....las mandas se organizaban... A nivel de toda la comunidad, porque toda la comunidad participaba y habían distintas maneras de pagar las mandas, si usted le ofrecía con gaitas o acordeón tenía que buscar el grupo que tocara con acordeón o con gaitas y si eran 2 días de gaitas y uno de acordeón había que cumplirle, porque a él le gustaba mucho la gaita... al santico......al niño Dios". (Grupo Focal de la vereda el Palmar. Colectivo de Comunicaciones Montes de María Línea 21, 2013:14)

En estas condiciones los campesinos de VillaColombia y Borracheras, construyeron sus vidas alrededor de la comunidad, lo cual a su vez, estructuró las disposiciones socio culturales y espaciales que antaño los unió, dando sentido a lo que hacían, a lo que creían, generando afecto y arraigo, donde se producían y reproducían conocimientos $u$ otras expresiones tangibles e intangibles de su modo de vida campesino (López, 2010).

Entre estos conocimientos y expresiones de lo campesino, las prácticas configuradas alrededor del trabajo, son las que nos permiten aprehender la estructura organizativa del modo de vida de estas comunidades antes de los desplazamientos. 
En un primer abordaje, es importante señalar que alrededor del trabajo, no solo se organiza la vida individual, sino que éste -el trabajo- determina la posición de los sujetos dentro de las relaciones familiares y comunitarias (división social, técnica, de género y generacional).

De allí que el trabajar la tierra, sea uno de los principios estabilizadores de la propia auto identificación como campesinos. Así, para las comunidades de VillaColombia y Borracheras, el trabajar la tierra no solo constituye el medio de subsistencia, sino que es a través de ésta (la tierra) que las familias de se unen, a la vez que afianzan lo que ellas mismas denominan como el "tejido social", es decir, el plano de las relaciones sociales estructuradas y estructuradoras de lo comunitario.

"En la comunidad, cuando se lograba la cosecha, todo mundo pasaba a poyar, ya sea para sembrar o para recoger. Si un día, le vecino no podía ir a acompañar al otro vecino, seguro, el otro día estaba temprano presto a colaborar. Ósea, así había una unión entre todos, porque todos nos apoyábamos en la época de lluvia (de siembra)" (Testimonio Mujer Campesina, Vereda Borracheras, abril de 2012)

Así, la tierra y el trabajo se funden en un mancomunado y particular modo de reproducir las relaciones sociales, la historia y el sistema de valores que orientan las conductas comunitarias de los campesinos.

Por consiguiente, el ser y el estar de los campesinos de VillaColombia y Borracheras antes de los desplazamientos no solo puede ser entendido como resultado del acumulado histórico compartido, sino de aquello que se ha encarnado de manera durable en el cuerpo [social] en forma de disposiciones permanentes (Velazco, 1998: 3), que en palabras de Bourdieu podría traducirse como habitus (1988a, 1988b, 1990), o para Almeida (2006) en un habitus campesino.

A pesar que la relación entre el habitus y las prácticas espaciales de los campesinos retornados va a ser objeto de análisis en capítulo IV y en las consideraciones finales, quisiera anotar a manera de introducción, que dicho habitus para el caso de los campesinos de VillaColombia y Borracheras, puede ser entendido como una manifestación tangible e intangible - y a la vez no 
consciente $^{40}$ - de un modo de ser y de vivir campesino ${ }^{41}$. Por consiguiente, las prácticas que sustentan ese modo de ser, encuentran en la familia, la comunidad y el trabajo en la tierra (la agricultura), sus máximos exponentes, en cuanto a estabilizadores y generadores de conductas, percepciones y apreciaciones se hable, así como de organizadores de la acción individual y colectiva (Bourdieu, 1988).

En síntesis, ese habitus campesino es entendido como el sentido práctico que atraviesa la constitución de los campesinos, sitúa a los sujetos orientando las explicaciones de mundo, creando símbolos, códigos, estructuras mentales que dan sentido a los que hacen y a lo que son, manifestando todo esto mediante sus fiestas, sus rituales, sus prácticas productivas, sus relaciones sociales y sus relaciones con la naturaleza (López, 2010:15). Al presentarse el desplazamiento forzado, dicho habitus se volca inestables, sin querer decir, que antes haya sido totalmente estable, lo que sucede, es que el desarraigo modifica violentamente el sentido del ser y del estar, con lo cual los sujetos reconfiguran radicalmente la estructura y principios generadores de la acción. Para comprender este proceso en los campesinos de VillaColombia y Borracheras, el siguiente apartado abordará el recorrido del desplazamiento y sus implicaciones tanto a nivel individual como colectivo.

\subsection{El irse: el contexto del desplazamiento}

\subsubsection{Los avatares de la montaña de María}

El desarraigo que vivieron las comunidades campesinas de las veredas de VillaColombia y Borracheras, ha sido una constante en la historia social de Los

\footnotetext{
${ }^{40}$ La referencia a la no conciencia está relacionada a la idea de conformación genética del habitus, es decir, las prácticas orientan ciertos fines del sujeto, pero el establecimiento como la consecución de dichos fines nunca son buscados de manera consciente. De acuerdo con Bourdieu "el habitus, al funcionar como principios generadores de prácticas pueden estar adaptadas a su fin sin que ello suponga la búsqueda consciente de fines y el dominio de reglas", Ver Hernández, 2006.

${ }^{41} \mathrm{El}$ modo de ser y de vivir campesino, puede ser rastreado en los trabajos sobre campesinos y campesinado en Colombia como "ethos campesino" (Fals Borda, 1986). Para el caso de los estudios rurales en Brasil existe una corriente que insiste en abordar el modo de vida campesino a través de la categoría de "Campesinidad» (Woortmann, 1990). También ver una visión crítica de esta categoría en Almeida (2006)
} 
Montes de María. El ejercicio de desterritorialización e imposición de espacialidades a partir del desplazamiento, se puede rastrear -como se expuso en el capítulo anterior- desde el cruento proceso de conquista y colonización. Esta mirada de larga duración permite comprender cómo diferentes grupos, en diferente momentos históricos han producido espacios y territorialidades desde prácticas concretas y en medio de fuertes disputas por posicionar y/o resistir lo que Lefebvre denomina "representaciones del espacio ${ }^{42}$ ", esto es, una lógica que produce y reproduce una conceptualización funcional y racionalizada del espacio.

Dichas representaciones del espacio no son construcciones apresuradas, gobernadas por el capricho de tal o cual sujeto o actor social. Por el contrario son resultado de complejas relaciones de poder sostenidas en el tiempo. Ahora, si reconocemos la historicidad como moldeadora de la producción y la organización espacial, esto nos lleva a abordar la historia de la subregión como base explicativa de las actuales tensiones socioespaciales que atraviesan los retornos campesinos. De este modo, muchas de las disputas que actualmente recorren los territorios montemarianos, son producto de las relaciones sociales y de producción, sustentadas en la concentración de la tierra y en un sistema sociopolítico heredado del periodo de la hacienda; relaciones que han logrado mantenerse, hasta el punto de constituirse -casi como un mal endémico- en la base de la actual estructura agraria, la cual, además, se ha caracterizado por introducir la violencia como estrategia legitimadora de dicha estructura.

De esta manera:

"Desde el siglo XVI, esta zona se ha visto afectada por periodos de conflictos sociales asociados principalmente a la organización territorial y la tenencia de la tierra. Estos ciclos casi siempre han estado mediados por dinámicas de violencia, despojo y desplazamiento de la población" (Hernández, 2010:10)

\footnotetext{
${ }^{42}$ Para Nantes (2001) El espacio representado "refleja las características mentales de las lógicas de los individuos y sus valores. Cada una de sus acciones es la manifestación, es producto del proceso mental que surge después de haber percibido, procesado e interiorizado su realidad. Estando presente en lo político, social, económico, cultural y ambiental"(Nates et al., 2001:24)
} 
Siguiendo a Hernández (2010), estos ciclos se han traducido -la mayoría de las veces- en formas violentas de imposición de espacialidades. Desde los años noventa, estas formas se han materializado en la sistemática utilización del desplazamiento forzado como estrategia de guerra, especialmente por parte de los grupos paramilitares.

\subsubsection{Disputa y confrontación armada}

"Los contextos regionales del conflicto armado en Colombia deben entenderse como una combinación de los problemas estructurales y conflictos acumulados del pasado sobre los cuales se insertan las lógicas nacionales de la guerra y las decisiones estratégicas de cada uno de los actores armados" (CNRR-GMH,2010)

De entrada, es importante considerar que como parte de esas dinámicas cíclicas de violencia, entre finales de los setenta e inicios de los ochenta del siglo XX, emergieron en la zona grupos subversivos de distintas denominaciones que más tarde se disputarían el control territorial con grupos de autodefensa vinculados con el narcotráfico, con algunos ganaderos y latifundistas de la región (Observatorio del programa presidencial para los DDHH y el DIH, 2003; citado en Hernández 2010:10) $)^{43}$

La coyuntura regional y la correlación de fuerzas $^{44}$ que se disputaba en los Montes de María y en general en la región Caribe desde los años setenta, abonaría el camino para que diferentes actores armados se instalaran en la región; a modo de exposición, el proceso de inserción y expansión armada en la subregión puede ser rastreada a través de tres etapas, a saber: i) la llegada y la instalación de los primeros grupos revolucionarios; ii) los ejércitos privados y la

\footnotetext{
${ }^{43}$ Al respecto, ver Reyes Alejandro (2009) Guerreros y campesino: el despojo de la tierra en Colombia.

${ }^{44}$ Esta correlación debe ser entendida dentro del escenario de confrontación que se disputaba en los Montes de María entre los intereses del campesinado organizado (primero en los sindicatos tabacaleros y en la Federación Nacional Agraria-FENAL- y después en la ANUC) y, el mantenimiento de los privilegios por parte de los terratenientes y ganaderos de la subregión. Desde los años setenta, el movimiento campesino en cabeza de la Asociación Nacional de Usuarios Campesinos ANUC, logró no solo articular el campesinado en un gran movimiento nacional, sino que se enfrentó directamente el status quo rural, en una ardua lucha por modificar la vieja estructura agraria de Colombia. De esta manera, por varios años el campo colombiano se debatió entre una redistribución y una tenencia de la tierra desde abajo y, una estructura agraria basada en la concentración de la tierra y el poder latifundista. Hoy esta tensión no ha desaparecido.
} 
aparición del paramilitarismo; y, iii) la disputa territorial entre el paramilitarismo y la guerrilla de la FARC-EP.

\subsubsection{Insurgencia en la montaña de María}

Los primeros grupos armados de tendencia revolucionaria se instalaron en la subregión a mediados de los años ochenta. El contexto de su aparición, estuvo en marcado por la abierta disputa entre el campesinado y los terratenientes de la subregión, especialmente en el departamento de Sucre. De este modo, la dinámica del conflicto sobre la tierra abrió la puerta para la entrada de grupos guerrilleros.

Las diferencias ideológicas y la cada vez más evidente radicalización del movimiento campesino, que por ese entonces estaba sufriendo una intensa persecución por parte del Estado y los ejércitos privados de terratenientes y ganaderos, sentaron las bases para que algunos grupos revolucionarios se insertaran dentro de las dinámicas regionales e intentaran direccionar o por lo menos influir, en el carácter político del campesinado.

Entretanto, los grupos insurgentes que habían entrado tímidamente por esa época a la zona -como el Ejército de Liberación Nacional (ELN), el Partido Revolucionario de los Trabajadores (PRT), la Corriente de Renovación Socialista (CRS), y en menor medida el Ejército Popular de Liberación (EPL)-, fueron creciendo en número de efectivos y en territorios dominados. La presencia de las guerrillas de izquierda respondería a una lógica asociada a varios elementos. En primer lugar, su llegada a los Montes de María correspondería a una especie de oportunismo político. Aunque a finales de los 70 y recién entrada la década de los 80 la ANUC había tomado tal fuerza que los miembros de la Asociación cerraron los espacios ante una eventual intervención de cualquier guerrilla que pudiese incidir en el desarrollo político de la región, hacia mediados de los 80 la cuestión era a otro precio. El revés sufrido a través del Pacto de Chicoral ${ }^{45}$ y

\footnotetext{
${ }^{45}$ Dentro de la historia del siglo XX en Colombia, el pacto de Chicoral, significo el retroceso definitivo a las reformas agraria que había abierto la ley 200 de 1936. "En enero de 1972, el gobierno Pastrana confirmó oficialmente la reorientación de la política agraria por medio del Acuerdo de Chicoral. Es esa ocasión, el gobierno había reunido a los representantes de los gremios agrarios y los políticos más importantes de los partidos tradicionales relacionados con asuntos agrarios, a excepción del sector Llerista del Partido Liberal. En Chicoral se abandonó completamente la política agraria reformista y redistributiva para dar un
} 
posteriormente con la promulgación del Estatuto de Seguridad durante el gobierno del Presidente Julio César Turbay (1978-1982) para enfrentar a los grupos rebeldes, la situación de persecución y eliminación de miembros destacados de los movimientos sociales se radicalizó. Dadas estas circunstancias, las guerrillas, que se fueron acercando al territorio intentando aprovechar la frustración ante una reforma agraria paralizada, lograron instalarse por completo. (Idepaz, 2011)

Algunos de estos grupos insurgentes, como el Ejército Popular de Liberación EPL- provenían del departamento de Córdoba, y contaban con un acumulado de lucha y resistencia que se remontaba desde mediados del los años sesenta. De acuerdo con el informe de Memoria Histórica, el EPL hizo presencia en la región sinuana desde 1965, pero fue en 1967 cuando apareció formalmente en Córdoba. En diciembre del mismo año, la hoya hidrográfica de los ríos Sinú, Manso y Tucurá fue declarada por el EPL como zona de guerra (CNRR-CMH, 2010:94)

No obstante, solo hasta mediados de la década del ochenta éste, junto con otros grupos guerrilleros llegarían a los Montes de María, de éstos los que tendrían mayor influencia política y militar en toda la subregión serían el Ejército de Liberación Nacional -ELN-; el Partido Revolucionario de los Trabajadores -PRT, y la Corriente de Renovación Socialista -CRS-

Con la desmovilización de los miembros del EPL y el PRT en 1991, más la desmovilización de la CRS el 9 de abril de 1994, se creó un vacío de poder que fue aprovechado por la guerrilla de las FARC-EP, la cual tenía presencia en el departamento de Córdoba desde 1980 a través del V Frente y, en 1983 a través del XVIII Frente. A partir de ese momento la estructura militar de las FARC-EP se expandió no solo en Córdoba sino que poco a poco fue ampliando sus Frentes hasta entrar a los Montes de María. En la década del noventa se presentaría la consolidación militar y política de esta guerrilla en la subregión, lo

impulso a las explotaciones de tipo capitalista, a la vez que se proponía obligar a los terratenientes tradicionales a realizar una transformación capitalista de los latifundios de baja productividad" (Rudqvist, 1983:8). Para consultar información más detallada, ver: Rudqvist (1983); Mondragón (2002). 
cual acarreó una prolongada disputa territorial con los frentes paramilitares que se movilizaban desde el Departamento de Córdoba y el sur de Bolívar hasta el interior de la subregión.

\title{
4.2.2.2. Ejércitos privados y el paramilitarismo.
}

Las primeras expresiones de ejércitos privados en la subregión, tienen que ser relacionadas a dos fenómenos regionales, por un lado al poder del hacendado y el terrateniente, y a la presencia del narcotráfico por otro.

Dentro del primero, es importante recordar que el poder continuado por los terratenientes y los ganaderos dentro de las dinámicas de la subregión, fue fuertemente disputado en los años setenta y ochenta por la ANUC, los cuales según la lectura de los latifundistas- se constituían en los enemigos de clase que ponían en riesgo sus privilegios. Así se radicalizarían las acciones por parte de los terratenientes, optándose por eliminar cualquier manifestación que atentara contra el sistema establecido.

Como método de represión al movimiento campesino que había promovido la redistribución de la tierra a través de la organización y las denominadas "recuperaciones" 46 , fueron apareciendo pequeños grupos armados que, con presunta complicidad de miembros de la fuerza pública y los poderes políticos locales, se dedicaron al asesinato de dirigentes y líderes campesinos.

\begin{abstract}
Alarmados por el cambio súbito de un orden que por siglos había permanecido inmóvil, algunos dueños de fincas comenzaron armar a sus peones para golpear a todo aquel que amenazara su feudal modo de vida. Esa fue una semilla de venganza, que quince años después cobró miles de vidas (VerdadAbierta, 2010)
\end{abstract}

Estas pequeños grupos armados, terminaron convirtiéndose en las primeras expresiones del accionar criminal de los terratenientes en contra del campesinado montemariano, no obtente, estos primeros grupos armadas no

\footnotetext{
${ }^{46}$ Las recuperaciones fue la denominación que utilizó el movimiento campesino en las décadas de los 70's y 80 's para legitimar sus acciones de vía de hecho. Se entendía que los campesinos recuperaban las tierras, pues era el derecho que tenían por haberlas trabajado en décadas pasadas o por constituirse en la base de su propia existencia.
} 
lograron trascender o convertirse en estructuras militares con poder de operación a nivel regional, pues su rango de acción casi que obedecía a la "autoprotección" de haciendas y grandes propietarios a nivel local. A finales de los años 80's surgiría un fenómeno paralelo, pero esta vez exhortado por la llegada del narcotráfico a la subregión. (...) a lo largo de la década de 1980, varios personajes asociados al narcotráfico compraron tierras en la zona costera de los Montes de María (Tolú, Tolúviejo, Coveñas, Palmito y San Onofre), especialmente en aquellas tierras que se encuentran a lo largo de la carretera que comunica a Cartagena con el Golfo de Morrosquillo. Dichas tierras eran utilizadas como zonas de refugio, recreo y para asegurar el tráfico de estupefacientes y armas a través de los corredores naturales de la zona. Alrededor de estas propiedades se organizaron pequeños ejércitos privados, que básicamente eran unas estructuras fragmentadas y autónomas (Idepaz, 2011) cuyas acciones militares estaban orientadas a controlar los corredores estratégicos tanto para el tráfico de armas y como de drogas. La inserción del narcotráfico en la subregión, se constituiría en la pieza clave para el sostenimiento y la financiación de otros grupos armados en la región, especialmente del paramilitarismo.

Antes de continuar con el surgimiento del paramilitarismo en la subregión, es necesario explicar porque no se entiende a esta expresión armada, como un ejército privado. El paramilitarismo es comprendido en este trabajo como una respuesta cívico-militar contrarrevolucionaria, agenciada por la acción u omisión del Estado Colombiano y sus instituciones de inteligencia y seguridad, en este sentido, no podría considerarse como un ejército que persigue fines privados aunque en ocasiones, se asocie con actores particulares como narcotraficantes, empresarios o políticos-, su finalidad siempre estará asociada con el mantenimiento del Estado.

Con relación a la presencia de este actor armado en la subregión, hay que señalar, que el fenómeno del paramilitarismo empieza a ser referenciado por los campesinos desde finales de la década del ochenta:

La primera finca con 'paras' fue en corregimiento de Carboneros, municipio de Chinú (Córdoba) por allá al comienzo de los ochenta", recuerda Jesús 
Pérez, líder del movimiento agrario de Palmitos de 75 años y conocedor reputado de la historia local. Y luego explica que en la vereda Bajo de la Alegría en San Pedro y en La Mojana, al sur de Sucre, aparecieron también hombres armados (VerdadAbierta, 2010)

Así, hacia fines de la década de los 80 , brotaron simultáneamente como hongos, unos pequeños grupúsculos de matones armados en distintos puntos de la quebrada geografía Montemariana y en las regiones aledañas de Sucre, en el Golfo, las Sabanas y la Mojana. En la zona urbana de El Carmen de Bolívar estaba La Mano Negra. En Sincelejo, había una banda Ilamada La Cascona, que incluso figuraba en la lista de paramilitares que reveló en octubre de 1987 el entonces Ministro de Gobierno César Gaviria ante el Congreso. En esa misma lista, aparecía la banda Muerte a Secuestradores y Comunistas' en el departamento de Bolivar. Y estaban Los RR en San Juan Nepomuceno, Los Benítez en San Pedro y los Encapuchados de Colosó (VerdadAbierta, 2010)

Así desde mediados del ochenta, diversos grupos encubiertos de extrema derecha agenciaron una oleada de terror en todos los Montes de María. De acuerdo con el informe de VerdadAbierta (2010) desde 1989 hasta 1994, grupos similares de 'paras', fueron usados como brazo clandestino para perseguir a incómodos líderes sociales. Mataron por lo menos a doce dirigentes agrarios de la región, según los registros de la época. Otros muchos sobrevivieron porque se exiliaron en otras regiones o en el exterior. También mataron políticos cívicos y de izquierda (en especial de la Unión Patriótica) y maestros sindicalizados.

4.2.2.3 La consolidación de los actores: la confrontación entre los "paras" y las FARC.

La década del noventa marca el inicio del escalonamiento del conflicto, no solo en la región caribe y los Montes de María sino, en el resto del país.

Los diferentes grupos paramilitares que habían empezado a formarse a finales de la década del ochenta pasan por dos importantes momentos: el primero, la conformación de las Autodefensas Unidas de Córdoba y Uraba -AUCC- al mando de los hermanos Carlos y Vicente Castaño Gil, el cual logró organizar 
varias estructuras paramilitares a nivel nacional; y en segundo lugar, la creación de un marco jurídico que pretendió en 1995 legalizar el accionar cívico-militar (contra revolucionario) a través de las denominadas "Convivir" (Cooperativas de Vigilancia y Seguridad Privada para la autodefensa agraria ${ }^{47}$

Si hay un ingrediente esencial en la consolidación del fenómeno paramilitar moderno en la región, fue la figura de las Cooperativas de Seguridad Convivir, que entre 1996 y 1997 experimentaron una expansión significativa en el territorio montemariano. Con lugar a pocas dudas, las Convivir fueron los semilleros donde se consolidaron las AUC, es en su seno donde nace, entre otros, el frente La Mojana y el frente Rito Antonio Ochoa, que sería integrado en el año 2000 al Bloque Héroes de Montes de María. (Idepaz, 2001:10)

En 1997, la Corte Constitucional limita el accionar de las "Convivir", generando con ello, que la mayoría de las estructuras organizadas bajo esta figura optaran por la clandestinidad. Es en este mismo periodo que se consolida el paramilitarismo en los Montes de María:

El paramilitarismo nació en 1997 en una reunión en la finca Las Canarias de la zona rural de Sincelejo que pertenecía al ex gobernador Miguel Nule Amín. (...). Se hizo para sellar una alianza contra-guerrillera entre un centenar de finqueros y políticos con algunos jefes paramilitares que vinieron del vecino departamento de Córdoba. (VerdadAbierta, 2010)

Es a partir de ese momento que el paramilitarismo, enarbola el nombre de las Autodefensas Unidad de Colombia -AUC-, con presencia en la subregión a partir del "Bloque Héroes de los Montes de María" y de tres frentes estratégicos, a saber:

Frente Canal del Dique (al mando de alias "Juancho Dique", se ubicó, en municipios aledaños a este canal, teniendo un área de influencia desde las costas del mar Caribe del departamento de Bolívar hasta el municipio de el

\footnotetext{
${ }^{47}$ Las CONVIVIR responde a una estrategia por parte del Estado colombiano, por blindar jurídicamente los ejércitos privados y garantizar el mantenimiento, esta vez por vía legal a los grupos de paramilitares. Desde el marco jurídico, esta nefasta figura, fue entendida como "servicios especiales de seguridad privada", las cuales operarían en zonas de combate donde el "orden público fuese precario".
} 
Carmen de Bolívar; Frente Golfo de Morrosquillo y, Frente Sabanas de Sucre); Frente Central Bolívar (cuyo comandante era alias "Román Zabala"); y el Frente Golfo de Morrosquillo (comandado por alias "Rodrigo Cadena"). En su conjunto, estos frentes ocuparon el norte y centro del departamento de Sucre, hasta inmediaciones de donde operaba el Frente paramilitar conocido como "La Mojana".

Paralelamente, después de las desmovilizaciones del PRT, EPL, CRS, las FARC fueron consolidando su presencia en la subregión. A partir de 1994 las FARC establecen el Frente 35, expandiéndose con énfasis en la Mojana donde operaba el Ejército Revolucionario del Pueblo -ERP-, por otro lado desde 1999, esta guerrilla fortalece su presencia con otros frentes y refuerzos traídos de otras regiones. Por ejemplo, Según el Observatorio del Programa Presidencial de Derechos Humanos y DIH, en 1999, el Frente 35 de las FARC (José Antonio Sucre) tenía en la región 200 efectivos que operaban tanto en Bolívar como en Sucre. La organización del Frente se dividía en tres estructuras: la compañía Carmenza Beltrán, con 50 integrantes, registrando actividad armada en Morroa, Colosó, Ovejas, Tolúviejo, San Onofre, Corozal, Chalán y Los Palmitos. La compañía Robinson Jiménez, que operó con 60 hombres, haciendo presencia en los municipios de Betulia, Sincé, Buenavista y Galeras. Y la compañía Policarpa Salavarrieta, conformada por 80 efectivos, que actuaba en Bolívar conjuntamente con el Frente 37 de las FARC, desplazándose esporádicamente al departamento de Sucre.

Tanto las FARC, como los paramilitares, a partir de 1997 empezaron una ofensiva militar cuyo saldo aún no es posible calcular. Por un lado, las FARC generalizaron los ataques a la infraestructura, los secuestros, las extorciones y el asesinato selectivo, mientras que los paramilitares iniciaron una verdadera guerra sucia contra la población civil: los asesinatos, las masacres y los desplazamientos fueron las huellas que dejaron los "paras" en su camino por consolidarse en la montaña de María. Así, desde 1997 la espiral de violencia de paras y guerrillas fue en ascenso. No fue, como han querido hacerlo ver algunos de los ex jefes paramilitares para justificar la barbarie que desataron, que la ofensiva paramilitar llegó como reacción la andanada guerrillera. Los primeros paramilitares fueron asesinando, al tiempo que los primeros guerrilleros fueron 
secuestrando y matando selectivamente a ganaderos e incendiando sus fincas. Era una guerra de baja intensidad, que desde el principio se peleó más contra los civiles que entre los armados. Y a medida que los paramilitares traían refuerzos y crecían, los guerrilleros hacían lo mismo (VerdadAbierta, 2010)

\subsubsection{El saldo de la violencia.}

El proceso de expansión y consolidación militar, tanto de los "paras" como de la guerrilla de las FARC-EP, desde mediados de la década del noventa, generó profundas alteraciones en el orden público, así como en la vida y en las prácticas sociales de los pobladores montemarianos, especialmente en las relaciones sociales y organizativas de la subregión ${ }^{48}$.

A mediados de esta década se generaliza el uso del terror como estrategia de guerra. Las masacres ${ }^{49}$ y el desplazamiento forzado fueron las principales consecuencias de dicho accionar.

De acuerdo con información suministrada por el Observatorio de DDHH y DIH de la Vicepresidencia (2003), se registra en 1996 la primera masacre cometida por los paramilitares, la cual ocurrió el 30 de noviembre en el municipio de El Guamo (departamento de Bolívar), donde asesinaron a cuatro personas. A partir de este momento se registran una serie de homicidios colectivos que tienen como objetivos consolidar el corredor que comunica a la Serranía de San Lucas a la costa Caribe, así como evitar el paso de la guerrilla de los Montes de María hacia las zonas por donde pasa el río Magdalena.(Garzón, sf:3)

\footnotetext{
${ }^{48}$ Para el periodo de 1990, se observa una profunda crisis en el movimiento social montemariano, la crisis interna de la ANUC más la criminalización estatal y la continua violencia paramilitar hacia el campesinado genera un debilitamiento en las acciones y las reivindicaciones del movimiento campesino en la subregión. Los asesinatos selectivos a líderes y el desocupamiento de territorios son las principales acciones que los violentos ejercen en un intento por desarticular los procesos sociales en Los Montes de María. Ver La tierra en Disputa (GMH: 2010)

${ }^{49}$ Las masacres son entendidas como un homicidio intencional de cuatro o más personas en estado de indefensión y en iguales circunstancias de modo, tiempo y lugar; generalmente, estos homicidios son cometidos con una manifiesta intención de "ejemplificar" y de disciplinar a la población sobreviviente. De igual manera, los actos que generan las muertes son cometidos bajo altos niveles de sevicia, es decir, la causación de daño más allá del necesario para matar. Su operacionalización más habitual son las mutilaciones y las laceraciones del cuerpo, y se extiende hasta el número de heridas causadas y su distribución por áreas corporales (Suarez, 2008)
} 
A partir de 1996, se puede evidenciar que la expansión del paramilitarismo dentro de la subregión estuvo presidida por el ejercicio sistemático de masacres (ver gráfico No.1). Así, la violencia contra la población civil hizo parte de una estrategia basada en el terror para eliminar el presunto apoyo o base social de la guerrilla. Bajo este marco, se perpetran 42 masacres que dejan 354 víctimas fatales. Entre ellas, se encuentran la de Tolúviejo en 1999 y El Salado en el año 2000. También deben señalarse las de Chengue (2002), Pichilín (2002), Ovejas (2002) y Macayepo (2002). (Idepaz, 2011:11)

\section{Gráfico 2. Masacres en la Subregión de Los Montes de María. Periodo 1993-2009}

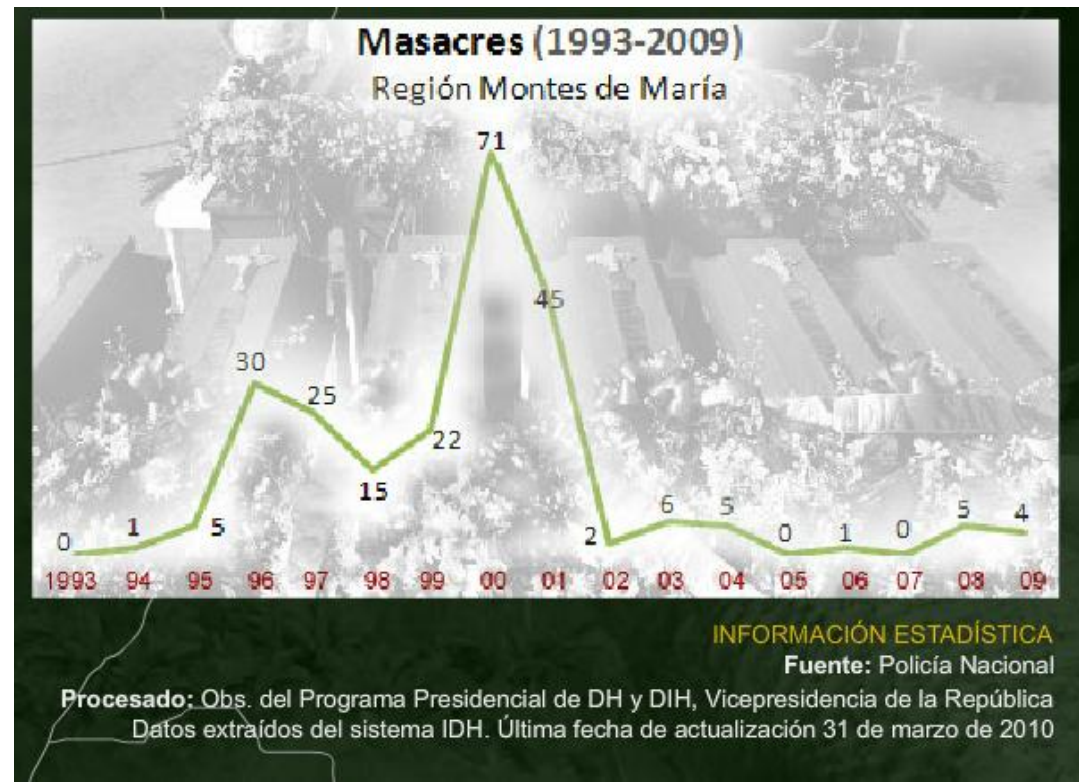

Fuente. VerdadAbierta.com consultado el 14 de noviembre de 2012.

Así, durante los primeros años de contraofensiva paramilitar (1999-2002), la región de Montes de María padeció alrededor de 18 masacres, entre ellas, las de El Salado, Chengue y Macayepo, que generaron un desplazamiento masivo de personas y el abandono de tierras hacia los cascos urbanos de Sincelejo, Ovejas y El Carmen de Bolívar. (CNRR-CMH, 2010: 102)

Ahora, si nos concentramos en el departamento en el que se encuentran las veredas con la cuales se realizó el trabajo de campo, es pertinente señalar que no hay información precisa acerca de las primeras masacres cometidas. Dentro de la revisión bibliográfica, encontramos que frente este accionar se encuentran dos versiones, la primera ubica la primera masacre en el mes de septiembre de 1992, en el corregimiento El Cielo de Chalán (Programa Presidencial de DDHH y DIH, sf: 18), Por otro lado, la Comisión de Memoria Histórica, ubica la primera 
masacre en el año de 1997 en el corregimiento de Pichilín en el municipio de Morroa. (CNRR-CMH, 2010: 102). Lo cierto es que Sucre, fue uno de los departamentos dentro de la subregión de los Montes de María que más víctimas generó por causa de la las masacres.

En el departamento de Sucre se han registrado desde 1995 hasta agosto del 2003, 184 víctimas de masacres en un total de 28 casos. Lo cual representa el $2.76 \%$ del total de víctimas de masacres existentes a nivel nacional y el $2.37 \%$ de los casos de masacres que se cometen en Colombia. (Programa Presidencial de DDHH y DIH, sf: 19)

Si desglosamos esta cifra departamental y la analizamos a nivel municipal, encontramos que los principales municipios afectados por masacres desde 1995 hasta agosto del 2003 en cuanto al número de víctimas han sido Ovejas con un total de 80 , es decir el $43.4 \%$ de las víctimas de masacres en el departamento, seguido por Toluviejo el cual registra el $20.1 \%$ con 37 víctimas y en tercer lugar San Onofre con el 12\% con 22 víctimas respectivamente. Estas cifras no deben tomarse a la ligera, pues son medulares a la hora de analizar y particularizar el impacto de la violencia en la subregión. El impacto generalizado de las masacres y su relación directa con el desplazamiento, son la base explicativa, del por qué el desarraigo de las comunidades campesinas de VillaColombia y Borracheras.

Como mencionábamos anteriormente, las masacres han sido utilizadas como vehículos que despliegan e imponen rápidamente un ambiente de terror. En medio del miedo se genera una serie de efectos, que terminan por modificar los escenarios locales y las relaciones locales y regionales. Sus principales efectos pueden ser sintetizados a través de dos fenómenos:

i) la desmovilización (en términos organizativos y comunitarios) y el disciplinamiento y acatamiento de los pobladores a un nuevo orden, por ejemplo para el caso de Sucre:

(...) es clara la utilización de las masacres como recurso para someter bajo el terror a la población de las zonas que tienen gran interés para los protagonistas de la confrontación armada. En esa medida, "el recurso del terror por parte de los grupos irregulares pone de presente la existencia de una lógica que se expresa en el propósito de romper la relación entre el 
actor armado de signo opuesto con la población; ésta enfrenta, en consecuencia, la disyuntiva de plegarse al nuevo dominio o desplazarse" (Programa Presidencial de DDHH y DIH, 2010:8)

ii) el desplazamiento de la comunidad que sufrió directamente el accionar violento, así como de otras poblaciones que a través del conocimiento de la sevicia de los homicidios, deciden abandonar y/o desocupar territorios para evitar convertirse en las nuevas víctimas. Frente a estos impactos sociales, es importante señalar que ambos fenómenos permiten al actor armado territorializarse y ejercer su territorialidad ya sea para fines militares o económicos (tráfico de armas y/o estupefacientes). Así, la masacre y el desplazamiento forzado estrechan sus vínculos, hasta el punto en que la primera se constituye en la causante de la segunda.

No obstante el desplazamiento forzado como estrategia de desocupamiento del campo, no responde exclusivamente a las masacres, pues este ha sido orquestado por otros intereses y otras dinámicas propias del conflicto armado: El escalonamiento del conflicto, reflejado por el incremento de las confrontaciones armadas entre los grupos, que ponen a la poblaciones rurales en medio del fuego cruzado; el señalamiento, la estigmatización y la criminalización hacia los campesinos, sus líderes y organizaciones; las amenazas directas; la desaparición forzada, la quema y destrucción de viviendas y enseres e infraestructura productiva; así como las presiones de terceros para hacerse a la tierra, han sido otras causantes para que en los Montes de María se haya generalizado a partir de 1997, que cientos y miles de campesinos recorran sin rumbo por carreteras y caminos, acompañados tan solo de la esperanza de no ser las próximas víctimas.

Al revisar las cifras del desplazamiento forzado, hallamos que a nivel nacional, los Montes de María es una de las subregiones más afectadas por este fenómeno, no solo como expulsora sino como receptora de población desplazada; según cifras del Programa presidencial de Derechos Humanos y Derecho Internacional Humanitario, para el 2003 los Montes de María habían expulsado el $2.7 \%$ de su población, a la par que había recibido el $3.3 \%$ de desplazados de otras subregiones o regiones cercanas, constituyéndose así, en 
un escenario donde se presenta tanto la expulsión como la recepción de población desplazada.

Concentrándonos en la magnitud del desplazamiento y en su dimensión de expulsión, encontramos que entre los años 1998 y 2009 fueron desplazados forzadamente en la subregión de los Montes de María un total de 215.505 personas. El Carmen de Bolívar es el municipio que presenta la mayor expulsión de personas con el 33\% del total que registra la región, seguido por los municipios de San Onofre con el 11.7\%, Ovejas con el 9.6\%, y María la Baja con el 8.3\% y el municipio de Córdoba (Bolívar) con el 7.19\% (Ilsa, 2012: 28)

Aunque no contamos con datos estadísticos exactos, podríamos afirmar -según el trabajo de campo realizado y la experiencia de trabajar en la subregión- que el gran porcentaje de las personas desplazadas entre los años de 1998 y 2009 corresponde a pobladores rurales, y de éstos, las familias campesinas fueron las más afectadas. De ahí que concordemos con el Centro de Memoria Histórica, cuando afirma que como consecuencia inmediata de las acciones violentas de los actores armados, son precisamente los campesinos los que tienen que abandonar sus tierras por el desplazamiento forzoso (CNRR-CMH, 2010:107). Así se observa -para el caso de los Montes de María- que la mayoría de la población desplazada estuvo constituida por campesinos que se trasladaron a las cabeceras municipales más cercanas [como el Carmen en Bolívar y Ovejas en Sucre], mientras los que contaban con familiares en las ciudades o los que habían padecido episodios de horror a causa de las masacres y demás atrocidades cometidas en la zona, decidieron irse principalmente a ciudades como Sincelejo, Cartagena, Barranquilla y en menor medida Bogotá o Medellín. (Hernández, 2010:11)

Considerando lo elementos expuestos anteriormente, a continuación se abordará el impacto de la violencia sobre la población campesina de VillaColombia y Borracheras con relación a las dinámicas que soportaron a causa del desplazamiento forzado. 


\subsection{El irse: historia de un éxodo}

Los desplazamientos forzados de las comunidades de VillaColombia y Borracheras, no fueron procesos que se dieron de forma simultánea, entre uno y otro desplazamiento hubo por lo menos un año de diferencia, sin embargo la causa de los dos éxodos puede ser considerada como la misma: las incursiones de los paramilitares (Bloque Norte y el Bloque Héroes) que en convivencia con la Fuerza Pública, sitiaron la subregión de los Montes de María desde mediados de los años 90.

La primera comunidad en desplazarse fue la de Borracheras. Este desplazamiento fue generado por el terror producido los paramilitares como parte de la estrategia militar implementada, para copar gran parte del territorio de los Montes de María, a través del uso generalizado e indiscriminado de las masacres y el consecuente desplazamiento forzado.

El 19 de febrero del año 2000, tras conocerse las primeras víctimas de la masacre paramilitar en el corregimiento del Salado (Municipio del Carmen de Bolívar, Departamento de Bolívar), varios corregimientos y veredas tanto de Sucre como Bolívar -entre ellos Borracheras, San Francisco, El Bálsamo, Morrocoy y Bajo grande - optan por desplazarse masivamente.

La segunda masacre ocurrida en el Corregimiento de El Salado en febrero del año $2.000^{50}$, significó el éxodo de la totalidad de sus habitantes y de todas las veredas circunvecinas que se encontraban en la denominada "ruta de la muerte" dejada por los escuadrones paramilitares que cercaron esta zona de montaña de la región de los Montes de María (CCMML21, 2013:24).

La masacre del Salado se constituyó en el principal motivo para que los campesinos de Borracheras tuvieran que abandonarlo todo. La sevicia con la

\footnotetext{
${ }^{50}$ La primera masacre ocurrió "en 1997 [cuando] un grupo armado, enviado al parecer por ganaderos de la zona, con lista en mano, asesinó a cinco personas, entre ellas a la maestra del pueblo. En cuestión de horas El Salado se había convertido en un pueblo fantasma. Absolutamente todas las familias salieron desplazadas, con sus trastos y sus animales, a la espera de garantías para regresar. A los tres meses, la Armada se instaló por unas semanas en el pueblo y poco a poco las familias retornaron. Para entonces, El Salado quedó reducido a la mitad de lo que era. La guerra había traído consigo la pobreza. Las tabacaleras se fueron y las incipientes exploraciones de petróleo y gas fueron suspendidas". En http://www.verdadabierta.com/nunca-mas/435-la-masacre-de-el-salado.
} 
que actuaron los "paras" en El Salado sobre pasó los límites de la irracionalidad y la deshumanización ${ }^{51}$, por lo que en muy poco tiempo, el miedo y el terror se apoderaron de las comunidades campesinas cercanas o no del lugar de los asesinatos:

"Lo de El Salado eso fue general, mataron en El Salado y mataron cerquita a donde nosotros, asesinaron a una persona. De allá, como ahí estaba un señor que le asesinaron a un vecino del lado, entonces los que 10 asesinaron dijeron que iban a acabar con todo el mundo. Entonces donde se dice a "todo", es porque era a toda la región. Entonces ellos se salieron desplazados y cruzaron por allá, entonces uno no se iba a dejar matar. Cuando eso yo tenía treinta días de parida de mi última hija que tengo. Yo me llené de nervios y como teníamos todos los pelados pequeños entonces yo le dije al marido mío que me sacara. $Y$ ese día nos salimos toditos. Eso fue el 22 de febrero". (Testimonio mujer, Ovejas CCMML21)

\begin{abstract}
"Verdad que yo fui la última que salió porque yo dije que yo no me volvía a salir de allá. De último llegó un señor y me dijo: -"Oye usted que piensa, la van a matar aquí, ¿se va dejar matar aquí?"-. Entonces yo recuerdo que estaba fritando una olla de chicharrón. Y yo decía: - "Yo todavía no he visto que venga nadie por ahí cerquita. Yo no voy a andar más de allá para acá"-. La cuestión mía es que yo decía: - 'El día de morir, es uno solo"-. Pero yo estaba equivocada porque sí estoy viendo a toda la gente salir corriendo. La cosa mía era también salir, dejar todo eso ahí otra vez. Pero yo decía - "voy a esperar otro rato"-. Entonces un señor me dijo: -"Ahí vienen y la van a matar"-. Entonces ahí sí cogí lo que pude, cogí mis hijos y a mi esposo "vámonos, vámonos"- y me vine. Yo me vine el 22 de febrero. Y sí se dio el caso de que (esos señores) llegaron". (Testimonio mujer, Ovejas CCMML21).
\end{abstract}

A pesar del miedo generalizado, algunos campesinos decidieron resistir en el territorio el mayor tiempo posible, sin embargo el contacto directo con los

\footnotetext{
${ }^{51}$ La masacre del saldo como casi todas las masacres cometidas por los paramilitares tanto en los Montes de María como en el resto del país, se caracterizaron por el uso e implementación de diferentes actos violentos que podría tipificarse como tratos crueles e inhumanos (torturas físicas y psicológicas, mutilaciones, violaciones, ... etc,.)
} 
paramilitares y el ver su vida y el de sus familias peligrar, los obligó a iniciar un desarraigo que duró, para el caso de Borracheras 4 años.

"Yo vivía en Borracheras, yo no le tenía miedo a nadie. Vivía feliz y contenta, pero después de lo del Salado... no fue lo mismo. A mi esposo lo maltrataron mucho, el sufría mucho y mis hijos también. Yo no sé de donde tuve tanta fuerza para decirle a esa gente (paramilitares) que lo dejaran tranquilo, que ellos no tenían derecho de hacerle eso. Ellos maltrataron psicológicamente a mis hijas, porque ellas, mis hijas, vieron como maltrataban a su papá,... le mostraban un machetico, le iban a cortar las orejas; entonces mis hijas estaba tan pequeñas que una de ellas se desmayó. ¿Quiénes eran esos grupos? Yo lo único que recuerdo de ellos, es que usaban un cintillo amarillo en el brazo, y unos tenían unas pañoletas verdes... daban miedo. Me daban miedo porque no eran jóvenes, eran gentes ya como que vieja de estar en eso... fue por eso que decidimos venirnos al Carmen" (Testimonio Mujer, Vereda Borracheras, abril, 2012)

En relación a este desplazamiento es preciso señalar que a diferencia de otras zonas de la subregión, en la vereda de Borracheras, se dio lo que se podría denominar como un desplazamiento reactivo, es decir, un desplazamiento que se origina no por el accionar directo sobre una población determinada, sino como efecto o consecuencia del terror ejercido por un actor armado (los paramilitares para nuestro caso particular) sobre otra población. Este hecho es de vital importancia, a la hora de analizar las condiciones que posibilitaron el retorno, pues, el carácter traumático del desplazamiento cuando no es motivado por la vivencia directa de hechos violentos como una masacre, viabiliza o por lo menos, mengua el miedo inherente del volver.

"Usted si cree que si en su casa le matan 7 individuos, que usted los vea en la puerta de su casa o en la sala de su casa pá usted regresar, eso es fácil?, eso no es fácil!!, eso no es fácil!!, eso es manda como dijo el otro, es mandar cojon!!!..." (Testimonio Campesino, Vereda VillaColombia, Noviembre del 2012)

Un año después, el 4 de marzo 2001 las comunidades de VillaColombia, el Palmar y Medellín se desplazan. Este desplazamiento se originó como consecuencia de la reiterada criminalización por parte de la fuerza pública hacia 
las comunidades campesinas. En este punto, es importante señalar que desde la entrada de los paramilitares en la subregión, los campesinos de los Montes de María fueron situados -por las dinámicas del conflicto- en el medio de los actores armados. La tradición de lucha y de organización, por parte del campesinado de toda la región, fue la escusa para tildarlos de subversivos o cómplices del "terrorismo", por lo que después de 1997, este señalamiento se convierte en una nueva manera que el ejército y los paramilitares utilizan para victimizar a las poblaciones campesinas. La sindicación -hacia los campesinosde ser colaboradores de la guerrilla, era una constante práctica en la región.

\begin{abstract}
"Del 95 al 96 la guerrilla empieza a incursionar, entraba pintando las albercas, los postes de la luz, con sus consignas, el frente tal y así, entonces si pintaban eso hoy más tarde llegaba el ejército a patearnos a nosotros y diciéndonos que nosotros éramos cómplices de ellos porque dejábamos que pintaran eso... hasta el 98, ya que ya le gente le cogió miedo cuando fueron las masacres, bueno las masacres aquí no, pero fueron las masacres de Bajo Grande, El Salado, los alrededores y ahí fue cuando la gente cogió miedo y se fueron...." (CCMML21, 2013)
\end{abstract}

Estos señalamientos se incrementaron a la par que los paramilitares fueron copando algunos territorios anteriormente controlados por la guerrilla. La mayoría de estas sindicaciones terminaron en asesinatos selectivos o masivos, tal como en el caso de las masacres señaladas. Si se considera la extrema violencia con que actuaban los actores armados en dicha zona, el ser señalado como colaborador de una de las partes, era una explícita sentencia de muerte, para lo cual era mejor salir de la vereda antes de que el bando contrario "ajusticiara" a los supuestos "colaboradores" señalados.

Bajo este contexto y desde finales de los 90's, los campesinos de VillaColombia sintieron la presión de vivir cerca de un corredor estratégico controlado por la guerrilla de las FARC. Esta situación tendió a empeorarse en los primeros días del mes de mayo del 2001, pues la guerrilla había desplegado una ofensiva militar contra varios objetivos en la subregión. La zozobra y el miedo empezaron a anidarse en el interior de las familias, pues como siempre, éstos se verían en medio del fuego cruzado. Finalmente en la madrugada del día 4 de marzo, la guerrilla ataco la estación de policía de Sn Juan de Nepomuceno, como 
respuesta el Ejército y la Infantería de Marina intentaron contrarrestar el ataque enviando destacamentos a la zona. En las horas de la tarde, la guerrilla emboscó una caravana de la Infantería de Marina que se movilizaba por la Troncal del Caribe, específicamente, entre los municipios de Ovejas (Sucre) y EI Carmen de Bolívar (a unos pocos kilómetros de la entrada de la vereda VillaColombia).

La verdad es que aquí la gente se fueron, se ahuyentaron, desde que pusieron una bomba aquí, en la orilla de la carretera esa... de aquí pá los lados de la pista hubieron unos muertos, de esa vez una plomera que se armó ahí.... Bueno después pusieron una bomba aquí en la ceiba ahí hubieron otra tajada de muertos, eso el 4 de marzo, entonces los soldados se metían de noche ahí a las casas, y decían que uno era cómplice de lo que estaban haciendo por ahí, que si nosotros no respondíamos con la verdad nos quemaban con todo y rancho, y nosotros con el miedo, qué ibas hacer?, si no sabíamos nada, todo el mundo comenzó a recoger el rabito y se fue, nos fuimos pues". (Testimonios, Vereda Medellín; CCMML, 2013)

Esta situación, más los enfrentamientos que siguieron a las acciones de la guerrilla y el ejército, provocó un desplazamiento masivo, que en cuestión de pocas horas desocupó la vereda de VillaColombia como de todas aquellas veredas cercanas. Iniciándose así, el éxodo que solo terminaría -por lo menos en el ámbito formal- con el retorno.

“... fue cuando pusieron una bomba en el 46, donde Taboada. Eso fue horrible. Felipe se había ido para Bogotá y yo me quedé con los pelados. Él se fue ese día para una reunión en Bogotá. Los pelados estaban en la carretera. Yo me tuve que ir. Yo cogí dos sabanas, las dos muditas de la ropa de ellos, la metí en un bolso y fuera. Los terneros amarrados y las vacas... Y nos fuimos. Yo ahí en la carretera veo toda esa fila de gente. No más la gente de allá atrás. Cuando estábamos en la carretera venía un bus de esos grandes de los amarillos. El paró porque no traía más de cinco pasajeros, el paró en vista del poco gente. Yo le dije: -"Chofer, por su madrecita hágalo, me lleva a Ovejas-. Entonces el ayudante le dijo: -Allá en el 46 como que hay un poco de muertos-. Y yo le dije: -Yo no sé qué habrá pasado, pero por ahí todavía están dándose el poco de plomo. Nosotros nos vamos". Así fue embarcaron ese poco de gente y al poco rato cuando em- 
barcaron a la última viejita, llegaron ese poco de soldados. El bus arrancó y yo dije: -"Si nos hubieran agarrado nos habían levantado a plomo con esa gente"-. Duramos tres días en Ovejas. Hubo gente que se devolvió al día siguiente. Este pelado dijo: -"Vamos para el monte a ver qué pasó, si ya se pasó la marea"-. Y los soldados les dijeron: -"Niños ¿ustedes son los dueños de esto?”-. - “Sí, mi papá no está y mi mamá está en el pueblo, nosotros venimos a verle los animales que dejaron sin ordeñar y los vamos a ordeñar"-. Entonces prendieron el fogón y se pusieron a cocinar. Entonces cocinaron la leche y me la llevaron allá. (Testimonio mujer, VillaColombia CCMML21, 2013).

Desde el desplazamiento masivo del 4 de marzo, la mayoría de los pobladores de VillaColombia no volvieron a residir en sus parcelas. Gran parte de estos campesinos tuvieron que vivir un peregrinaje forzado por fuera de su territorio.

\subsubsection{Sobreviviendo en medio del desarraigo}

Desde el día que los campesinos de VillaColombia y Borracheras dejaron de habitar sus veredas hasta el momento de retornar a las mismas pasaron al rededor de tres a cuatro años de desarraigo ${ }^{52}$.

En medio de esos años, los hombres y mujeres acompañados de sus familias tuvieron que idear maneras de sobrevivir a un ambiente tan adverso como el impuesto por el desplazamiento forzado. Viviendo en medio de escenarios ajenos, como una ciudad o un pueblo; alejados de su ambiente comunitario y de producción, sin recursos económicos y muchas veces con las familias fraccionadas, estos campesinos fueron obligados a rehacer su hacer en el mundo, su estar -entendido como prácticas- tuvo que ser modificado y re orientado por algunas estrategias que intentaron reducir los efectos de todo lo anterior.

Estas estrategias no son entendidas como un proceso regulable, predeterminado y mediado conscientemente, por el contrario, estas estrategias responden más a lo contingente que a lo determinado. Nadie estaba preparado para el desplazamiento, sin embargo cada familia intentó -a su manera-sobrellevarlo:

\footnotetext{
${ }^{52}$ Tres años para los pobladores de VillaColombia y cuatro para los de Borracheras.
} 
insertándose a otro tipo de actividades económicas como las ventas ambulantes; modificando los roles y las jerarquías de los miembros de las familias; aprovechando la oferta de servicios dados en los lugares de recepción, especialmente, la educación para los niños o jóvenes, ...etc.,

A pesar de la multiplicidad en las acciones tomadas por las familias durante el proceso de desplazamiento en pro de su supervivencia, el trabajo de campo, nos permite señalar algunos elementos compartidos, que trazan líneas de acción generalizadas. Para el propósito del trabajo, nos centramos en exponer aquellas acciones fundadas alrededor de la apropiación y el dominio espacial; como fueron acciones compartidas, en adelante no se especificará si son propias de los campesinos de VillaColombia o Borracheras.

Antes de continuar es importante resaltar un hecho particular de estos desplazamientos: nunca hubo un alejamiento total por parte de los campesinos de sus parcelas. Desde el inicio de los desplazamientos, los campesinos optaron por no irse de la subregión, la gran mayoría de los pobladores se instalaron en el Carmen de Bolívar o en Ovejas, solo unos pocos se desplazaron hacia Sincelejo, Cartagena o Barranquilla, todo lugares relativamente cercanos a los lugares de expulsión. Esta decisión facilitó que no rompieran del todo su relación con la tierra. Este no alejamiento con la tierra y las actividades productivas del campo, pueden ser rastreados en un proceso constituido por tres fases.

i). Durante los primeros días de desplazamiento, las veredas quedaron vacías, solo esporádicamente algunos miembros de las familias -generalmente los hombres- regresaban para "dar vuelta" de las cosas, plantaciones y animales dejados. En esta primera fase, los hombres cabeza de hogar decidieron permanecer en las parcelas, únicamente durante el día, pues en la noche, se iban a dormir al "monte".

"Después de lo que pasó, hubo como 3 días que por aquí no venía nadie, pero después veníamos con mucho temor a buscar que la yuca, el plátano, lo que hubiera, porque no teníamos que comer y otra vez para atrás porque había presencia militar, y uno estaba muy asustado porque ellos donde veían la gallina, los huevos o algo que coger lo cogían.....porque yo cuando sentía un militar en la zona, me iba y hasta me tocaba dormir en el 
monte.......usted se podrá imaginar, dentro del monte a la intemperie, todo picado amanecía uno y expuesto a una mordedura de serpiente" (Testimonio hombre campesino, VillaColombia)

La decisión de refugiarse en el monte, estaba atada a las condiciones materiales de las familias desplazadas. El no tener un lugar seguro y con las condiciones para poder solventar los gastos que una familia requiere, hizo que en los primeros días del desplazamiento, se reusara a dejar todo lo que se tenía a los violentos, se requería vigilar y proteger lo que con tanto sufrimiento se había logrado, claro está, sin descuidar la propia seguridad, pues en caso de observar algo extraño o de ver llegar a algún desconocido, lo primero que hacían los campesinos era protegerse en el "monte" y esperar a que todo pasará. Hubo campesinos que tuvieron que dormir en el monte por ocho días seguidos.

ii). Después que por sus propios medios o a través de algunos familiares, amigos o instituciones (como la iglesia), estos campesinos se instalaran en otros lugares como El Carmen de Bolívar o el casco "urbano" de Ovejas, la práctica de dormir a la intemperie fue abandonada de manera progresiva. Además de evitar los peligros propios de dormir sin ninguna protección, el evitar las noches en las veredas, les permitía sortear la presencia de los "paras", pues es en las horas de la noche que estos grupos transitaban por las zonas rurales.

Así, los campesinos, se dedicaban a trabajar la tierra o a atender a los animales durante el día, y ya en las tardes, se regresaban a sus lugares de vivienda, las cuales en su gran mayoría estaban en condición de hacinamiento y precariedad.

"yo era la que iba, todos los días. Me metía yo solita y él me decía "no vayas, no vayas, te van a matar!" Yo entraba le regaba agua a mis animales, les daba de comer, barría y en la tardecita me devolvía" (Testimonio Mujer Campesina, Vereda Borracheras, entrevista abril del 2012)

iii). Ya después de dos o tres años de desplazamiento, algunos hombres deciden, por presión económica, devolverse del todo a las parcelas para seguir trabajando. El vivir en la ciudad 0 en los pueblos -siendo campesino 0 campesina- no permite poner en práctica sus conocimientos productivos, el trabajo, por lo tanto es escaso y mal pago. Consecuentemente no se puede sostener y cubrir las necesidades básicas de las familias. La pobreza y la 
condición de "desplazado" profundizan las relaciones desiguales y excluyentes en los lugares de recepción.

El factor económico es decisivo en la toma de decisión frente al regreso al "monte". La vida urbana se desenvuelve a través del dinero, lo que necesitas tienes que pagarlo. Sin querer decir que antes de los desplazamientos estas poblaciones no utilizaran el dinero, lo que sucede, es que, las dinámicas urbanas, hacen que paguen por recursos o alimentos por los que antes no pagaban, este es el caso de la yuca (base de la alimentación en la subregión, la cual era cultivada por los campesinos antes de tener que abandonar su vida en el campo) el agua (para el caso de los que se instalaron en el Carmen de Bolívar, es inaudito tener que pagar todos los días una suma de dinero -que para ellos es considerable- para poder tener agua para cocinar) la vivienda (todos los campesinos, antes de los desplazamientos poseían viviendas, la gran mayoría más grandes y más cómodas que las que les ha tocado pagar para vivir de forma hacinada).

Entre otros, estos elementos, se constituyeron en razones para que los hombres, decidieran regresar y trabajar del todo en las parcelas. Esta decisión trajo consigo, un profundo cambio en las relaciones familiares pues, no solo se fragmentabas las relaciones entre los miembros del hogar (los hombres se iban y las mujeres y los hijos se quedaban) sino que modificó la idea misma de trabajo familiar.

A pesar del impacto en los roles y la vida familiar, la decisión tomada por la mayoría de los hombres en regresar solos a trabajar, facilito, posteriormente la organización para que el resto de la población, incluida las familias dejadas en los pueblos o ciudades retornaran.

Frente a este proceso, en el siguiente capítulo, encontramos que el ejercicio del volver, no es como despausar una vida dejada en el pasado, por el contrario significa reconfigurar una serie de relaciones y sentidos prácticos que intentan reacomodar al sujeto al nuevo contexto: el retorno. 


\section{CAPITULO V \\ ENTRE EL IRSE Y EL VOLVER: \\ EL RETORNO}

\subsection{El volver: reinvención del ahora.}

\subsubsection{El contexto del volver.}

En el 2004, después de tres y cuatro años de desplazamiento forzado 14 familias de VillaColombia y 16 de Borracheras optaron por regresar a sus veredas de origen ${ }^{53}$. Este proceso fue dirigido por un grupo de líderes que viendo las condiciones y el padecimiento por el cual pasaban sus vecinos y ellos mismos, deciden reunir a sus familiares y amigos para emprender junto a ellos, el retorno a sus parcelas.

Hay que decir que la organización de este retorno no fue un proceso fácil y expedito, éste llevó aproximadamente un año de ires y venires, en donde los campesinos que lideraban la iniciativa, tuvieron que sortear un escenario adverso, no solo por las condiciones de violencia que aún imperaban en todos Los Montes de María, sino por la impavidez del Estado y de sus instituciones (nacionales, departamentales y municipales) frente al deber de garantizarles el derecho a retornar a sus hogares.

Acá se perdieron muchas cosas, se perdieron los animales, se perdieron los cultivos,... y eso nos trajo como resultado la miseria!, la necesidad en nosotros los desplazados! Ni la alcaldía ni el gobierno nos dio una mano... gran parte de nosotros siempre estuvimos solos (...) (Grupo Focal. Vereda VillaColombia. Noviembre 2011)

A propósito del contexto en el que se desarrolló el retorno es primordial aclarar que tanto los testimonios de los campesinos, como los datos procesados por diversas instituciones y organizaciones muestran, como durante los primeros años de la década del 2000 se produjo una serie de acciones violentas que

\footnotetext{
${ }^{53}$ Estas familias representan para el caso de VillaColombia el $74 \%$ de las familias que vivían en la vereda antes del desplazamiento; para el caso de Borracheras las 16 familias que retornan representan el $15 \%$ de las familias que vivan en la vereda antes del desplazamiento.
} 
dejaron por saldo un número considerable de víctimas. (ver tabla No.2)

Para nosotros la región, por esos años (2000-2004) estuvo golpeada muy duro, muy duro, porque de pronto se aparecía la gente y nadie sabía quién era, si era guerrilla o si eran paracos. (Grupo focal. Vereda VillaColombia. Noviembre 2011)

Por ejemplo, para el caso del desplazamiento forzado, los municipios que componen Los Montes de María ostentan entre el 2000 y el 2010 la cifra de 250.838 víctimas, el 6,39\% del total de los desplazados a nivel nacional. Estos mismos datos observados por departamento muestran como en el periodo comprendido entre el año 2000 al 2004, se concentra más de la mitad de las víctimas por desplazamiento forzado en la subregión; 87.003 víctimas en Sucre (71\%) y 103.277 víctimas en Bolívar (79\%)

Tabla 2. Desplazamiento forzado. subregión de los Montes de María 2000-2010

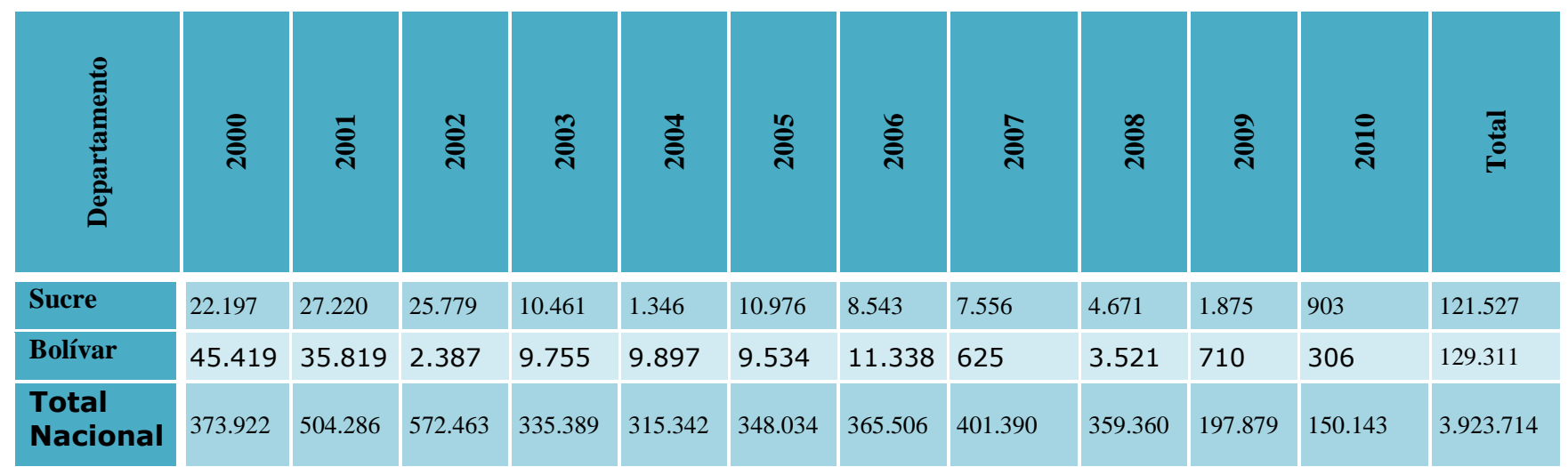

Fuente. Elaboración propia con base en datos Sipod y Registro Único de Víctimas (RUV). Procesado por Observatorio de Programa Presidencial de DDHH. Los datos fueron sistematizados por VerdadAbierta. Fecha de Actualización 15 de enero de 2013. 
Tabla 3. Casos de masacres subregión de los Montes de María 2000-2010

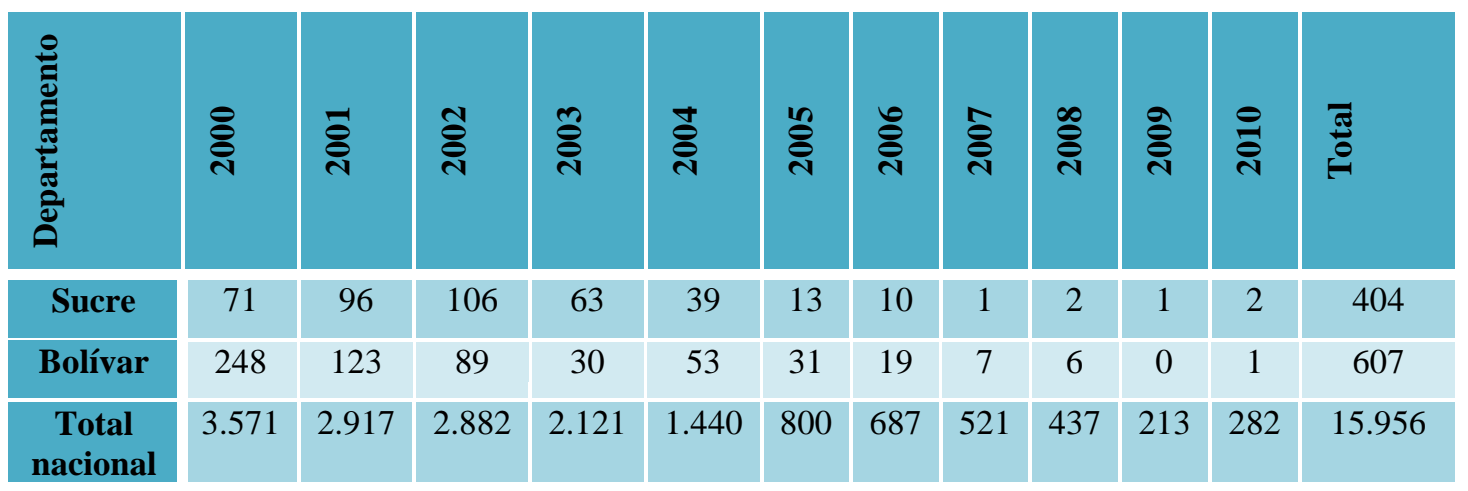

Fuente. Elaboración propia con base en datos de la Policía Nacional. Procesado por PNUD Colombia, 2011.

Si abordamos de manera independiente la información de la tabla 3, vemos como en el periodo 2000-2004 el número de masacres tan solo en el departamento de Sucre ascendía a 375 casos, el 92\% del total comprendido entre los años 2000-2010. Este mismo ejercicio para el caso del departamento de Bolívar nos arroja como resultado 543 masacres, el 89\% del total del periodo observado. Cruzando esta información con los datos suministrados por los campesinos a través de las entrevistas y el trabajo de campo, se podría establecer que más del $92 \%{ }^{54}$ de las masacres cometidas en los Montes de María, resultaron -directa o indirectamente- en casos de desplazamiento masivos, tal como lo ocurrido en la vereda Borracheras después de la masacre del Salado.

Lo que interesa recalcar en este punto, es como los casos de masacres y de desplazamiento -entre otras acciones violentas- generaron las condiciones para que Los Montes de María se convirtieran durante los primeros años del 2000 en un escenario sombrío, donde la población civil, en especial la campesina, sufría los más cruentas consecuencias de la violencia. Esta situación significó para los campesinos desplazados de VillaColombia y Borracheras un verdadero reto a la hora de regresar, pues la idea de retornar era un auténtico riesgo, que no muchas familias desplazadas quisieron sortear.

\footnotetext{
${ }^{54}$ Analizando los casos de masacres acaecidos en los departamentos de Sucre y Bolívar durante los primeros años del 2000, podríamos establecer como uno de los objetivos principales de los paramilitares fue el establecer un régimen de terror, cuyas consecuencias fue la consolidación de los procesos de desterritorialización campesina.
} 
Como mencionamos arriba, los obstáculos para el retorno no solo se encontraban en el contexto violento de la subregión, también incidió el escenario institucional y las relaciones que los desplazados intentaron establecer con las entidades estatales. Al respecto es importante señalar que pese a que este retorno es el resultado de un esfuerzo colectivo y comunitario, los campesinos buscaron el acompañamiento del Estado con el fin de garantizar sus derechos, no obstante desde antes del desplazamiento, como durante el proceso de retorno, dicho acompañamiento estatal ha sido escaso, y hasta el día en que se escribe este trabajo, casi inexistente ${ }^{55}$.

No obstante, por encima del contexto adverso y a la falta de garantías institucionales estos campesinos continuaron con la decisión de regresar. Entender la naturaleza y las múltiples implicaciones que tuvo esta decisión en el marco de unas prácticas espaciales y de un relacionamiento social, nos obliga a presentar los principales factores que atravesaron el proceso de retorno, el "volver" de estas comunidades.

\subsubsection{La voluntad de retorno ${ }^{56}$}

Tal como hemos presentado para los años 2000 al 2004, las condiciones de seguridad no estaban dadas, como para que las familias desplazadas decidieran regresar a sus veredas, pero también era bien conocido por parte de los campesinos de VillaColombia y Borracheras que en un corto y mediano plazo dichas condiciones tampoco iban a llegar, la decisión era ¿permanecer en condición de desplazamiento o retornar? y asumir para cada una de las opciones sus respectivas implicaciones.

Nosotros tenemos problema con el retorno, porque a nosotros no nos han

\footnotetext{
55 De acuerdo a la legislación nacional (LEY 387 DE 1997) y los instrumentos del sistema universal de derechos humanos (Naciones Unidas, 1998), el Estado debe garantizar a las comunidades que fueron objeto de desplazamiento forzado un regreso o retorno bajo una serie de condiciones, que en su conjunto den forma a una política pública de «reparación integral» que busque -entre otras- resarcir el daño y evitar nuevos procesos de revictimización. Empero, en medio de estos ocho años de retorno (2004-2012) las comunidades de VillaColombia y Borracheras siguen siendo objeto de hostigamientos y presiones, no solo por parte de grupos armados ilegales, sino por algunas dinámicas y actores económicos.

${ }^{56}$ Se relaciona con el elemento de voluntariedad del retorno, es decir, como derecho de la población desplazada a regresar consciente y voluntariamente a sus hogares.
} 
dado nada, porque el retorno lo hacen los campesino con las ayudas del Estado, nosotros no lo hicimos así, porque nosotros ¿cuando íbamos a esperar de que el Estado iba a poner no sé cuantos policías, no sé cuántos soldados pa' nosotros retornar?, nosotros vamos de una!, si nos vamos a morir, o si nos van a matar o lo que sea, vamos pa' allá!! (Grupo focal. Líderes campesinos vereda VillaColombia y Borracheras. 2011)

Así, la posibilidad de regresar o lo que se ha denominado como el deseo de retorno ${ }^{57}$ no dependía de las garantías que el Estado estaba dando para que los campesinos retornaran, pues era más que evidente que el conflicto y los actores ilegales permanecían en todo el territorio. Entonces ¿cómo explicar la decisión de retornar cuando las condiciones que generalizaron el desplazamiento aún se mantenían? Podemos disipar este interrogante por medio de tres factores que se constituyeron -en su momento- en piezas fundamentales para la concreción de ese "volver", a saber: a) la capacidad organizativa; b) las dinámicas y el tipo de desplazamiento $\mathrm{y}$; b) las condiciones socioeconómicas propias de vivir como desplazado, veamos algunas de sus particularidades:

a. La capacidad organizativa. Respecto al primer factor, conviene recordar que el 5 de marzo del 2004, 30 familias, 14 de VillaColombia y 16 de Borracheras regresaron a sus respectivas veredas. Lo importante de este hecho, no fue el retorno en sí mismo, sino lo modo en que lo hicieron. A pesar de haberse desplazado en periodos distintos (Borracheras en el 2000 y VillaColombia en el 2001), estas familias regresan de forma conjunta y organizada, no solamente en relación a unos criterios compartidos que les permitía acompañarse en tan trascendental momento, sino bajo una estructura organizativa que ellos denominaron como Asociación de Campesinos Desplazados Retornados ASOCARES-, estructura que les permitiría no solo materializar la necesidad de volver sino el proyectar comunitariamente la reconstrucción de sus propios

\footnotetext{
${ }^{57}$ De acuerdo con Ana María Ibáñez, la decisión de retornar, a diferencia del desplazamiento forzoso que es involuntario, se asemeja un poco más a la decisión de migrar. Los hogares o miembros del hogar evalúan las diferentes alternativas, sopesan los beneficios y costos de cada uno y escogen estratégicamente la mejor alternativa para consolidar sus condiciones de bienestar. La decisión de retorno en el marco del desplazamiento forzoso no carece, empero, de diferencias importantes frente a la decisión de retornar tras una migración voluntaria y por razones económicas. Las condiciones de seguridad, el trauma vivido por la victimización y la pérdida de activos son presumiblemente factores preponderantes en el proceso de decisión (2008:217)
} 
proyectos de vida ${ }^{58}$

Si consideramos el contexto de terror que vivía la subregión en los primeros años de la década del 2000, la conformación de una asociación para poder retornar podría entenderse -en un primer momento- como una estrategia para menguar colectivamente el miedo o como medida de autoprotección en un ambiente de violencia extrema. Frente a este aspecto, Serpa afirma que las personas vinculadas a procesos organizativos, reconocen que el estar asociados y mantener esa vocación de agremiación los ha protegido de las diversas formas de violencia que han imperado en la [sub]región a lo largo de estos últimos años (Serpa, 2010:4). Por lo que los campesinos desde antaño han encontrado, justamente en los diferentes espacios organizativos, una manera de contrarrestar los diferentes periodos de violencia que han vivido.

Empero, los procesos organizativos y/o la tendencia de los campesinos montemarianos a asociarse ${ }^{59}$, no podrían ser reducidos a simples respuestas frente a agresiones externas. Más allá de la estrategia de autoprotección, el carácter asociativo para el caso estudiado, debe entenderse como un acumulado sociohistórico a partir del cual, y sobre todo en el siglo XX, los campesinos montemarianos han articulado a su modo de vida una fuerte inclinación frente a un tipo de relacionamiento comunitario. De este modo, el volver a asociarse se constituyó en una valiosa herramienta para empezar a reencontrar a las comunidades, a la vez que se reducía el abismo que había abierto el desarraigo entre las familias, los compadres, los vecinos y los amigos. Así, las diferentes reuniones previas al retorno, se convirtieron en el pretexto para acercar a una comunidad que había sido desintegrada años atrás. Según los testimonios de

\footnotetext{
58 Frente a la creación de ASOCARES, es importante anotar que a diferencia de otros ejercicios organizativos de desplazados cuyo énfasis asociativo está centrado en la sola pertenecía a un sector: "población desplazada», la elección del nombre "asociación de campesinos» para el caso de VillaColombia y Borracheras, está íntimamente ligado, en primer lugar, a un referente identitario, lo campesino, y en segundo lugar, hacia su intensión de regresar y reapropiarse de su territorio.

${ }^{59}$ Desde finales del siglo XIX, se pueden rastrear diferentes experiencias donde los campesinos se han asociado con el fin de lograr objetivos mancomunados en relación con diferentes aspectos de su organización social, dichos aspectos van desde lo meramente económico hasta reivindicaciones trascendentales, como la tierra y la cultura campesina.
} 
Ios campesinos, ASOCARES fue el primer paso para empezar a reconstruir eso que ellos mismos denominan como "tejido social", es decir, el marco de relaciones y el sistema de valores que antes los determinaba y los unía. Con lo cual, la solidaridad y el encontrar apoyo en el "otro" fueron las fuerzas que finalmente facilitaron el retorno, al respecto Ibáñez \& Querubín (2004) afirman que la sensación de seguridad y protección, no solo proviene de las fuerzas del Estado, sino de redes sociales o comunidades muy cohesionadas, con lo que en nuestro caso- "las familias se sentían más seguras de regresar acompañadas de sus amigos" (Entrevista, mujer campesina. Carmen de Bolívar. Abril 2012)

En síntesis la capacidad organizativa estaría relacionada a dos principios: uno más pragmático, relacionado con la idea de autoprotección y otro más sociohistórico, vinculado con las posibilidades de recuperar los espacios y el tipo de relacionamiento comunitario, no obstante, estos dos principios no terminan de advertir el porqué del retorno ni el fundamento del porqué éste tomó la forma de una «asociación». Este hecho es importante, ya que es bien sabido, que no todos los campesinos desplazados retornan a los lugares de origen y no todos los retornos se dan masivamente ni mucho menos, por medio de estructuras sociales como las asociaciones.

Advertimos en este punto, que cuando nos referimos a la capacidad organizativa de estos campesinos, estamos hablando de aquellos elementos que les han permitido configurar un ser y un estar asentado en la idea de asociatividad y de comunidad. Tal como veíamos en el capitulo anterior, dicha asociatividad se ha instalado en los sentidos y las prácticas socioespaciales que han producido y reproducido estos campesinos, articulando -en medio de ello- el espacio familiar y privado al escenario comunitario; estableciendo un relacionamiento a partir del cual se toman decisiones, se ordena el espacio y se regula la vida y la cotidianidad a fin de determinados objetivos que pueden estar atados al plano material o simbólico.

Insistimos para el caso particular de las comunidades estudiadas, que este potencial organizativo debe ser rastreado desde el surgimiento mismo de los primeros núcleos campesinos en la costa Caribe, tratando de encontrar en dicho ejercicio las particularidades culturales, identitarias e ideológicas en relación a la 
constitución de los sujetos individuales y colectivos. Bajo esta premisa, el rescatar la historicidad del campesinado por fuera del marco economicista, nos ha permitido comprender el desenvolvimiento del campesino montemariano en sus diferentes dimensiones, y con ello identificar los elementos que to han fundado; de este proceso, lo comunitario emerge como uno de los ejes que ha configurado a estos sujetos en relación con su identidad y su memoria.

De ahí que el crear una asociación y el organizase para iniciar un proceso de retorno, no pasa solamente por un aspecto coyuntural o pragmático dado por el desplazamiento. Lo que acá queremos señalar, es que la posibilidad de organizarse tiene que ser leído como un acumulado histórico que ha determinado las relaciones sociales y el desarrollo del campesinado en la subregión. Desde antes del siglo XX, han existido diferentes maneras en que por medio de la organización o procesos asociativos los campesinos y los demás pobladores rurales han reivindicado un sin número de peticiones y derechos. Se podría decir que la asociatividad es parte de la constitución de los sujetos campesinos en esta parte del país. Tal vez la ANUC y el rol que jugó en la historia social en cuanto al fortalecimiento comunitario y gremial, sea el marco más próximo para entender porqué este retorno pasó por la creación y formalización de una asociación como ASOCARES.

Recordemos en este punto que los campesinos que lideraron el proceso de retorno y que finalmente le dieron vida a la asociación de ASOCARES, eran - y aún siguen siendo- líderes reconocidos en todos Los Montes de María, la mayoría de ellos hicieron parte de los procesos de recuperación de tierras liderado por la ANUC en la década de los 70s y de los 80s. Esta experiencia acumulativa confirió cierta madurez en las reflexiones que se establecieron en su momento frente al tema del retorno, movilizando algunos repertorios, previamente adquiridos en la organización y el movimiento campesino de ataño, para el beneficio de su empresa actual: el retorno.

Yo te cuento como inicio el proceso de retorno, porque yo fui uno de los autores, ósea fui uno de los que encabece el retorno con el compañero Jader y el compañero Carmelo. Como en esa época Jader y yo vivíamos en Sincelejo y Carmelo en el Carmen, lo primero fue empezar a encontrarnos y hablar, pues inquietos de la situación queríamos hacer algo,...nosotros 
teníamos que buscar otros contactos, entonces como yo siempre he sido más que todo el que ha tenido buenos contactos con las ONG's y las organizaciones gremiales, entonces empecé a hablar con algunas instituciones de la problemática del desplazamiento en nuestras comunidades,... Ilevamos la inquietud a una ONG que ha venido trabajando por la ayuda del campesino, en cuanto a proyectos se refiere,...entonces comenzamos a conversar con ellos y ellos dijeron que estaban en condiciones de colaborarnos, entonces empezamos a buscar los contactos con los compañeros desplazados, en Borracheras, finalmente se nos unieron 16 familias y aquí en VillaColombia 14 familias.(Grupo focal. Vereda VillaColombia. Abril de 2012)

El retorno bajo la figura de una asociación fue entendida, por parte de los líderes como una estrategia para proyectarse en el territorio y superar los efectos socioeconómicos del desplazamiento forzado. De esta manera para poder materializar el retorno era necesario no solo que las familias volvieran sino desplegar toda una serie de disposiciones para garantizar las mínimas condiciones para mantenerse dignamente en sus veredas. Si regresaban era para quedarse y para eso la Asociación les posibilitó convertirse en un actor con interlocución tanto a nivel municipal como con algunas ONG's que colaboraron con el proceso.

b. Dinámicas y tipo de desplazamiento. A pesar que lo organizativo se estableció en uno de los principales aspectos que posibilitó el retorno del 2004, este tiene que ser leído junto con otras particularidades propias del proceso de desplazamiento. Las dinámicas y los motivos que generaron el desplazamiento marcan una especificación que no debe pasarse por alto, muchas de las razones que determinan la posibilidad de retornar 0 no, tienen que ver con estas dinámicas y motivos.

Cuando nos referimos a las dinámicas y al tipo de desplazamiento, estamos contemplando las particularidades de la expulsión, entre ellos los actores y el motivo de desplazamiento, a la vez que revisamos las estrategias utilizadas por las comunidades para sopesar el desarraigo, como por ejemplo la búsqueda de redes sociales (amigos y/o familiares en otras veredas o municipios) y la "elección" de los lugares de recepción. 
A pesar que el desplazamiento es un fenómeno generalizado en el país desde finales del siglo XX, este no podría ser estudiado como un todo homogéneo, ya que sus dinámicas dependen de las condiciones propias a partir de las cuales se genera el desarraigo. Dichas condiciones pasan por: i) el tipo de actor que comete el crimen; ii) el tipo de población a la que se victimiza; iii) las acciones que generan el desplazamiento; iv) la región; v) los actores económicos involucrados, etc., Es decir, pasa por un amplio espectro de relaciones que atraviesan las causas y los efectos de tal fenómeno. De esta manera y para el caso observado, la motivación o la acción que genera el desplazamiento se constituye en un primer determinante para que las poblaciones decidan regresar o no.

Recordemos que el desplazamiento masivo tanto de VillaColombia como de Borracheras no fue producido por una acción violenta directa sobre la población. A diferencia de otras experiencias de desplazamiento masivos en la subregión, como el caso de Chengue ${ }^{60}$ y Pijiguay ${ }^{61}$ que fueron antecedidas por horrendas masacres, lo sucedido en las comunidades de VillaColombia y Borracheras puede ser leído más como un efecto -leas miedo- de las acciones paramilitares en veredas o corregimientos vecinos que por acciones directas sobre ellos. Con ésto no queremos decir que las implicaciones de un desplazamiento cuyo origen fue una masacre frente a otro en la que la población se desplazó por otros motivos "menos directos" no sean igual de graves, simplemente, lo que afirmamos es que las reacciones y las emociones frente a los lugares de expulsión, en cuanto a una posibilidad de retorno, varían de pendiendo del caso; es más, el vivir una experiencia traumática de victimización torna a los hogares más renuentes a regresar (Ibáñez, 2008:222-221) de ahí, que un campesino

\footnotetext{
${ }^{60}$ La masacre de Chengue perpetrada el 17 de enero del 2001 en el municipio de Ovejas, departamento de Sucre, dejó como saldo 27 muertos, y cientos de campesinos desplazadas. "Después de provocar un verdadero 'océano' de sangre, los paramilitares pintaron en las paredes de algunas casas letreros que decían "fuera, guerrilla comunista". Luego saquearon y quemaron algunas viviendas. Antes de partir, les dijeron a las mujeres y a los niños que se hicieran a la idea "de que ya perdieron este pueblo. Si a la próxima regresamos y los encontramos, terminamos con todos ustedes". (Revista Semana, 2008)

${ }^{61}$ El 6 de septiembre de 1997, en el corregimiento de Pijiguay, municipio de Ovejas, departamento de Sucre, una incursión paramilitar asesino a seis de sus pobladores e incendió una de las tiendas principales del corregimiento. Después de los asesinatos sus pobladores tuvieron que abandonar sus hogares por miedo a más represalias.
} 
frente al caso de Chengue afirmará que: "no es fácil regresar a una casa donde te mataron a un ser querido" "no es fácil pasar por una calle o por un parque donde mataron a más de un compañero" (Grupo focal, Líderes campesinos, veredas VillaColombia y Borracheras. 2011) De este modo, los lugares y los sujetos quedan cargados de sentimientos, angustias, tristezas,... que muchas veces obstruyen la decisión de retornar ${ }^{62}$.

Volviendo a nuestro caso, el hecho de haberse desplazado sin haber sufrido directamente pérdidas humanas o acciones de extrema violencia como violaciones, desapariciones o masacres, incidió para que la valoración de volver fuera menos espinosa.

Por otro lado, la naturaleza del hecho violento que generó el desplazamiento no solamente posibilitó una menor afectación en términos psicosociales ${ }^{63}$, sino que además permitió que los campesinos nunca perdieran contacto con su espacio, con las veredas y sus parcelas.

Al respecto conviene aclarar que a pesar que durante tres y cuatro años los campesinos estuvieron viviendo fuera de sus parcelas, este desplazamiento no fue del todo "consumado", es decir, nunca hubo un alejamiento total de las parcelas; la estrategia de ir a trabajar de día a las parcelas y volver de noche a los lugares de recepción, es una muestra de cómo los campesinos se resistían a la idea de estar fuera de su espacio de reproducción social y económico; a diferencia de otros casos en la subregión, estos campesinos jamás se desplazaron por fuera del marco subregional o inclusive del regional. Este aspecto está íntimamente relacionado con las dinámicas del desplazamiento como «movimiento espacial».

\footnotetext{
${ }^{62}$ Además de estos elementos propios de los traumas sociales, es importante anotar que esa imposibilidad de retornar está ligada también a las limitaciones materiales y a la falta de garantías institucionales, pues en la mayoría de los casos, los victimarios aún se encuentran activos en los territorios.

${ }^{63}$ A pesar que el desplazamiento en si mismo genera una serie de alteraciones sicosociales en todos los sujetos, es importante considerar que el tipo o el grado de afectación en muchas circunstancias depende del hecho violento que generó el desplazamiento. Así una tortura, una violación o el haber perdido de manera violenta a un ser querido produce una serie de traumas que necesariamente tienen que ser abordados por especialistas. Ver Peritaje psicosocial de ASOCARES (2013)
} 
Mapa 6. Zonas de explosión / zonas de recepción. Veredas VillaColombia y Borracheras

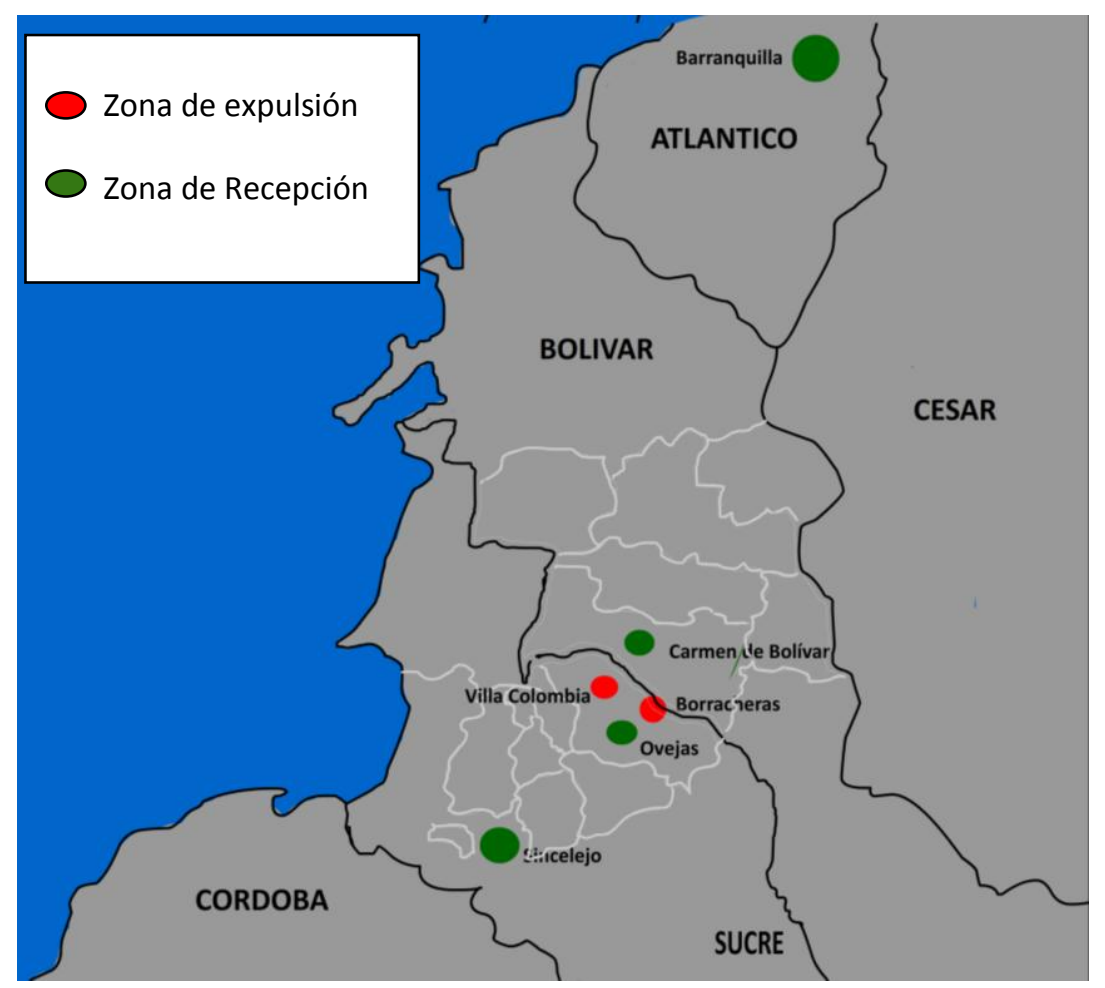

Fuente. Elaboración propia con base en anotaciones de campo.

En el mapa 6 vemos como los lugares de recepción no están muy alejados de los lugares de expulsión. La mayoría de los campesinos desplazados de VillaColombia y Borracheras se instalaron en los cascos municipales de Ovejas, Sincelejo o el Carmen de Bolívar, solamente uno de los campesinos de Borracheras y por dinámicas laborales estuvo un tiempo radicado en la ciudad de Barranquilla. Esta movilización espacial, confirma la hipótesis de que lo sucedido en VillaColombia y Borracheras fue más un desplazamiento intermunicipal que interregional, pues los desplazamientos, es decir, el movimiento espacial de estas familias no fue más allá de los municipios cercanos del propio municipio de Ovejas y del Carmen de Bolívar.

El mantenerse dentro de la subregión y el no desplazarse a otros municipios o regiones, puede obedecer a varias causas, entre ellas, a las redes de apoyo generalmente de familiares- que los campesinos poseían en el momento del desplazamiento: ... Si usted tiene la familia pa' allá pa' Bogotá, entonces la familia lo recoge de alguna manera y se lo lleva pa' allá; [por ejemplo] si yo tengo 
la mía en Barranquilla, también hacen lo mismo, me llevan pa' Barranquilla, y así sucesivamente,... uno como desplazado se iba a donde lo recibían... (Grupo Focal. Vereda VillaColombia. Abril 2012)

En el caso de VillaColombia, los primero días de desplazamiento, los campesinos se refugiaron en la escuela del municipio de Ovejas, después de un mes de refugio, cada familia buscó a donde irse. Ese irse, estuvo asociado a la casa de algún familiar (padres, hermanos, primos, tíos,...) o de algún amigo. De igual manera, los pobladores de Borracheras buscaron a sus familiares, los cuales -en su mayoría- se encontraban en la cabecera municipal del Carmen de Bolívar: Que aquí cuando vinimos desplazados, no teníamos a donde ir, uno andaba desubicado, ahí es cuando mi máma me dio alojo acá en el Carmen. Esta casa es de mi máma! (Entrevista mujer. Carmen de Bolívar)

El vivir en las cabeceras municipales cercanas a sus veredas, les permitió a los campesinos de VillaColombia y Borracheras, no solamente estar pendientes de sus parcelas y por ende mantener un contacto real con la tierra, sino que además facilitó la organización del proceso de retorno, pues las 30 familias que regresaron el 5 de marzo del 2004 se encontraban agrupadas en tres cabeceras municipales muy cercanas entre ellas, a saber: Carmen de Bolívar, Ovejas y Sincelejo.

c. Las condiciones socioeconómicas. En cuanto al tercer factor, no hay que olvidar las condiciones socioeconómicas que influyeron en la decisión de retornar. De acuerdo con Ana María Ibáñez (2008) una de las variables que determina el deseo de retorno de las poblaciones desplazadas, está dada por las condiciones de sostenibilidad económica que brinda el lugar de recepción frente al lugar de expulsión. Si el lugar de recepción me brinda una serie de garantías como el de seguridad, de servicios, de infraestructura o de oferta de generación de ingresos que antes no poseía, entonces es menor la posibilidad de regresar a mi lugar de origen. Bajo esta lógica, propia de la acción racional, los campesinos evalúan en un ejercicio comparativo su condición actual con su condición anterior y de allí toman su decisión frente al retorno. Así las decisiones de retorno están influidas por las preferencias por los lugres de origen y recepción, por las condiciones económicas y por el proceso de asimilación en el lugar de 
recepción (Ibáñez, 2008:225)

Sin querer detenernos en las críticas que podríamos establecer a esta excesiva racionalización de los sujetos frente a la idea de pérdida y ganancia ${ }^{64}$, lo cierto es que para el caso de las comunidades de VillaColombia y Borracheras, la situación económica anterior al desplazamiento generaba mayor estabilidad que la obtenida en los tres y cuatro años de desplazamiento.

En todas las entrevistas realizadas, los campesino tienden a caracterizar el antes y el después de su modo de vida a través de la idea de la abundancia y la escasez. La abundancia se caracteriza por la capacidad productiva que tenían como resultado del trabajo en la tierra (el cultivo) o la cría de animales._Uno sembrando se mantenía de eso, que uno tenía la facilidad, compraba la vaquita, ya tenía dos cajas de leche, ya había el suero ya la cosa era diferente,... pero vivíamos de otra manera, no se aguantaba hambre, había de dónde coger. (Entrevista. Hombre campesino, vereda VillaColombia, 2011).

Sin embargo, es notorio encontrar que de las narraciones de estas comunidades se desprende un sentimiento que va más allá del aspecto puramente material, la abundancia también está estrechamente vinculada con la idea de "tranquilidad"; el vivir tranquilos es una manera en la que los campesinos traducen el sentir de la "abundancia". "Todo antes del desplazamiento estaba bien, pa' mi bien, para mis hijos bien, para todos bien, ... yo me sentía como mejor, tenía una vida feliz, yo no sé pero mis hijos no se me enfermaban no se pero yo sentía un ambiente excelente y me gusta estar allá (...) allá un día para mí, era como estar en un paraíso, estar tranquila no tenía que comprar nada, yo iba y recogía, estaban mis gallinas que me ponían mis huevos y yo todo, y era una vida tranquila" (Entrevista, mujer campesina, vereda Borracheras, 2011)

Así, la vida antes del desplazamiento no solamente significó un periodo de solvencia económica sino social, en donde las familias se sentían a gusto con lo que tenían en el marco de un relacionamiento familiar y comunitario.

\footnotetext{
${ }^{64}$ El estudio econométrico de Ibáñez (2008) generaliza los factores de los llamados "deseos de retorno" sin considerar las particularidades de los casos, la construcción sociohistórica y espacial de los sujetos o antecedentes regionales.
} 
Contrario a ello, los días de desplazados en las cabeceras municipales significaron pobreza, hacinamiento, penurias, donde la dependencia hacia el dinero era mucho más radical. Lo que antes cultivaban y consumían ahora tenían que pagarlo, así, muchas veces tuvieron que pasar días sin poder comprar los alimentos básicos. Esta idea de la abundancia y escases, puede comprenderse de una mejor manera a través del siguiente testimonio:

(...) teníamos una parcelita de 20 hectáreas, pero era propia porque fue de herencia que le dejaron los papas del marido mío y entonces a él le tocaban 10 hectáreas, entonces él cómo puedo compró otras 10 más de un hermano.... ósea él vivió toda la vida allá porque él fue nacido y criado allá, después yo cuando viví con él, que me case, ya nosotros teníamos 15 años de estar allá. (...) allá en la finca uno las actividades que tenía era sembrar la yuca, el maíz, el ñame, sembrar tabaco, porque de ahí era que uno se sustituía de la siembra del tabaco (...) mensualmente ya cuando se recolectaba el tabaco, uno sacaba como dos millones de pesos, ósea mensualmente entre toda la familia uno recolectaba, éste,... dos millones de pesos, además uno criaba la gallina, el pavo, el cerdo, y todo eso lo perdimos cuando nosotros nos desplazamos (...) bueno y entonces fue cuando el desplazamiento fue el que nos dio duro, duro nos dio, porque aquí entonces uno para sobrevivir en el pueblo se fue comiendo los animalitos, te voy a decir que yo tenía 15 vaquitas cuando eso, ya grandes fuera de los terneritos y eso, y entonces de ahí uno, las vendió casi todas pa' uno venirse. (...) En el desplazamiento nos tocaba dormir en el piso, aquí, duramos todos los años mientras nos desplazamos, aquí dormíamos en el piso, porque aquí nunca nos dieron ayuda como desplazados (...) uno a veces en este pueblo acá en el Carmen está resignado, es que uno amanece sin plata que pa' comprar el agua y si uno no compra el agua no come (Entrevista mujer. Carmen de Bolívar. Abril 2012)

La escases, también es un referente de la imposibilidad o por lo menos la dificultad que tienen los campesinos desplazados en la continuación de su saber práctico como base de sus sustento económico. La especialización del saber agrícola de los campesinos (identificación de tipos de suelo, ciclos productivos, manejos de plagas, aprovechamiento de los recursos naturales,...) se constituye en un saber inerte en los cascos urbanos o en las ciudades, de ahí las pocas posibilidades de insertarse en las ocasionales ofertas de empleo que podían 
ofrecer las cabeceras municipales como el Carmen u Ovejas, por lo cual, en los años que vivieron en situación de desplazamiento, éstos campesinos vieron reducir drásticamente su capacidad adquisitiva, con lo que tuvieron que vivir en condiciones de pobreza extrema. Bajo esta lectura, tal situación socioeconómica se constituyó en un motivo más para que el retorno pudiera ser llevado a cabo, pues el retornar les permitiría -a pesar de las dificultades acá presentadasintentar reconstruir y recuperar lo que la violencia y el desplazamiento les arrebato: su tranquilidad y la posibilidad de trabajar en la tierra ${ }^{65}$.

\subsection{Familias campesinas retornadas: sentidos y prácticas espaciales en juego.}

Tomada la decisión y organizado el proceso de retorno, el 5 de marzo del 2004, 30 familias regresan a las veredas que años atrás habían tenido que abandonar. Ese día junto con el miedo y la incertidumbre de lo que podría pasar con su retorno, estas familias comprendieron que el regresar no significaría volver a un estado anterior, y que la abundancia y la tranquilidad con la cual ellos mismos caracterizaban el estado previo al desplazamiento, no la encontrarían con el regreso.

El desplazamiento no fue una "pausa" de un discurrir vital susceptible de "despausar» en el instante en que se decidiera a retornar. Sus modos de vida, la estructura familiar, las relaciones sociales, las prácticas socioespaciales y los sentidos que las generaban, pasaron por un proceso de reconfiguración desde el primer día que salieron de sus veredas. Los años que vivieron como desplazados terminaron por reajustar al ser (campesino) y al modo de estar de ese ser en términos individuales y colectivos. Advertimos e insistimos en este punto, que ese ser es observado no como una esencia, síntesis de un conjunto de cualidades dadas a priori o connaturalmente, sino por el contrario, como el resultado de una serie de acciones, percepciones, tensiones, contradicciones y saberes producidos y reproducidos históricamente; entendido así, el estar no es más que la manera en que ese ser se ha relacionado históricamente tanto con los hombres en un contexto social, familiar, cultural, tradicional, económico, etc., como con el medio que lo rodea; y es justamente ese estar el que resultó

\footnotetext{
${ }^{65}$ Consideremos que la tierra es la base para la reproducción material e inmaterial de los campesinos, sin ésta o sin acceso a ella, su desenvolvimiento económico queda bastante limitado
} 
reconfigurado.

Así el reajuste o la reconfiguración que enunciamos, implicó un cambio en la propia autodefinición y en el heteroreconocimiento de ese ser y de las acciones materiales e inmateriales que lo conformaban, con lo cual, los sentidos que generaban unión y esquemas de interpretación y acción (individuales 0 compartidos) se reestructuraron en muy corto tiempo. Seguramente la relación familia, comunidad, trabajo, tierra, nos permite comprender y exponer más fácilmente algunos de los resultados obtenidos frente a estas reconfiguraciones.

\subsubsection{Reconfiguración de prácticas espaciales.}

Las reconfiguraciones del ser y del estar, involucran reelaboraciones en los sentidos, las acciones y los discursos que constituyen a los sujetos y a sus modos de vida. Dicho proceso pasa -en el caso de los campesinos de VillaColombia y Borracheras- por ajustes o reacomodaciones de los escenarios privados y comunitarios así como en los modos en los que los sujetos se relacionan en dichos espacios. Acá, la principal fuerza que motiva y acelera estas reelaboraciones es el desplazamiento y el desarraigo producido por él. Paralelamente, estas reconfiguraciones al ser expresiones de cambios acelerados y drásticos de los sujetos, resultan ser también procesos reconfiguradores de la producción espacial de dichos sujetos. Recordemos que la producción social del espacio, se origina, justamente en el escenario "social», por lo que el reajuste del estar de los sujetos, termina reajustando ciertas prácticas concretas (materiales o inmateriales) en cuanto al relacionamiento de los hombres con los hombres y el medio.

Bajo esta mirada, si rastreamos las reconfiguraciones dadas en el ámbito social, encontraremos los ajustes o reelaboraciones espaciales que se derivan de éste en relación a las maneras en que los campesinos ocupan, usan, controlan y dominan su espacio después de los procesos de retorno. Reconociendo la complejidad que acarrea el observar todo el espectro de lo social, encontramos que para el objetivo de nuestra investigación, es el ámbito de lo familiar en relación con el trabajo y la comunidad, los principales factores que nos permitieron comprender este proceso de reconfiguración. De esta manera, la familia, el trabajo, la comunidad no solo son los principales factores que 
resultaron modificados, sino que en su conjunto, son la explicación de lo que se mantuvo, se transformó o se recreó en relación con las prácticas espaciales de estas comunidades retornadas.

Con el fin de comprender esta relación, en un primer momento presentamos las implicaciones particulares de cada uno de estos escenarios, para poder al finar, articular y presentar las relaciones que los unen en cuanto a las prácticas espaciales.

\subsubsection{Prácticas campesinas en medio del retorno: Familia, trabajo y comunidad}

Siguiendo las corrientes clásicas que han abordado el tema de lo campesino y el campesinado (Chayánov, 1974) encontramos que dichos estudios han tenido una excesiva fijación hacia el componente económico. Se ha sintetizado al campesino a su relación con la tierra y a ésta se le ha reducido a medio de producción, de igual manera la familia campesina solo se ha entendido como unidad de trabajo.

Com grande frequência, na literatura pesquisada, o campesinato foi construído como uma economia. Ou seja, o termo camponês era designado para compreender a manifestação de formas econômicas distintas (e retrógradas) das sociedades industriais. A economia camponesa era analisada sob uma ótica puramente economicista, não considerando as possibilidades qualitativas de compreensão das práticas sociais mais amplas (Ferreira \& Vieria, 2011:49)

Bajo esta mirada, la familia campesina se ha entendido como una unidad domestica de producción ${ }^{66}$, de allí que el concepto de agricultura familiar se encuentre presente en el origen mismo del campesinado. De este modo, la

\footnotetext{
${ }^{66}$ Woortmann (1995) afirma al respecto que: "ao analisar a perspectiva teórica dos economistas europeus sobre o campesinato, destaca criticamente a abordagem de Chayanov (1974), interlocutor fértil da antiga escola austríaca-lemã e crítico da perspectiva marxista à época em que aquele autor analisa o campesinato russo. Chayanov (1974) considera a família uma unidade de força de trabalho e de consumo. Esta é vista como grupo doméstico sob uma "ótica econômica" e não um valor cultural. Essa ótica se vincula à perspectiva clássica da economia que, assim como mostrou Abramovay (2004), atomiza os atores e exclui elementos não econômicos do campo analítico da economia. A família é, sob este prisma, uma unidade econômica ocupada em reproduzir seus fatores de produção (CHAYANOV, 1974) e, a terra, constitui o principal fator de produção, independente de seu conteúdo ideológico. Ver Ferreira \& Vieria, 2011:53
} 
familia se torna en el núcleo central de la producción y del control del establecimiento productivo (Minin, 2008:) con lo que, la economía campesina sería el resultante de la ecuación simplista que conjuga exclusivamente la producción agrícola como receta total, substraída de la demanda interna de la familia (autoconsumo/subsistencia) y de los gastos para la adquisición de productos esenciales no producidos por ella (...) En síntesis, la unidad doméstica [familia] es concebida como una unidad de producción y consumo. (Ferreira \& Vieira, 2011:46 traducción libre)

Al respecto, Woortmann (1995) afirma que Todos os autores da vertente econômica européia da teoria do campesinato consideram a família como central para a compreensão do campesinato. Mas, o que se enfatiza é, fundamentalmente, a produção econômica e capacidade produtiva da família, mais do que a produção social da família, como instituição e como valor, ou as relações entre famílias. $O$ foco de análise se ateve preponderantemente à unidade familiar e pouco se explorou sobre as relações externas à família (E. Woortmann, 1995: 311).

Siguiendo la crítica de Woortmann y considerando las particularidades, pero sobre todo la dimensión sociocultural de las familias campesinas de VillaColombia y Borracheras, se nos es imposible entenderlas como simples unidades de fuerza de trabajo y de consumo. La intensión a lo largo del trabajo ha sido el comprender lo campesino como una categoría social, para partir de allí leer las implicaciones que tuvo el retorno en cuanto a sus prácticas.

En este sentido, podríamos acreditar que para los campesinos de VillaColombia y Borracheras, la familia es más que una unidad de producción, pues ésta, en sus múltiples interacciones que va desde lo privado hasta lo comunitario, se constituye en un importante generador del modo de vida, del sistema de valores $y$ de los elementos que permiten una cierta coherencia entre lo que se "es» en términos individuales y colectivos; con ésto no queremos negar que la familia es el núcleo del proceso económico, pues es a partir de la estructura familiar que se establecen y se designan roles, jerarquías y relaciones de poder dentro de 
dicho proceso ${ }^{67}$. Cada persona de la familia campesina desempeña un trabajo útil y concreto, según el momento y la necesidad. De este modo, se estructura en el interior de la familia una división técnica del trabajo, articulada por el proceso de cooperación, resultando en una jornada de trabajo acordado por los miembros de la familia. En este sentido, la familia campesina se transforma en un trabajador colectivo" (Traducción libre. Texto original Santos, 1984:33-34, en De Almeida, Rosmeire. 2003:330)

\begin{abstract}
“(...) en eso trabajaban, los tres hijos míos varones, y estaban dos cuñados míos, trabajábamos y también a mi me tocaba porque a mí me tocaba también hasta de picar monte, a echar y todo eso, a mí también me tocaba, porque yo también sembraba mis cultivos fuera de la que el marido mío sembraba,... entre todos a veces recolectábamos hasta 6 hectáreas de cultivo entre toda la familia" (testimonio mujer. Vereda Borracheras)
\end{abstract}

Reconociendo que la familia y el trabajo son dos espacios de la vida social casi que inseparables en los escenarios campesinos, lo que queremos presentar acá, es que la relación que los articula no responde únicamente al sentido productivo. De acuerdo a lo encontrado y a lo manifestado por los campesinos entrevistados, el espacio de lo familiar y del trabajo se constituyen cada cual y de manera dependiente en espacios de vida:

El espacio de vida da cuenta de una experiencia concreta de los lugares, indispensables, en la construcción de las relación que se establece entre la sociedad y su espacio [vital] (Nantes et al., 2001:36)

Así, la familia más que posibilitadora de la economía, es junto con el trabajo (en la tierra) los espacios de vida de la reproducción socioespacial campesina. De allí, que en su correlación se generen las representaciones sociales, los códigos, los símbolos, los discursos y las prácticas que contienen la forma del modo de

\footnotetext{
67 "Cada persona de la familia campesina desempeña un trabajo útil y concreto, según el momento y la necesidad. De este modo, se estructura en el interior de la familia una división técnica del trabajo, articulada por el proceso de cooperación, resultando en una jornada de trabajo acordado por los miembros de la familia. En este sentido, la familia campesina se transforma en un trabajador colectivo" (Traducción libre. Texto original Santos, 1984:33-34, en De Almeida, Rosmeire. 2003:330)
} 
vida. Parafraseando a Bourdieu (1988a, 1988b, 1990), podríamos afirmar para nuestro caso que, la familia y el trabajo como mancomunión social y productiva, permiten a los sujetos campesinos producir e incorporar una serie de prácticas y representaciones (formas de actuar, de organizarse y de pensar) dentro de un proceso histórico y espacial determinado, lo cual les permite mantener más o menos estable el sistema identitario y de relacionamiento social. Acá cobra importancia la transmisión intergeneracional en el mantenimiento o (re)creación de dichas representaciones y prácticas.

Esta abstracción del campo de lo familiar y del trabajo y desde una perspectiva comparativa, nos permitió acercarnos a las reconfiguraciones que dichos campos sufrieron en el proceso de retorno iniciado en el 2004. Al respecto, los espacios de la familia y el trabajo como espacios de vida, pasaron por una serie de alteraciones que hasta el día de hoy siguen permeando las relaciones de estos campesinos. En primer lugar hay que mencionar que la estructura familiar para el $40 \%$ de las familias retornadas se vio seriamente modificada. Por causa del desplazamiento estos campesinos vivieron en extremas condiciones de vida por un tiempo no menor de tres años. En medio de este tiempo y por consecuencia directa de afectaciones emocionales derivados del proceso de desarraigo $y$ en muchas circunstancias, por afectaciones de tipo socioeconómicos, los miembros de las familias terminaron alejándose o en el caso de las parejas separándose.

"Nosotros como desplazados fuimos afectados psicológicamente, pues causó un impacto en la familia y de pronto eso trajo una consecuencia que... después del desplazamiento viene una guerra entre los hogares, yo lo digo porque yo lo viví en mi hogar...antes del desplazamiento, mi condición de vida era diferente yo tenía mis animales, mi esposa de pronto no tenía que estar aguantando esas necesidades que aguantó después de que nos desplazamos y eso causó un choque verbal entre los dos,... era la misma afectación que causó la guerra, el vivir en el pueblo... entonces yo sin trabajo, no cumplía con las necesidades de mi hogar, como cabeza de hogar no tenía como suplir los gastos,... de pronto era ella la que tenía que trabajar,... y todo eso generó que nos tuviéramos que separar..." (Entrevista. Hombre campesino, Municipio del Carmen de Bolívar. 2011) 
Desde el retorno del 2004 hasta la fecha en la que se realizó el trabajo de campo (2011-2013), estas familias campesinas no habían podido sortear estas fragmentaciones o reestructuraciones familiares.

La reestructuración del escenario familiar -como vimos en el testimonio anteriorha sido causada por las separaciones afectivas entre algunos de los miembros de los hogares retornados, no obstante otro factor atravesó dicha reestructuración. Entre las comunidades de VillaColombia y especialmente en los núcleos familiares de Borracheras se observa la implementación de una estrategia que les ha servido para contrarrestar la falta de ingresos económicos o como medida para garantizar la seguridad de una parte de la familia (mujeres, niños y ancianos). Dicha estrategia ha consistido en que los hombres cabeza de familia asumen de manera individual todo el peso del mantenimiento de las parcelas, mientras que las mujeres y los hijos menores se quedan a vivir en las cabeceras municipales más cercanas: "mis hijos están conmigo aquí y mi esposo está allá trabajando,... mi esposo viene cada ratico con la vitualla o nos envía dinero para que vallamos a visitarlo y a estarnos con él unos días, ... pero por lo general yo estoy en el pueblo con mis hijas" (testimonio mujer. Carmen de Bolívar).

Esta separación ha generado en el caso de las mujeres, una pérdida de una parte de de su autonomía y de su propio dominio territorial, pues antes del desplazamiento ellas participaban activamente del trabajo del cultivo : "nosotros tumbábamos todo el monte y entonces el dividía el pedazo, "este es el mío, y del cuñado mío" y entonces, yo cogía también mi pedacito de tierra, de ahí mismo pa' sembrar mi parte individual, claro que dé ahí también yo cogía pa' la comida, ósea entre todos los que estábamos ahí reuníamos pa' comprar comida pa' poder subsistir"(Testimonio mujer. Vereda Borracheras, 2012) "me gustaba ir a sembrar, de ayudarle, yo quería estar metida como todo eso, y es que me gusta el campo, la vida en el campo..." (Entrevista mujer campesina, vereda Borracheras, 2012)

Por todo lo anterior, podríamos afirmar que la realidad del desarraigo y las condiciones que generó, alteró la imagen construida por generaciones entorno al trabajo familiar y colaborativo; este desdibujamiento acarreó la división de los 
miembros de las familias, muchos de los cuales se abocaron a realizar otras actividades no exclusivas del campo.

Esta situación ha generado que gran parte de los jóvenes se aleje de las parcelas, del trabajo de la tierra y busque insertarse de manera constante en las pocas opciones económicas que les brinda las cabeceras municipales. Una parte de los miembros de las familias, especialmente los jóvenes con edades entre los 17 y 24 años se dedican al negocio del mototaxismo ${ }^{68}$. Este fenómeno cada vez más popular en los municipios de los Montes de María, permee la función social que cumplía el trabajo como reproductor del quehacer campesino:

El trabajo es como un ritual en que los hijos, todavía jóvenes, son iniciados, convocados a aprender el habitus campesino, (...) el trabajo en el campo cumple la tarea de representar el horizonte social y económico de las nuevas generaciones (Almeida, 2006:106.Traducción libre)

De tal manera y aceptando lo afirmado en líneas arriba, la transmisión generacional al ser interrumpida, dificulta el mantenimiento del sistema de valores y de representación que constituía a estos campesinos. Por ende, el espacio vital de la familia se ve reconfigurado a la vez que los sentidos que en ella se reproducían. A propósito recordemos que:

En cada una de la familias se crean espacios muy importantes como la hora de comida, o al terminar las jornadas de trabajo, donde se sientan en el patio de la casa, compartiendo sus experiencias vividas durante el día, sus sueños, preocupaciones, momentos alegres o tristes, ahí se cuentan sus historias de vida, es cuando la oralidad cobra relevancia como un medio indispensable para la perpetuidad de la cultura, para la trasmisión a las nuevas generaciones, donde los niños disfrutan al escuchar a sus padres o a los abuelos, porque se van imaginando como era antes sus comunidades, como se organizaban, como convivían (López, 2010:21)

Lo experimentado durante el proceso de retorno marca una ruptura con la familia

\footnotetext{
${ }^{68}$ El mototaxismo es un fenómeno que nace como resultado de las pocas opciones laborales en la mayoría de municipios de la costa Atlántica y Pacífica de Colombia. En los Montes de María la moto se ha popularizado como medio de transporte informal para el recorrido de tramos relativamente cortos. Esta actividad concentra un porcentaje considerable del empleo informal de estos municipios.
} 
y el trabajo como espacios de vida (como espacios donde se da forma a lo que se «es» en cuanto al modo de comprender e interactuar en la realidad). Entendido así, los efectos de tal escisión no solamente alteraron los espacios más íntimos, sino que modificaron a la vez, el entorno social más inmediato: la comunidad.

Para nosotros es en la relación familia-trabajo, donde el individuo aprende y construye formas particulares de relacionarse con el entorno, el tiempo, y los otros; [dando forma a] una construcción histórico-social que se expresa en la existencia de costumbres, normas, pautas, proyectos que definen el sentido de un "nos" afirmados y diferenciador (Bello, 2001:26). De tal manera, las relaciones comunitarias de estos campesinos emergen de los sentidos y las prácticas derivadas, pero no exclusivas- de la relación familia-trabajo; en este sentido la comunidad se materializa en la figura de la red vecinal y familiar cuyos rituales y tipos de comunicación e intercambio expresan relaciones de solidaridad y de conflicto (Bello, 2001:26).

La solidaridad como parte del sistema de valores que caracterizaba el modo de vida antes del desplazamiento, es constantemente rememorado por parte de los campesinos a la vez que lo identifican como un valor en desuso después del retorno; por ejemplo para la época de la siembra una de las mujeres entrevistadas manifiesta: "había una unión entre todos porque todos cuando lograba la lluvia se sembraba una parte, después se cogía la otra, todos nos ayudábamos,... cuando alguien mataba un animal, le daba al otro, y así se compartía, si alguien no tenía un pedazo de tierra para sembrar, se le cedía (...) era una vida que aquí yo no he podido ver, aquí no!, y todavía me cuesta mucho porque allá si un pelado se me enfermaba, enseguida, fulanito sacaba y me prestaba..." (Testimonio mujer. Vereda Borracheras).

Por otro lado, la correlación familia-trabajo-comunidad forjaba el sentido de pertenencia a la vez que posibilitaba la construcción de imágenes y relatos que daban cuenta de quienes lo constituían, un verdadero escenario donde lo privado y lo colectivo se fundía. En medio de este proceso, surgían espacios colectivos y ritualizados donde todos los miembros de la comunidad estaban prestos a participar. Tal como se pudo comprobar, dichos espacios hoy no son 
más que recuerdos sobresalientes de un pasado muy reciente.

A modo de exposición, estos espacios son sintetizados en dos niveles:

El primero corresponde al ámbito festivo, encuadrado en celebraciones de días festivos o patronales, propios de la idiosincrasia y las construcciones culturales de estas comunidades. Este primer nivel puede ser resumido por la expresión campesina «los sábados de gloria hay que romper la olla»: "nosotras, las mujeres,... uno se ponía a hacer dulces, haciamos actividades en pasteles y todo eso pa' hacer uno fiestas, o pa' hacer cualquier celebración... o para celebrarles algo a los niños, porque a los niños también, uno tenía que motivarlos, si cumplían años uno le hacia este, este uno que le mataba su gallina, que le hacia su sancocho y esas cosas (...) le voy a decir que las fiestas antes de la violencia le voy a decir que duraban las fiestas hasta tres días, hacían sancocho y ponían la música, los hombre se reunían para tomar ron y esas cosas (Testimonio mujer. Vereda Borracheras). Las formas rituales contenidas en la música, la oralidad, la leyenda, la comida y la bebida atraviesan la construcción de espacios donde, la familia, la comunidad y el trabajo son asumidos desde su componente más simbólico e inmaterial.

La representación de lo campesino desde su componente ritual e inmaterial puede encontrarse, para el caso de los campesinos de VillaColombia y Borracheras en medio de la articulación de los días santos y las creencias populares alrededor del ciclo de la cosecha. El antes, el durante y el después de la cosecha podía ser "recomendado" a algún santo; tal vez el referente más rememorado por estos campesinos es la celebración del «niño bombacho» o el «niño Dios»:

"Las tradiciones se han perdido, porque aquí se celebraban los cumpleaños, los grados, matrimonios, bautismos, fiestas patronales que les hacían a algunos santos todo eso se perdió. Por ejemplo: aquí había una tradición cuando el verano amenazaba los cultivos. En el verano se hacia una celebración que le hacían al niño bombacho que llamaban, bueno eso para que hubiera lluvia. Era un santo que lo traíamos a esta comunidad y aquí se le hacia una fiesta, entonces era una tradición. Para que lloviera y se le hacia todas esas fiestas. La celebración consistía en velación, entonces la 
gente de las comunidades venían y le ponían velas y eso era, bueno, eso se hacía en toda esta región del Salado, el Carmen, Ovejas, en toda esta región hasta las montañas, todo eso se hacían las velaciones, creo [la figura del santo] estaba en el Carmen, en la iglesia del Carmen, entonces lo buscaban y lo traían y la gente le hacía ofrendas,.." (Grupo focal. Líderes campesinos Vereda VillaColombia y Borracheras, 2012)

"Niño Dios?... lo velaban por acá también...! Eso era un santico así chiquito, negrito,... tenía su nicho donde estaba metido. Usted le pedía y si le hacia lo que usted le pedía, entonces usted iba a donde la dueña para hacerle la fiesta, bien fuera de gaita, fuera de acordeón, fuera de picó; ahí le hacia su altar bien adornado, le colocaban las velas,... y quedaba el santico velándose ahí. $A$ veces la fiestas duraban, dos noches con sus días, todo dependía de la promesa, si usted la prometía tres noches de velación eso era lo que duraba "te voy a velar dos noches si me haces este milagro!" Ah... si se lo hacia usted, usted le hacia las dos noches, los dos días... lo que usted le pidiera a él... Y se invitaba a la gente, el que tenía a las hijas, él iba con sus hijas al baile, que era acordeón, banda de música, o en disco... (Grupo focal. Vereda Borracheras. 2012)"

"Era que en la promesa que tu le hacías, ... bueno si tú me vas a dar ésto, yo te voy a dar dos noches de gaita, entonces tenías que buscar gaiteros, si le prometías acordeón tenías que buscar el acordeón, si prometías banda de música, como el porro, entonces se llevaba porro. Yo a las velaciones que fui, fueron de seis días!!! En eso era que las velaciones se movían por todo el territorio... es que a veces esta noche estaba aquí, ya se terminaba, y en eso ya estaba solicitado el santico para hacerle la fiesta allá en otra casa, y así... él [el santico] duraba hasta un mes en la calle!!!" (Grupo focal. Vereda Borracheras. 2012)

"Bueno, era tanta la fe que había con ese santo... más las velaciones se hacían en lo que eran los tiempos de verano, sobre todo en los tiempos de sembrar tabaco, para que lloviera en la zona; entonces esa era la petición que se le hacía y si llovía, se le hacía la fiesta... el que tenía semilla de siembra y no había llovido, le pedían!!!... aja si llovía de inmediato le hacían la fiesta!! (Grupo focal. Líderes campesinos, vereda VillaColombia y Borracheras. 2011)" 
En la celebración del niño bombacho el trabajo (la siembra) se ritualizaba, a la vez que se estrechaban los lazos de amistad y de vecindad. Las "velaciones festivas", eran aprovechadas para visitar parientes, renovar amistades y fortalecer identidades y memorias colectivas. En las velaciones, implícitamente se celebraba la vida, el conjunto de geosímbolos y el modo de ser que le daba coherencia a una comunidad.

Ahora, el otro nivel en la construcción de los espacios comunitarios, corresponde al ámbito del trabajo en cuanto a las prácticas de ayuda mutua o de trabajo solidario. En la subregión de los Montes de María antes de la intensificación del conflicto armado (1997-2002) era común encontrar un sistema de trabajo que se basaba más en una relación de dar-recibir-retribuir que en un intercambio monetario (jornal). "Eso era un trabajo colectivo,... cada uno hacía su trabajo individual pero el trabajo era colectivo, o sea se acompañaba a trabajar a cada persona lo que iba a sembrar,... prácticamente hasta el 2000 se trabajó así, porque ya lo que rompe todo eso es el conflicto" (Entrevista, Hombre campesino, vereda Borracheras. 2012)

El "día ganado" o el "ganar días" era el nombre que recibía este sistema, el cual en términos generales se basaba en un intercambio de trabajo, donde un campesino dejaba por algún tiempo (medido en días) sus quehaceres, su rutina y sus intereses personales y familiares para cedérselo a otros -generalmente vecinos o parientes- solo a cambio del mismo tiempo de trabajo invertido (un día, dos, tres o más) el cual sería "devuelto" cuando él lo necesitará:

"Si yo iba a picar el monte, yo ponía el día, entonces yo le decía a los vecinos «tal día voy a picar», si era el lunes, entonces todos venía conmigo y todo el que iba trabajando iba a lo mismo, y después uno a devolverle el día. Cuando era el día de él entonces íbamos con él,... es que antes había unión, antes había unión... pero ya ahora no, porque todo el trabajo se hacía a través del día ganado. Por ejemplo el papá de nosotros tenía diez mozos, esos diez tipos, trabajaban al día ganado, entonces después nosotros íbamos a devolverles el día a los mozos que habían trabajado con el papá de nosotros. Les devolvíamos los días! Y así hacia todo el mundo, así se iba trabajando" (Grupo focal. Vereda Borracheras, 2012) 
Cuando era día ganado, le voy a decir, que yo una vez me puse a ganar día, ganar día,... me gané 35 días; entonces mi papá iba a picar el monte y yo también iba a picar el mío; entonces yo le di 15 mozos para que él picara su monte, entonces yo me lleve el resto pa' picar el monte mío. Vino una familia visitar ese día y le tocó de ayudar de pelar ese poco de yuca para poder atender ese poco de trabajadores!!! Entonces en un día quedó listo el monte de él y el mío. (Grupo focal. Vereda Borracheras)

En medio de estas narraciones encontramos como estos campesinos bajo formas más ritualizados e intangibles se describen como sujetos y como comunidad; la discontinuidad en los elementos, los factores, los sentidos y los contextos que enmarcan dicha descripción son el reflejo innegable de otro tipo de narración y por ende de otro tipo de sujeto y de comunidad. Se establece de esta manera una separación entre lo que se era y lo que se es, una fractura que separa la correlación construida socio-históricamente entre la familia, el trabajo y la comunidad.

\subsubsection{Prácticas de apropiación y dominio espacial.}

Ahora, las reconfiguraciones en los escenarios familiares, comunitarios y del trabajo pueden ser rastreadas a partir de las maneras y las formas en que estos campesinos dominaban y controlaban su espacio.

Para empezar recordemos que el proceso de retorno marcó una profunda escisión entre la unidad familiar y la tierra como espacio de vida. Para el caso de las familias que dividieron sus miembros entre las cabeceras municipales y las parcelas ubicadas en las veredas, se genera una desintegración no solo de los miembros (de la unidad) sino también del lugar que cumplía cada uno de ellos en la reproducción social. En tal sentido, la apropiación y el uso del espacio, es decir, los usos que las familias y sus miembros le daba a la tierra, a los ambientes construidos como la casa, el caney, el jagüey, los caminos etc., así como a los demás espacios sociales y comunitarios son reajustados en relación a los nuevos rolles y a los nuevos lugares de residencia. Por ejemplo, los hombres cabeza de hogar, son los que han asumido los deberes de la tierra, 
además de ocupar los lugares que antes eran ejercidos por la familia. En cuanto a las mujeres, éstas quedan desprovistas de su relación directa con la tierra, pues al tener que estar viviendo en las cabeceras municipales pierden su lugar dentro de las rutinas diarias de la siembra, la recolección y las demás tareas derivadas de ello; "a mi gustaba ir a sembrar, de ayudarle, yo quería estar metida como todo eso, y es que me gusta, me gusta tener mis animales, y así [en el pueblo], yo no sé estar". (Entrevista mujer. Carmen de Bolívar. 2012)

De igual manera, los hijos menores acompañando a su madres han tenido que asumir la vida en las cabeceras municipales, apropiando las dinámicas y las nuevas espacialidades que les ofrece los municipios. Solo en determinados momentos y por cortos periodos de estadía, las madres junto a sus hijos van a acompañar a los hombres en las veredas, mientras que los hijos mayores, ya independizados pueden optar -dependiendo del contexto laboral- por ayudar en las temporadas de siembra/recolección o por trabajar de manera informal, ya sea jornaleando o de mototaxista en los municipios cercanos. Así para la mayor parte de estas familias la apropiación y uso del espacio anterior al desplazamiento es reajustado hasta el punto de alejarse completamente o parcialmente de la tierra y las relaciones derivadas de ella.

En cuanto a las familias que aún se mantienen unidas en las veredas ${ }^{69}$ la reconfiguración de sus prácticas de apropiación y uso del espacio se deben más a la imposibilidad de accionar sobre su espacio más próximo «el territorio» que al distanciamiento de sus miembros por residir por fuera de sus parcelas y veredas. Esta imposibilidad es dada por varias razones, la primera está referida a la relación poblamiento-uso de la tierra, la segunda está determinada por el tipo de relación con la tierra y la tercera es una consecuencia del reordenamiento del territorio por parte de actores económicos.

Apropósito es importante mencionar que durante los 8 años de retorno (20042012), las familias que regresaron se han visto en una situación muy difícil en cuanto al acceso y al trabajo en la tierra. Antes del desplazamiento, los

\footnotetext{
${ }^{69}$ Hay que señalar que no todas las familias que retornaron optaron por fragmentar su núcleo familiar, gran parte de ellas, especialmente las localizadas en la vereda de VillaColombia se han mantenido en sus parcelas.
} 
campesinos distribuían de forma equilibrada el espacio de vivienda y el espacio de cultivo de tal manera que lo uno no limitara a lo otro, después del 2004 y gracias a la compra masiva de tierras y a la consecuente concentración de tierras por parte de actores económicos privados, los miembros de las familias que antes salían a buscar sus propias parcelas (hijos mayores con sus propios núcleos familiares), han tenido que quedarse en las fincas de sus padres, provocando lo que los mismos campesinos denominan como "sobrecupo":

"hay parcelas de campesinos que están en sobrecupo, tienen hasta cinco familias trabajando en una parcela" (Grupo focal. Líderes campesinos Vereda VillaColombia y Borracheras).

Esta situación ha generado que el espacio destinado para el cultivo se reduzca cada día más, obligando a que los campesinos busquen otras tierras para poder cultivar. Por ejemplo, en una familia retornada de la vereda de Borracheras, observamos como en la parcela -prácticamente- no había espacio para cultivar, por lo cual tuvieron que alquilar una porción de tierra para poder trabajar.

El problema de alquilar o arrendar, radica en tener suficiente dinero para ello. En un contexto caracterizado por unos bajos ingresos y después de perderlo todo después de tres o cuatro años de desplazamiento, la posibilidad de alquilar tierra no es una opción factible para muchos campesinos. Ahora, en el caso de poder reunir el dinero necesario, no solo para arrendar sino para todo lo relacionado con la siembra y el mantenimiento del cultivo hasta la recolección final, los campesinos cuentan con otra dificultad, en las veredas e inclusive en las veredas cercanas, no se cuenta con espacio para poder sembrar, pues muchos de los antiguos paisajes campesinos (Mançano, 2008) han sido copados por las reforestadoras y sus cultivos de teca. De ahí, que los campesinos tengan que caminar alrededor de dos o tres horas para poder encontrar tierra disponible para poder trabajar en ella.

Esta problemática es doblemente agobiante para aquellos campesinos que no tenían una relación formal y estable con la tierra, que no eran adjudicatarios en el momento anterior al desplazamiento. La condición de arrendatarios o de tenedores de 10 familias de la vereda de Borracheras ocasionó que después de tres años de retorno (2004-2007) tuvieran que salir de nuevo de sus parcelas, 
esta vez desplazadas por un terrateniente local.

"hasta el 2000 que nuevamente la violencia los desplazan de este predio y bueno retornan en el 2004 en el retorno de las comunidades de Borracheras, entonces retornan nuevamente, a la finca ésta, y bueno comienzan sus labores nuevamente en la finca y se ubican cada uno en su sector donde estaban sus viviendas, que tuvieron nuevamente que construirlas por el abandono en el que estaban por causa del desplazamiento, llegan a mejorar un poco sus viviendas, pero en el 2007 nuevamente son desplazadas por el propietario de la finca" (Entrevista. Líder campesino vereda Borracheras.2012)

Hoy en día estas familias se encuentran en su mayoría en el casco urbano del Municipio del Carmen de Bolívar, tratando de sobrevivir lejos de su tierra y de su comunidad. Algunos de estos campesinos que aún se resisten en abandonar su condición rural buscan incansablemente a través de los nuevos procesos comunitarios y organizativos volver a la tierra; muchos de ellos aún mantienen la esperanza de volver a sus prácticas y espacios construidos: "si algún día el gobierno decidiera llevar a cabo una verdadera reparación y dar tierras a nosotros, nuestro deseo es que nos reubiquen en esta finca porque, porque ésto es una tierra que nosotros la conocemos y sabemos los pedazos donde se puede sembrar y todo lo demás y las familias que estábamos aquí todavía tenemos contacto,... nos conocemos y creo que sería muy bueno y sería muy viable que nuevamente retornáramos a esta finca” (Entrevista. Líder campesino vereda Borracheras.2012)

Ahora, tanto para las familias que aún se mantienen en su totalidad en las veredas como para aquellas que se encuentran repartidas entre la vereda y el casco urbano, encontramos que la reconfiguración de sus prácticas también ha sido determinada por un factor que va más allá del marco relacional dado por el escenario familiar y comunitario. Como hemos anotado, la relación con la tierra y el acceso a ella son elementos determinantes para la realización y el desenvolvimiento del modo de vida campesino. En este sentido, el no poder mantener una relación directa sobre la tierra y disponer de ella según sus criterios, ha ocasionado un profundo reajuste a las prácticas y a los modos en que los campesinos usaban y apropiaban el espacio. Esto nos lleva a sostener 
que el análisis de las prácticas de apropiación y uso del espacio no se pueden dar sin considerar también las maneras en que se domina y controla un determinado espacio. El territorio en este sentido, no solo se construye en medio de las relaciones que los hombres crean y recrean en función de la apropiación y el uso sino que también es determinado a través del modo en que se mantiene esa apropiación y se garantiza el sostenimiento de esos usos, de ahí que al reconfigurar dicho dominio se esté reconfigurando a la vez los modos de apropiación y uso que determinaban la relación hombre-medio-hombre.

Para el caso de los campesinos retornados, la reconfiguración en las prácticas de dominio y control espacial, pueden establecerse a través de dos momentos interrelacionados pero a la vez divididos por la escala y los actores que los originan. El primer momento lo encontramos en los intersticios derivados del encuentro entre la violencia y las memorias territoriales, mientras que el segundo es originado por la reorganización del sistema de producción en la subregión.

La relación del primero con respecto al dominio y el control espacial, está determinado por los efectos o si se quiere, por las marcas territoriales que dejó la violencia en la memoria de los campesinos. El miedo y el terror de años anteriores se han mantenido en la memoria de los pobladores rurales, modificando las maneras en que ellos actúan y apropian el espacio. Por ejemplo, después del retorno del 2004 ellos mismo han construido un «manejo preventivo del espacio y del tiempo», es decir, han limitado su movimiento espacial y temporal a ciertos lugares contemplados como seguros, así han creado estrategias para anticipar ${ }^{70}$ los posibles efectos de una nueva intensificación de la violencia : “(...) eso sí, estábamos pendientes de que tú ya no vas a estar a las seis de la tarde buscando el agua en el pozo, de que tú no vas a estar metido en el monte a las seis de la tarde, ... a las cinco de la tarde ya todos estábamos en la casa, nadie se asomaba por fuera de la casa. (Entrevista. Mujer vereda Borracheras. 2011). La anticipación para nuestro caso, tiene que ser abordada

\footnotetext{
${ }^{70}$ Al respecto, Velazco afirma que "Un aspecto del sentido de la anticipación (...) tiene que ver con la lectura que hace del efecto pasado respecto del objetivo que se quiere anticipar y que le hacen prever un porvenir inscrito en el presente y que excluye toda deliberación explícita" (Velazco, 1998:12)
} 
en relación al miedo y a la incertidumbre, y cómo a partir de éstos los campesinos construyen estrategias para salvaguardarse en el territorio, "el esposo mío dejó de ir a buscar madera por otra parte, a cortar palos por otra parte, ya no..., él me decía, no!, yo por allá no me meto, entonces, ya pa' ir al pozo a buscar el agua él se iba más temprano pues aunque quedara ahí mismito el no salía entrada la tarde" (Entrevista. Mujer vereda Borracheras. 2011) generalmente este manejo preventivo está asociado -tal como lo demuestran los testimonios recolectados- a una especie de autocensura espacio-temporal, no se circula por ciertos espacios en ciertos horarios. De esta manera al limitarse el movimiento por el espacio, se reduce el dominio que el sujeto pueda ejercer frente a su espacio, el "veto espacio-temporal" que han implementado los campesinos como medida de seguridad y autoprotección no solo reajusta su capacidad de apropiación en cuanto a las prácticas espaciales sino que limita a la vez, su propia articulación comunitaria, pues esta prevención se constituye en una causa más de la no reactivación de los espacios socialmente construidos. Las celebraciones en este sentido han sido afectadas, las tradicionales velaciones al niño bombacho hoy no son posibles, pues entre otras, las familias no se atreven a salir de noche, es más, pareciera que existieran fronteras imaginarias que separan las veredas y que los campesinos no se arriesgan a atravesar.

La otra escala en la reconfiguración de las prácticas de dominio, está relacionada con la entrada de los actores económicos en la subregión a partir del 2002.

Recordemos que aprovechando el abandono forzado de tierras, algunos empresarios del interior del país, así como "inversionistas extranjeros" -muchos de ellos relacionados con el paramilitarismo- compraron de forma fraudulenta $y / 0$ a muy bajos precios las tierras que los campesinos habían tenido que dejar a causa de la violencia y el terror. Esta compra masiva significó un reajuste en las dinámicas de acumulación de capital en la subregión, la cual se concentró después del 2002 en la inversión pública a cultivos específicos a través del desarrollo tecnológico, la financiación, la infraestructura, los incentivos a la inversión privada, el impulso a las cadenas productivas, y la cobertura de riesgos y estímulos a proyectos de exportación. Como resultado se insertó en la 
subregión una producción agroindustrial, asociada principalmente a las cadenas productivas de los biocombustibles (palma aceitera y yuca amarga) y a partir del año 2007, a proyectos agroforestales (cultivos de Teca) vinculados al mercado de emisiones de carbono ${ }^{71}$.

Estas nuevas actividades económicas junto con las tradicionales haciendas o fincas ganaderas, más las políticas agrarias y de desarrollo territorial impulsados por los gobiernos de turno, han generado una fuerte reconfiguración en los vínculos socioterritoriales, afectando las prácticas de dominio y control que manejaban los campesinos frente a sus territorios, es decir, han modificado los usos y vocaciones del suelo, tal como venía siendo trabajado por los campesinos.

Cuadro 2.Caracterización de los Paisajes Campesinos y del Agronegócio

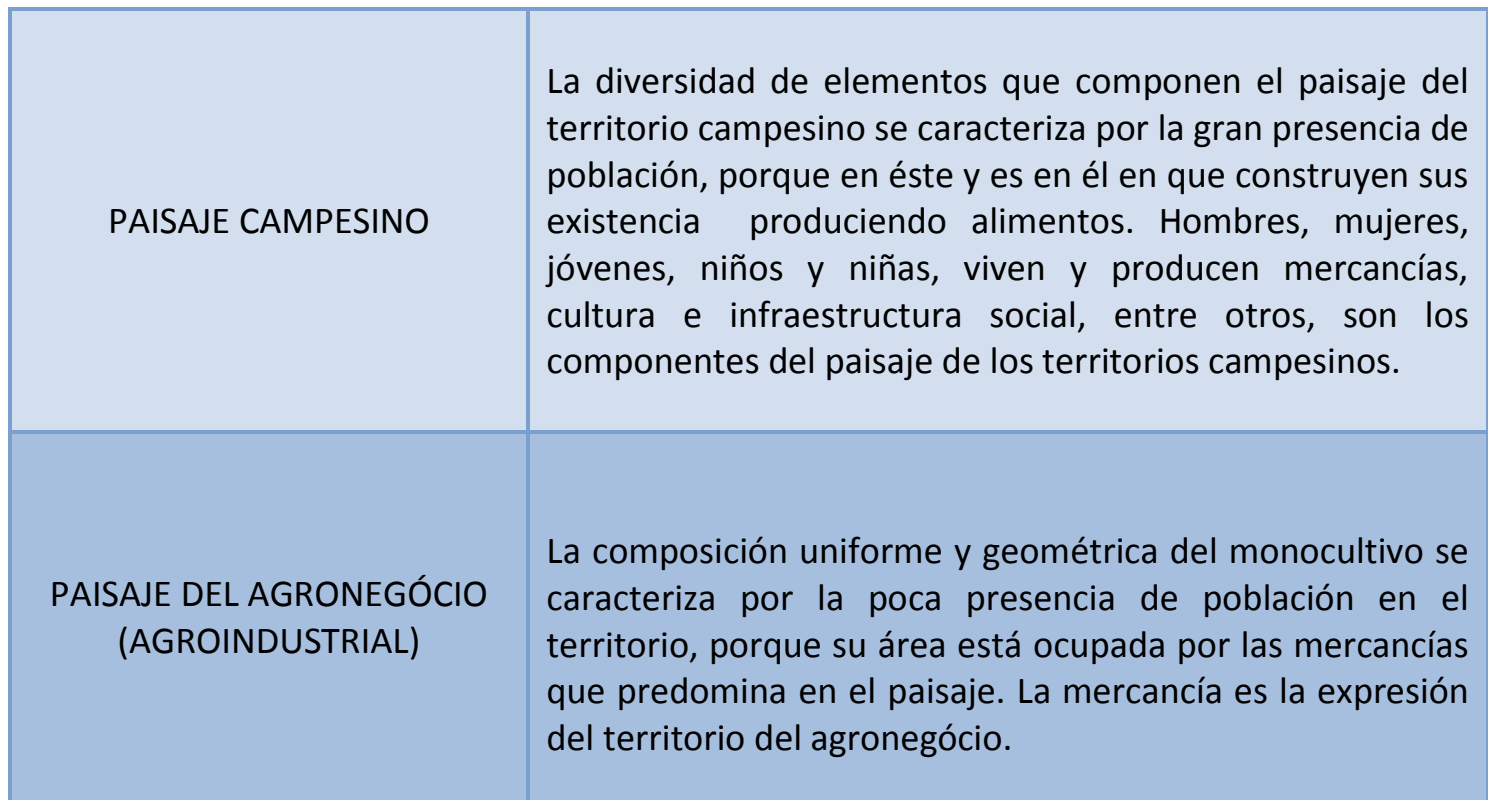

Fuente. Elaboración propia con base en Mançano 2010.

La principal reconfiguración está relacionada con la transformación en el paisaje

\footnotetext{
71 “Durante los dos gobiernos de Uribe (2002-2010) se impulsó el mercado de carbono en Colombia, creando un marco legislativo y promocionando, entre las empresas minero-energéticas, el gran potencial que podía tener Colombia en este mercado. La Ley 788 del 27 de diciembre de 2002 ofrecía incentivos tributarios en proyectos de reducción de emisiones de carbono a través de sus artículos 18 y 95, ampliando las oportunidades de mercado para las empresas de reforestación y las hidroeléctricas" (Tenthoff.2011)
} 
campesino (cuadro 2) y en la perdida de la autonomía frente a los productos cultivados. Cuando nos referimos a las transformaciones en el paisaje campesino, no nos estamos refiriendo simplemente a la disposición y/o al ordenamiento de ciertos objetos-formas del espacio. Como afirmábamos en el segundo capítulo, lo que nos interesa es observar cómo dichos paisajes se constituyen una parte fundamental del proceso de configuración de sentido que diferentes actores le otorgan al espacio. No son los objetos-formas en sí, lo que nos interesa, son los sentidos y la carga geo-simbólica que los constituyen como base de prácticas concretas.

De esta manera, la entrada de nuevas dinámicas productivas no solo alteró el territorio en cuanto a la homogenización del paisaje (grandes extensiones de monocultivos de teca o palma) sino que en medio de dicho proceso, eliminó la parcela campesina, fraccionando a las comunidades y limitando el uso de la tierra a mera mercancía, lo que en si mismo representó un desajuste en su modo de ser y en las prácticas que sostenían ese modo de ser (el estar).

Entre las comunidades que retornaron en el 2004, la que más han vivido la limitación de su territorio por causa de la reconfiguración espacial de la empresa privada, son las pertenecientes a la vereda de Borracheras.

Mapa 7. Organización espacial Vereda Borracheras. 1997-2000 (antes del desplazamiento)
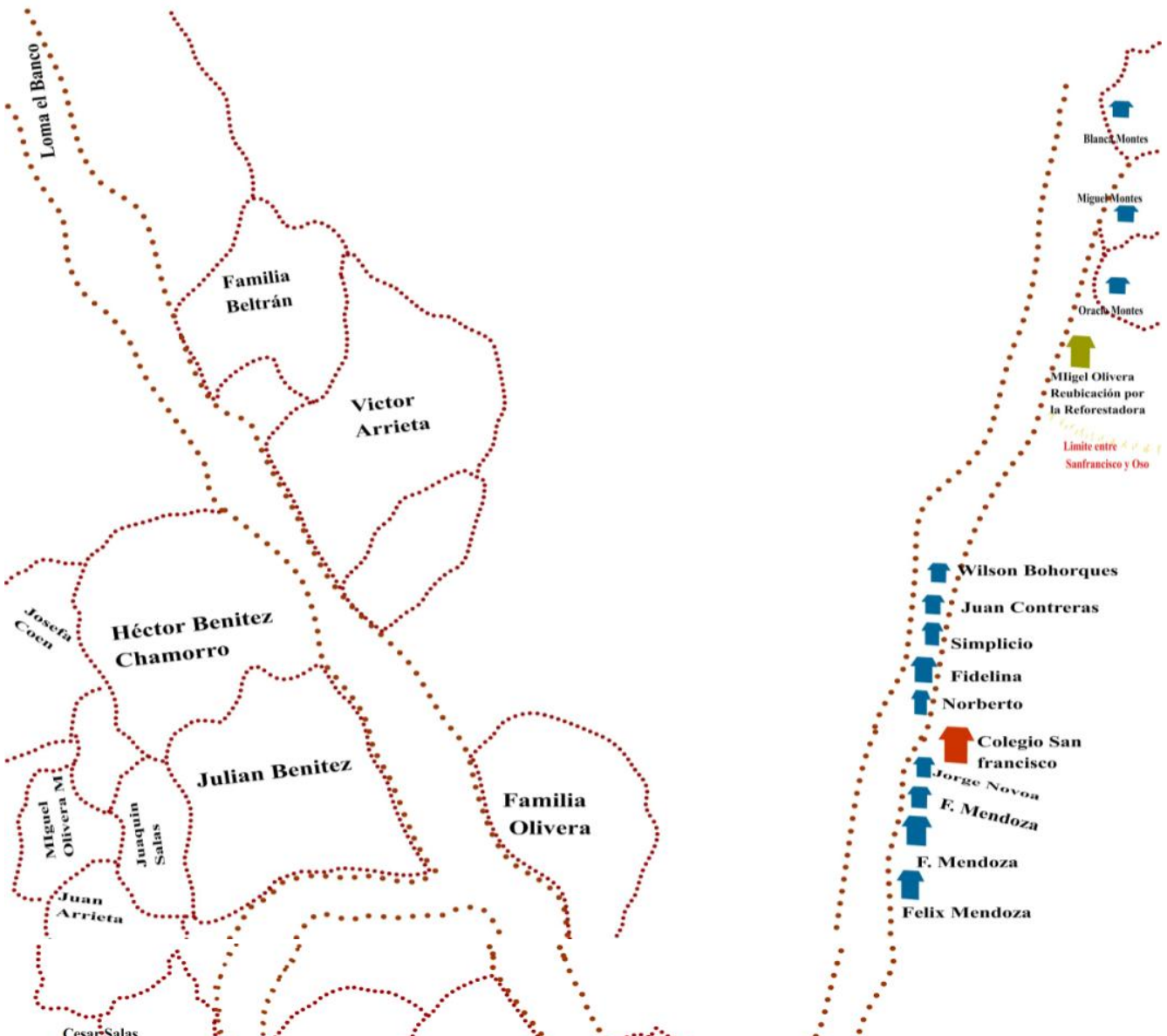
Fuente. Elaboración propia con base en los talleres de cartografía social.

En el territorio de Borracheras es evidente la transformación en la reorganización espacial, el mapa 7 describe la ubicación de las familias campesinas para el año 2000 (antes del desplazamiento), la cual estaba constituida por cerca de 25 familias, en todas las parcelas se cultivaban los productos tradicionales de la región: yuca, ñame, y principalmente tabaco: "en la parte que tu alcanzas a ver hay un camino, ese camino lo usábamos nosotros para llegar a lo que son las viviendas que teníamos nosotros que era la familia Marques, ahí donde hace la planada y todo eso, ahí era la vivienda de nosotros, y por acá en el medio donde está la torre es donde Ubualdo tenía la vivienda, y en ese lado, de la parte de arriba, era donde estaban las familias Vásquez, la familia Conder, la familia García,... todas esas tierras son tierras mecanizadas, que nosotros mecanizamos para cultivar las tierras, lo que era el tabaco, la yuca, ñame, maíz que cultivábamos, y bueno, eran, son unas tierras muy fértiles, y bueno hoy en 
vista del desplazamiento están convertidas todas en ganadería o teca. (Entrevista. Líder campesino. Vereda Borracheras)

Después del desplazamiento muchos campesinos no decidieron volver, y algunos de los que regresaron, al contemplar sus condiciones económicas -y al desconocer los derechos adquiridos como población desplazada- se ven obligados a vender o permutar sus tierras.

Estas tierras, que en un primer momento fueron negociadas entre los campesinos y una persona natural, finalmente y por medio de una serie de ventas y compras intervenidas por testaferros privados, terminaron por pertenecer a una sola empresa. De este modo la cementera Argos S.A. por medio de su filial la Reforestadora del Caribe, englobo las tierras que originalmente eran de campesinos, concentrando una muy importante cantidad de tierra entre los límites del departamento de Sucre y Bolívar. 
Mapa 8. Organización espacial Vereda Borracheras. 2006-2013

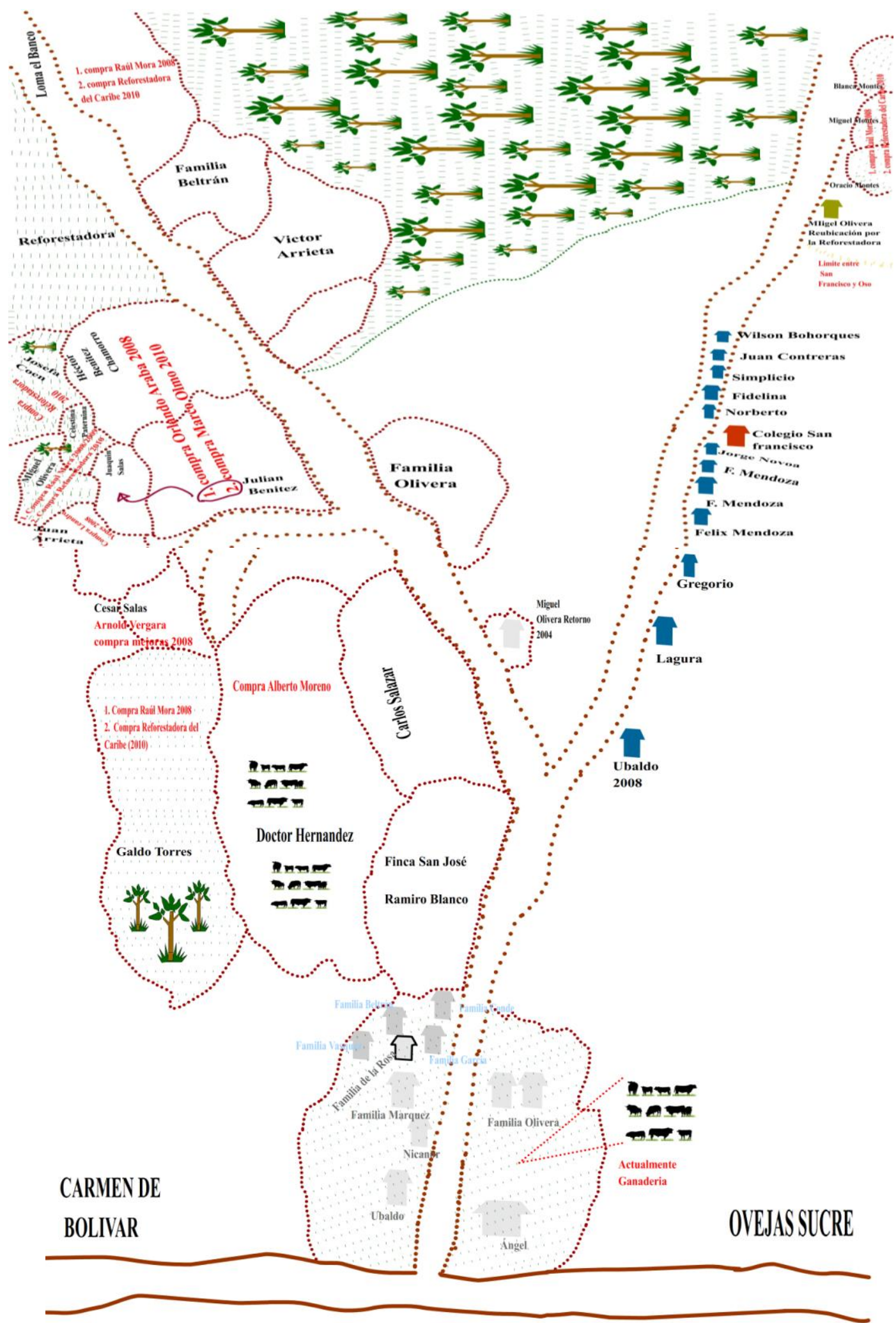

Fuente. Elaboración propia con base en talleres de cartografía social. 
Las reorganización del espacio, en relación a la compra de tierras y a la puesta en marcha de un gran proyecto de cultivo de teca, ha modificado el escenario campesino, de ahí que las relacione sociales que sostenían sus prácticas tanto en el escenario familiar como comunitario también se hayan reorganizado, el tener como vecino a una plantación de teca no es lo mismo que el tener al hombre o a la mujer que comparten tu modo de vida. "Estas fincas que eran de campesinos y que las trabajaban los campesinos, las que no están en teca están en ganadería, entonces vemos que a nosotros nos ha perjudicado todo esto porque, nos ha afectado la seguridad alimentaria para nosotros como campesinos y bueno también la vocación campesina que teníamos ya se ha ido perdiendo con todo ésto, con todos estos proyectos que han llegado a nuestras comunidades y el trabajo colectivo y la integración que se hacía entre las comunidades, ... entonces se ha ido perdiendo todo ese tejido social que tenían las comunidades, por medio de todo ésto, se ha ido perdiendo toda esa cultura esa costumbre que teníamos como campesinos, porque la ciudad nos ha transformado en otros, a nuestros hijos, a nuestras familias, a nuestros nietos,... se va perdiendo toda esa conexión con la tierra, con el campo y con las comunidades y todo eso ha sido en vista de las compras de tierras que se han dado en nuestro territorio" (Entrevista. Líder campesino. Vereda Borracheras. 2012)

Así, la entrada de un actor económico al territorio como la Reforestadora, no solo ha generado un fuerte impacto en la organización de los elementos naturales, sino que poco a poco ha ido controlando los espacios socialmente construidos, el dominio de los campesinos frente a su propio territorio se ha reducido. Los caminos y las fuentes de agua, antes de uso comunitario y reglados por valores fundamentados en la reciprocidad y la horizontalidad, hoy se encuentran bajo el control de la empresa; los espacios organizativos dirigidos y sostenidos por las relaciones de vecindad, ahora se hallan cooptados bajo la supuesta "responsabilidad social" de la empresa privada; los montes donde se iba a buscar los palos y las hojas de palma necesarios para la construcción de los tradicionales caney's hoy se encuentran cercados y vigilados. La imposición de un nuevo paisaje, significo para la vereda de Borracheras, la modificación de su estar en el territorio. 
De igual manera, la llegada de otros grandes proyectos productivos a la subregión ha limitado el dominio que tenían los campesinos sobre lo que producían. Tanto los campesinos de VillaColombia como de Borracheras han tenido que ajustarse a los nuevas dinámicas del mercado agrícola, el cual ha generalizado una desvaloralizado de los cultivos tradicionales en relación a los cultivos y productos que requiere la agroindustria. Por ejemplo, la Philip Morris introdujo desde mediados del 2000 la siembra del tabaco rubio, generando una baja en los precios del tradicional tabaco negro, y obligando a los campesinos a sembrar del nuevo tabaco (más rentable para la tabacalera). Así mismo ha ocurrido con la siembra de yuca. Hoy la gran mayoría de la producción de yuca de la subregión se va hacia las plantas procesadoras de biocarburantes, produciendo una carestía en uno de los alimentos base de la dieta de las comunidades del Caribe y sostén de la identidad cultural Montemariana.

Así mismo, desde mediados del 2005, cada vez es más común que los campesinos por falta de semilla tradicional -cuyo ciclo de almacenamiento se rompió con el desplazamiento- utilicen semillas "mejoradas" que traen las empresas con el fin de maximizar sus beneficios. Para los campesinos que han retornado, el cambio de semilla y de cultivos es asumido como un cambio de su propia identificación cultural "porque a mí no es aceptable que también a nosotros nos cambien, porque eso sí, no me ha gustado a mí, de que a nosotros nos cambien el cultivo que nosotros cultivábamos antes, ósea antes era el ñame espino, espino, por uno que trajeron ahora que es mejorado, que ese ñame espino no tiene sabor, uno hace un mote con queso que uno hacia con aquel propio, salía espeso y sabroso!!, y éste no tiene sabor. Uno hace un mote de este mejorado y cuando uno lo va hacer se pone el agua claritica arriba y se sienta abajo lo otro y en cambio con el ñame criollo con el espino criollo usted se hace un mote espeso!!!! En estos términos, la identificación cultural y la carga histórica de estos campesinos representada en el modo en que utilizaban, distribuían y disponían de ciertos lugares, objetos y formas del paisaje, así como sus formas inmateriales de construir su territorio y su territorialidad (comidas, música, leyendas, festividades) también han sido reajustadas en el instante mismo en que su dominio espacial ha sido cooptado por terceros. Las empresas reforestadoras y los grandes proyectos agroindustriales que llegaron a la 
subregión poco a poco han ido imponiendo una racionalidad espacial, una representación del espacio ajena a los espacios de representación que habían construidos estas comunidades. El actual ordenamiento del territorio en marcado en unas políticas públicas de desarrollo rural que buscan "transformar a los campesinos desplazados en empresarios" es reflejo de ello.

En síntesis, las prácticas de dominio espacial están constituidas por diferentes planos de la realidad social, pasan por las construcciones más intimas de control espacial, donde la familia y el trabajo son el punto de partida, de igual manera están conformadas por aquellas relaciones que superan a los sujetos, de ahí que la impronta de la guerra y las actuales dinámicas económicas en la región también sean determinantes de las maneras en que los campesinos de VillaColombia y Borracheras han apropiado y dominado su espacio desde que retornaron. De este modo, las prácticas que sostienen las maneras de reproducir el espacio no solo se refieran a las manifestaciones más materiales de esa producción, sino que necesariamente son resultado también de configuraciones del orden de los simbólico, que junto a las prácticas materiales pueden dar cuenta de las múltiples reconfiguraciones ${ }^{72}$ que los campesinos de VillaColombia y Borracheras han reajustado desde que un 5 de marzo del año 2004 decidieron retornas a sus tierras.

\footnotetext{
72 La comida y lo que ello implica en el propio proceso de autoreconocimiento de la identificación de lo campesino; lo que se cultiva, como se cultiva y las relaciones sociales y rituales que coexisten en medio de este proceso; así como la apropiación y el uso familiar y comunitario del espacio, son algunas de las manifestaciones de las prácticas que le dan sentido a la reproducción espacial de estos campesinos. Así las prácticas de apropiación, uso, dominio y control del espacio han sido el resultado de un devenir histórico donde los campesinos de Los Montes de María han construido unas relaciones sociales y una idiosincrasia particular; justamente el desplazamiento rompe con dicha construcción generando en muy corto tiempo una alteración, un cambio, un reajuste, de ahí que hablemos de reconfiguraciones, pues lo que se genera es una intensificación violenta del modo de ser, del conjunto de símbolos e imaginarios y de los sentidos que los sustentan.
} 


\section{CAPITULO VI CONSIDERACIONES FINALES}

\subsection{Retornos, prácticas espaciales y campesinos en Los Montes de María}

El retorno, por mucho que los campesinos desearon no los devolvió a un estado ideal de vida. El "volver" no significó retomar una historia -abandonada forzadamente- en algún momento del pasado, por el contrario, el retorno puso de manifiesto un cambio arbitrario de su modo de relacionamiento, en los espacios más importantes de su reproducción social: la familia, el trabajo y la comunidad. Más aún, el retorno marco un punto de inflexión en el reconocimiento de las prácticas y las representaciones socioespaciales, pues fue a partir del "regreso" que se exteriorizó ${ }^{73}$ de manera consciente la discontinuidad de los espacios socialmente construidos, del sistema de valores y el complejo geo-simbólico que los identificaban.

La discontinuidad y la reconfiguración de estos espacios, generó un desajuste en las representaciones sociales -individuales o colectivas- de los campesinos de VillaColombia y Borracheras, pues la irrupción de su modo de vida por casusa de la violencia obligó -de manera repentina- a la recreación de todo aquello que se constituía en soporte de la propia subjetividad y de las maneras en que éstos interactuaban entre sí y con el medio (el estar del ser).

La identificación de la acción, más fácilmente asida a través de las prácticas concretas, fue una de las maneras en las que los campesinos pudieron dar cuenta de dicha reconfiguración. Para los campesinos retornados, el no continuar con un hacer específico (el cultivo, la fiesta, el encuentro,...), es reflejo de la alteración de lo que eran como individuos, familia y comunidad; de ahí, que el "dejar" en el pasado prácticas como el "día ganado" o las celebraciones

\footnotetext{
${ }^{73}$ No estamos afirmando que antes del retorno estas comunidades no experimentaran sentimientos frente a los espacios y las prácticas familiares y comunitarias perdidas. Lo que acá pretendemos establecer es que es a partir del retorno que las familias y en general las comunidades, bajo la intensión de evaluar el impacto del desplazamiento, en relación a establecer los daños frente a lo que eran, a lo que hacían y a lo que tenían, generan las condiciones para exteriorizar un sentimiento abstraído durante el desarraigo.
} 
festivas, o los mismos espacios familiares fueron muestras inequívocas de un cambio, que entendido como negativo, reprodujo una añoranza frente a lo que eran en el pasado.

Frente a esta evocación del pasado, el retorno concentró las expectativas por recuperar lo que se era en cuanto a su modo de ser y estar. No obstante tras 8 años de retorno (2004-2012), estas familias han comprendido que la realidad de ser retornado es una condición que pareciera no tener un fin claro, por lo menos en cuanto a la "recuperación" de su complejo simbólico y material basado en la correlación del espacio del trabajo, la familia y al comunidad. Lo vivido durante el desplazamiento marcó una ruptura con sus relaciones familiares, en su mundo inmaterial, en las condiciones materiales de existencia y en la proyección generacional de sus comunidades.

Ahora, estas profundas reconfiguraciones no pueden explicarse por fuera del marco contextual en el cual se desarrolló tanto el desplazamiento como el retorno de los campesinos. Insistimos que es importante considerar también, las propias dinámicas geohistóricas de la subregión, en tanto factores externos que determinaron y siguen determinando las condiciones, la estabilidad y la permanecía de los campesinos retornados en la subregión.

Si consideramos los diferentes espacios y proyectos de territorialidad que se han impuesto, se han resistido o han desaparecido de manera violenta a lo largo de la historia de Los Montes de María, es innegable que siempre ha existido una abierta disputa en la organización y la configuración espacial en la subregión. El desplazamiento forzado de finales de los años 90's y primeros años del 2000, tiene que ser estudiado en el marco de dicha disputa, pues lo que se logró imponer por aquellos años fue una revancha terrateniente (Gilhodes, 1974), una reapropiación de las tierras que había ganado el campesinado organizado del siglo pasado; la explicación del porqué de la violencia paramilitar frente a ciertos municipios y ciertos campesinos se debe a su participación en aquel momento histórico del campesinado colombiano. Así el desarraigo de aquellos años, estuvo enmarcado por una estrategia de guerra que buscó a través del terror desterritorializar a los campesinos para reterritorializar a los terratenientes. 
Las dinámicas que tomó el conflicto armado a partir de mediados del 2000, terminó de consolidar ese proceso de desterritorialización iniciado años atrás. A propósito recordemos que durante los años 2002 a 2008 las Fuerzas Armadas en cabeza de la Infantería de Marina, ejercieron una presión manifiesta en todos los territorios montemarianos. Este control militar y territorial por parte del Estado se incrementó a partir de la creación en el 2004 de los Centros de Coordinación de Acción Integral "CCAl» un plan de guerra basada en acciones cívicomilitares, donde se busca la "recuperación social y militar del territorio", dichos Centros de Coordinación responden a la política denominada "Plan Nacional de Consolidación" desarrollada durante los 8 años de gobierno de Uribe (20022006, 2006-2010) a partir del cual se implementó un estado de seguridad a la vez que se militarizaba el conflicto social a través de la llamada "política de seguridad democrática". En Los Montes de María el CCAl tomó la forma de Centro de Coordinación Regional CCR, el cual funcionó bajo una coordinación civil, una coordinación militar, una coordinación policial y un equipo civil de apoyo.

Dicho CCR además de militarizar la subregión y de ejercer medidas arbitrarias en contra de la población civil ${ }^{74}$, garantizó la entrada de las empresas y de la "inversión extranjera". Recordemos que uno de los objetivos del Plan de consolidación era mantener la "confianza inversionista", con lo que se implementó una política de desarrollo regional que intervino en todos los sectores productivos, en especial el agrícola. De este modo es a partir del 2007 que los grandes proyectos agroindustriales articulados a las cadenas comerciales de los biocombustibles y los biocarburantes se asentaron en la subregión, principalmente a través de los monocultivos de Palma y la inserción de la yuca amarga para la fabricación del bioetanol. De igual manera, para estos mismos años la empresa cementera ARGOS S.A. a través de su filial Reforestadora del Caribe se hizo de una considerable extensión de tierras en los

\footnotetext{
${ }^{74}$ En las 14 zonas que integran el Plan Nacional de Consolidación se presentaron numerosas violaciones de los derechos humanos de las poblaciones campesinas. En los Montes de María a demás los constantes desplazamientos forzados, se generalizó la violación del derecho a la libre locomoción, las detenciones arbitrarias, la retención de alimentos, entre otras violaciones al Derecho Internacional Humanitario.
} 
departamentos de Córdoba, Sucre y Bolívar, aproximadamente unas 14.225 (Tenthof, 2011) hectáreas para el cultivo de Teca, hay que advertir que muchas de estas tierras pertenecientes originalmente a pequeños campesinos adjudicatarios de la exigua reforma agraria de los años 70's y 80 's.

ARGOS destaca que a través de su programa de reforestación; se busca la explotación de la vocación forestal de los suelos (...) Contratación de mano de obra de la región y aprovechamiento de condiciones de retorno. La empresa argumenta que con su actividad forestal está generando empleo, ya que por cada 1.000 hectáreas sembradas se generan 74 empleos, es decir que 13.5 hectáreas de teca generan un empleo. En comparación, los cultivos de pancoger generan dos empleos por cada hectárea, 27 veces más empleo que los cultivos de Teca. El control territorial que generan estas plantaciones a largo plazo, entre otros por el hecho de dejar improductiva las tierras y porque los proyectos son de mínimo 25 años, permiten a la vez consolidar y legalizar la concentración de tierras que se ha establecido a través de la violencia durante los últimos 20 años. (Tenthof, 2011:5)

Considerando estos factores más objetivos, sería errado reducir la explicación de las reconfiguraciones de las prácticas espaciales y en general del modo de vida de los campesinos de VillaColombia y Borracheras a un simple efecto del desarraigo sin considerar antes las interrelaciones que puede haber entre el contexto más inmediato y el contexto geohistórico en el cual tomó forma dicho proceso de reconfiguración, es decir, las condiciones subjetivas y objetivas que atravesaron el ser y el estar de los campesinos. Bajo esta premisa cobra importancia el análisis del mundo vida de estos campesinos y como los sentidos ritualizados y subjetivizados producidos y reproducidos a través de las experiencias y las memorias fueron transformados, reajustados o simplemente eliminados; de igual manera no es posible aprehender dichas reconfiguraciones si no estudiamos el marco más material en relación a las condiciones socioeconómicas derivadas de las dinámicas y las disputas socioterritoriales que han moldeado las relaciones sociales de la subregión desde hace décadas.

Tal vez es por todo lo anterior, que las reconfiguraciones de las prácticas espaciales y en última del modo de ser campesino no obedezca a una sola causa, más bien lo que se percibe es que el motivo es múltiple y complejo, pues 
tiene que ver en un primer momento con la acción del desplazamiento, y los efectos inmediatos del vivir en desarraigo; también por los cambios en los sentidos que orientaban la organización familiar y del trabajo; es consecuencia de la pérdida de confianza, "lo que se perdió más que todo fue el tejido social, que ya uno regresa,... ve las misma personas pero ya no con la misma confianza, porque dice un dicho muy popular vemos caras, corazones no, entonces en eso se manejaba mucho los rumores, que mire que hay esto por aquí, que hay esto por allá, que un grupo de gente aquí, que todo esto por aquí, entonces ya uno, ya uno no como que,... perdió la confianza entre uno mismo, ósea que lo que se perdió más que todo fue el tejido social"; de allí que la base del relacionamiento comunitario se debilitara, pues la red vecinal no se ha podido recuperar no solo porque no todas las familias que se desplazaron decidieron retornar sino porque el miedo, la desconfianza y la zozobra han fraccionado a las comunidades; sin la estructura comunitaria, sin el escenario familiar y sin las prácticas colectivas alrededor del trabajo se descontinuaron los sentidos rituales y el complejo simbólico que los identificaba; también es consecuencia del orden público y de las dinámicas que esta adquirió durante los años 2004-2008 donde en medio del conflicto armado los campesinos retornados siguen siendo las principales víctimas; así mismo tiene que ver con el reordenamiento territorial dado después del 2007 a raíz de la entrada de importantes actores económicos que se hicieron de las tierras abandonadas forzosamente e impusieron nuevos modos de producción en la subregión.

Entendido así, el contexto socioterritorial, de orden público, político y social en Los Montes de María durante los años 2004-2012 más las implicaciones subjetivas e intersubjetivas provocadas por el desplazamiento han incidido en las maneras en las que los campesinos de VillaColombia y Borracheras han recorrido el arduo camino del retorno. 


\subsubsection{Apropósito de las prácticas espaciales}

Al respecto los retornos de campesinos tienen que ser leídos desde su condición de generadores de cambios, es decir como fuerza que acelera y (re) configura tanto las relaciones sociales como los modos de producción espacial de estas comunidades. Recordemos en este punto que nuestro horizonte teórico nos llevó reconocer que la producción espacial, que la espacialidad, es socialmente producida (Lefebvre, 1978), de allí que el proceso espacial pueda ser resumido como una correlación dinámica y conflictiva entre «hombre-medio-hombre», donde el resultado y la fuerza que produce se mixturan en un escenario donde lo segundo puede ser lo primero y viceversa (producir y ser resultado a la vez), ahora, descubrir y aprehender está dinámica no fue tarea sencilla pues a lo largo del trabajo se corría el riesgo de caer en lo que nosotros mismos criticamos: la metaforización del espacio en cuanto a su relacionalidad con el mundo de lo social. De tal manera el proceso de retorno de los campesinos de VillaColombia y Borracheras, nos obligó, en términos metodológicos, a leer sus prácticas espaciales no como hechos en sí, o como hechos acabados que pueden ser delimitados fácilmente por el investigador. La ruta emprendida fue justamente la contraria, lo que se intentó desde el principio fue primero acceder y comprender el modo de relacionamiento social de estos campesinos antes y después de los retornos, identificando en ello, las implicaciones espaciales derivadas pero a la vez productoras de dicho relacionamiento; esta decisión nos llevó a analizar lo social y lo espacial desde dos niveles que lejos de estar separados, se instituían mutuamente. Ahora, dar cuenta de esta doble institución exigió reducir las unidades de análisis, no todo lo social fue examinado; de allí que fuera la relación familia, trabajo, comunidad el marco social que nos permitió entender y analizar una parte de las reconfiguraciones espaciales de los campesinos retornados de VillaColombia y Borracheras, de igual manera no todo lo espacial fue abordado, el estudio se centró en las prácticas de dominio y apropiación espacial. Estas unidades espaciales respondieron no a una elección a priori sino a la posibilidad de comprender los cambios y/o transformaciones en cuanto al dominio y a la apropiación espacial de estos campesinos.

Siguiendo esta premisa, lo encontrado frente a estas prácticas específicas, nos demuestra que las reconfiguraciones frente a la apropiación y al dominio 
espacial de estos campesinos están dadas en dos sentidos. El primero obedece a un plano más material, a un aspecto más relacionado con las prácticas formales, más reconocibles de la espacialidad: al respecto encontramos una modificación de las maneras en que los campesinos disponían, ocupaban, organizaban y producían los objetos-formas y las relaciones socioespaciales: las parcelas, los jagüeys (ojos de agua), los caminos, usos de la tierra (en relación a cultivos tradicionales), es decir, la disposición de los elementos socioterritoriales y naturales de lo que Mançano (2010) denomina paisaje campesino fueron las reconfiguraciones más fácilmente reconocibles de este proceso de retorno, no obstante, tanto la apropiación como el dominio espacial, están constituidas también por elementos menos formales, propios del mundo inmaterial, de las representaciones sociales y de los acumulados históricos e identitarios de los campesinos y sus comunidades.

En este aspecto encontramos que la reconfiguración de las prácticas espaciales, no están atadas únicamente al plano de la materialidad y de las relaciones de producción, tal como en ocasiones pareciera concluir Harvey (2008), por el contrario lo que se evidencia del caso de VillaColombia y Borracheras es que la producción espacial, en cuanto a prácticas espaciales se refiere, tiene que ser abordada, también y no exclusivamente, por su componente simbólico o inmaterial. Las reconfiguraciones de los elementos que constituyen el paisaje campesino son resultado a la vez de reconfiguraciones en las construcciones individuales y colectivas de modos de vida, cuyo sentido -muchas veces- está dado por una serie de códigos y representaciones compartidos, creados y recreados a lo largo del mundo de vida, a lo largo de la historia individual y colectiva. La apropiación y el dominio del espacio son entonces parte y resultado de modos inmateriales de ser y de estar en el mundo.

Sin querer desconocer la importancia y la trascendencia que tiene el análisis de las relaciones de producción en la conformación y la reconfiguración del espacio, lo que este estudio nos ha señalado es que es importante articular ambos estadios -lo material y lo inmaterial- como parte de un complejo, cuyo balance posibilitaría sobrepasar los desafíos epistemológicos que los fenómenos sociales nos presentan constantemente. 


\subsection{Retornos, campesinos e investigación}

El devalar las condiciones tanto objetivas como subjetivas dentro del proceso de retorno de las comunidades campesinas estudiadas, nos lleva a replantear o por lo menos a proponer otras perspectivas o tentativas de investigación en cuanto al tema abordado.

En primer lugar, hay que considerar tal como hemos descrito arriba, que la tendencia por privilegiar el análisis sociojurídico frente al tema del retorno ha generado una limitada mirada sobre el fenómeno; recordemos que la poca literatura que se encuentra ha centrado su análisis ya sea a la descripción de experiencias locales o regionales de retorno, al análisis del deseo de retorno o a la revisión de los derechos de los retornados y del nivel de cubrimiento de la política pública, pero no sobre aquellas implicaciones socioculturales y espaciales que atraviesan tanto a los sujetos campesinos como la propia estabilidad y sostenibilidad de los retornos.

Es decir, precisamos que se amplié la propia idea que se tiene sobre el retornar, pues no es solamente el "volver" en el marco de unas garantías estatales (seguridad, estabilidad socioeconómica o de otros derechos), sino el comprender que el mismo volver pasa por entender las propias lógicas y sentidos que constituían las maneras de estar de estos campesinos. Sin pretender caer en una exagerada mira subjetiva sobre el fenómeno, lo importante acá es articular estos otros factores (menos formales) dentro de la misma política pública en un ejercicio que integre en una mirada más relacional las otras maneras en que se puede realizar y sostener de ese volver; alternativas que permitan en lo posible resarcir el daño y concebir planes de vida dentro de proyectos de territorio y economía campesina. El caso de VillaColombia y Borracheras nos permite abrir un espacio de reflexión en cuanto a las posibilidades de retornar y a las maneras como comunitariamente se puede hacer frente a un ambiente de zozobra y de incertidumbre.

Por otro lado, es preciso que ese repensar los retornos esté atado a una nueva manera de asumir al "retornado". Desde hace más de 16 años, cuando se 
empieza a generalizar el desplazamiento forzado en Colombia, nace junto al flagelo del desarraigo una nueva categoría de sujeto: el "desplazado" y posterior a éste el "retornado". Así tanto el "desplazado" como el más reciente "retornado" se han constituidos en maneras desde las cuales se ha generado un desdibujamiento de los sentidos y las cargar identitarias e históricas de los sujetos que viven procesos de desplazamiento, en el caso de los campesinos, esta nueva identificación lleva consigo una velada manera de deshistorizar al campesino. En este sentido las políticas públicas no buscan retornar campesinos sino desplazados; el problema no radica en un simple uso del lenguaje o en una manera particular de enunciar a los sujetos, sino a las implicaciones que esto tiene en relación al reconocimiento de las particularidades que constituyen a los hombres y mujeres que fueron obligados a abandonar sus territorios.

A pesar que frente a este asunto la Corte Constitucional en auto T025 a proferido una serie de directrices que obligan al Estado a garantizar el goce efectivo de los derechos a las poblaciones desplazadas desde una perspectiva diferencial, es decir desde el reconocimientos de las particulares socio culturales, de género y generacionales de la población en condición de desplazamiento, en la práctica esto se ha reducido a formular planes que generalmente se quedan en el papel frente a políticas públicas identitarias, pero que más allá, siguen sin reconocer las especificidades de los contextos enfrascando en un solo conjunto a todos los desplazados. Insistimos que el diseñar políticas públicas cuyos destinatarios son "los desplazados" y no los "campesinos" no solo homogeniza aquella masa de población sino que termina por consolidar la estrategia por la cual se generalizó el desplazamiento forzado en Colombia: la desterritorialización o descampenización del campo colombiano a través del no reconocimiento del campesino como principal víctima del conflicto socio político y armado. 


\section{Referencias Bibliográficas}

ACCIÓ SOCIAL (sf) Desplazamiento forzado en Colombia. Recuperado el 17 de agosto de 2013. http://www.dps.gov.co/documentos/Retornos/CIDH\%20Desplazamiento\%20Forz ado\%20en\%20Colombia\%20Marzo\%202010\%20para\%20Canciller\%C3\%ADa1. pdf.

ACNUR (2010) Retornar o reubicarse. Guía para la población en situación de desplazamiento. Unidad Técnica Conjunta -UTeC, Convenio ACCION SOCIAL ACNUR._Documento_en_línea_http://www.acnur.org/t3/fileadmin/scripts/doc.php ?file=biblioteca/pdf/7609

(2007) Desplazamiento Forzado en Colombia Derechos, acceso a la justicia y reparaciones Memorias de la Escuela de Formación en Desplazamiento Forzado 2007. CEDHUL-ACNUR. Documento en línea http://www.acnur.org/t3/fileadmin/scripts/doc.php?file=biblioteca/pdf/6922.

(2004) Balance de la política pública de prevención, protección y atención al desplazamiento interno forzado en Colombia agosto 2002 - agosto 2004. Alto Comisionado de las Nacionales Unidas para los Refugiados. Oficina para Colombia. ISBN: 958-33-7018-5, Documento en líneahttp://www.acnur.org/t3/fileadmin/scripts/doc.php?file=biblioteca/pdf/2983

(2002) Balance de la política de atención al desplazamiento interno forzado en Colombia 1999-2002, Capítulo VI. Alto Comisionado de las Nacionales Unidas para los Refugiados. Documento en línea http://www.acnur.org/t3/fileadmin/scripts/doc.php?file=biblioteca/pdf/1910

ACNUR-PNUD (2011) Desplazamiento forzado, tierras y territorios. Agendas pendientes: la estabilización socioeconómica y la reparación. Programa de las Naciones Unidas para el Desarrollo - PNUD/ Alto Comisionado de las Nacionales Unidas para los Refugiados ACNUR.

AGNEW John (1994) "representing space", en Place, cultura, representation, Duncan \& Ley eds, p251-271.

ALBECK, María Ester y PALOMEQUE, Silvia. (2009) Ocupación española de 
las tierras indígenas de la puna y "raya del Tucumán" durante el temprano período colonial. [online]. 2009, n.17-2 pp. 173-212. Disponible en: http://www.scielo.org.ar/scielo. ISSN 1851-3751 [Memoria americana versión Online ISSN 1851-3751]

ALMEIDA, Rosemeire (2006) A sociologia da practica de Bourdieu e o campesinato. Revista Eletrônica da Associação dos Geógrafos Brasileiros Seção Três Lagoas Três Lagoas - MS, V 1 - n. 3 - ano 3, Maio de 2006. ISSN. 1808-2553.

BECERRRA, Andrea (2012) El panorama incierto de la restitución de tierras: Ante la realidad del despojo. Revista Izquierda № 20, Marzo de 2012 - Bogotá, Colombia. ISSN - 22158332. P 4-10

(2011a) El espejismo de la restitución de tierras en Colombia. Revista Izquierda No 10, Abril de 2011 • Bogotá, Colombia. ISSN - 22158332. p 5-15

(2011b) Hay problemas de fondo y de proceso. En Razón Pública, Domingo, 12 de Junio de 2011

(2010) Una restitución de tierras sin reparación integral para las víctimas del desplazamiento forzado y del despojo de tierras y territorios. Revista Izquierda No 5, Octubre de 2010 • Bogotá, Colombia. ISSN - 22158332. p 5-15

BELLO, Martha Nubia. (2001)."Desplazamiento Forzado y Reconstrucción de Identidades". Premio Nacional de Ensayo Académico Alberto Lleras Camargo IV Convocatoria. Primera edición. Ministerio de Educación Nacional. Instituto Colombiano para el Fomento de la Educación Superior -ICFES. ARFO Editores e impresiones Ltda. Bogotá.

BENJAMIN Walter. (1999) "Sobre el Concepto de la Historia", en Ensayos escogidos, México, ediciones Coyoacán, S.A. de C.V. traducción del alemán: H.A. Murena. $201 p$

BOCCHI David (2011). Análisis del Plan Consolidación de Montes de María; una mirada desde el desarrollo, la democracia, los derechos humanos y la cooperación internacional, 
BOLAÑO, Nancy \& PÉREZ Liliana (2008) Memorias del territorio: hacía políticas e intervenciones sociales complejas frente al desplazamiento forzado. Revista Prospectiva. Universidad del Valle. No 13, octubre 2008. ISNN. 01221213. p 175-223

BORDA, Fals (1976) Capitalismo, hacienda y poblamiento en la Costa Atlántica. Editorial punta de Lanza.

BOURDIEU, Pierre (1988) Cosas dichas, traducción Margarita Mizraji. Editorial Gedisa, Buenos Aires.

(1988) La distinción: criterios y bases sociales del gusto, traducción de Ma. del Carmen Ruiz de Elvira. Editorial Taurus, Madrid.

(1990) El sentido práctico. Versión castellana de Alvaro Pazos, revisada por Marie-José Devillard. Editorial Taurus Humanidades, Madrid.

CARVAJAL, Jorge (2008) La seguridad dentro del estado de garantías. Textos de aquí y ahora. ILSA ISBN 978-958-8341-10-1. p 136.

CELIS, Andres (Traducción 2009) Desplazamiento y retorno en Colombia. En HPN Humanitarian Practice Network. Documento en línea http://www.odihpn.org/translated-content/desplazamiento-y-retorno-en-colombia

CENTRO DE MEMORIA HISTÓRICA (2013) ¡Basta Ya! Colombia: memorias de guerra $y$ dignidad. Documento en web http://centrodememoriahistorica.gov.co/micrositios/informeGeneral/descargas.ht $\mathrm{ml}$

CNRR (2009) El despojo de tierras y territorios. Aproximación conceptual. Área de Memoria Histórica - Comisión Nacional de Reparación y Reconciliación (CNRR) / Instituto de Estudios Políticos y Relaciones Internacionales (IEPRI) Universidad Nacional de Colombia. ISBN: 978-958-. P100.

CNRR (2010) La tierra en disputa Memorias de despojo y resistencia campesina en la costa Caribe (1960-2010).Grupo de Memoria Histórica, Ediciones Semana. ISBN: 978-958-???-???-6. P 528 
COLECTIVO DE COMUNICACIONES MONTES DE MARÍA LÍNEA 21 (2003) Evaluación del daño psicosocial en la Asociación Campesina Retornada del municipio de Ovejas ASOCARES por violación a los derechos humanos. Documento inédito.

COMISIÓN DE SEGUIMIENTO A LA POLÍTICA PÚBLICA SOBRE DESPLAZAMIENTO FORZADO. CODHES. (2008) VI Informe a la Corte Constitucional. La restitución como parte de la reparación integral de las víctimas de desplazamiento en Colombia. Diagnóstico y propuesta de líneas de acción. Junio de 2008.

CONCEJERIA EN PROYECTOS -PCS (2003) El proceso de retorno en el Catatumbo. Colombia Informe regional. Mayo 2003. Documento en línea http://www.acnur.org/pais/docs/301.pdf?view=1

CONGRESO DE LA REPÚBLICA (2011) ley de víctimas y restitución de tierra Ley 1448 de 2011.

CONGRESO DE LA REPÚBLICA DE COLOMBIA (1997) LEY 387 DE 1997. Por la cual se adoptan medidas para la prevención del desplazamiento forzado; la atención, protección, consolidación y estabilización socioeconómica de los desplazados internos por la violencia en la República de Colombia. Diario Oficial No. 43.091

CHAVEZ, Yuri \& FALLA Uva. (2005) Representaciones sociales acerca del retorno en población e situación de desplazamiento asentada en el municipio de Soacha. Universidad Colegio Mayor de Cundinamarca. Revista Tabula Rasa. Bogotá - Colombia, No.3: 271-292, enero-diciembre de 2005 ISSN 1794-2489. P 271-292

CHAYANOV, Aleksandr (1974) La organización de la unidad económica campesina. Nueva Visión, Buenos Aires.

ECONOMETRIA S.A. (2008) Evaluación del proceso de retorno del Salado.

ENCUENTAS NACIONAL DE VERIFICACIÓN. CENTRO DE INVESTIGACIONES PARA EL DESARROLLO, UNIVERSIDAD NACIONAL (CID- UN) (2007)I Encuesta Nacional de Verificación de los derechos de la 
población desplazada. (2008) II Encuesta Nacional de Verificación de los derechos de la población desplazada. (2010)III Encuesta Nacional de Verificación de los derechos de la población desplazada.

FAJARDO, Dario. (2002). Para sembrar la paz hay que aflojar la tierra. Comunidades, tierras y territorios en la construcción de un país. Bogotá: Universidad Nacional de Colombia - Instituto de Estudios Ambientales.

FERREIRA Alair, VIERIA Maria (2011) "Campesinato como ordem moral": (re)visitando clássicos e (re)pensando a economia camponesa. REVISTA NERA - ANO 14, №. 19 - JULHO/DEZEMBRO DE 2011 - ISSN: 1806-6755.

GANDLER Stefan (2003) “¿Por qué el ángel de la historia mira hacia atrás? Acerca de las tesis sobre el concepto de historia de Walter Benjamin", en Utopía y praxis latinoamericana, enero-marzo, año/vol. 8, número 020, Maracaibo, 2003. 7-39p

GARZÓN Juan C (Sin Fecha) Desmovilización del Bloque Héroes de Montes de María de las AUC. Recuperado el 13 de abril de 2013. En http://www.ertatcrg.org/cri6224/2008/paramilitaires/pdf/bloquemontesdemaria.pdf

GARZÓN, María A (2011) Andar los recuerdos: elementos para pensar el territorio desde los procesos de retorno de población desarraigada por la violencia Revista Encuentros ISSN 1692-5858. No. 1. Junio de 2011. p 83-94

GIDDENS Anthony (1984) La constitución de la sociedad. Bases para la teoría de la estructuración, Amorrortu, España. 416p

GILHODES, Pierre (1974) Las luchas agrarias en Colombia; traducción Jorge Orlando Melo. Libros de bolsillo de la carreta, Bogotá.

GIMÉNEZ, Gilberto (1997). "Materiales para una nueva teoría de las identidades sociales". En Revista Frontera Norte. Vol. 9. Núm. 18. México.

(2002) Introducción a la sociología de Pierre Bourdieu. Colección Pedagógica Universitaria No. 37-38. Universidad Veracruzana, Instituto de Investigaciones en Educación. Campus Veracruz - México

GONÇALVES P. Walter (2001) Geo-grafias Movimientos sociales, nuevas 
territorialidades y sustentabilidad, México, Siglo XXI. 298p

GUTIERREZ, Daniel: Reflexiones sobre la construcción del Objeto de estudio. Cuadernos de Trabajo 11, Facultad de Ciencias Políticas y Sociales, Universidad Nacional Autónoma de México.

HABERMAS Jürgen (2008) El discurso filosófico de la modernidad. Katz. Buenos Aires. 418p

HARVEY David (2008) La condición de la posmodernidad. Amorrortu/editores. ISBN. 978-950-518-659-4. P 401

------ (1996) Justicia, naturaleza y la geografía de la diferencia, Cambridge, Blackwell Publishers. 468p

HERNÁNDEZ, América E (2006). La impronta práctica para la formulación de sentido. Iberóforum, Revista de Ciencias Sociales de la Universidad Iberoamericana, vol. I, núm. II, 2006, pp. 1-17, Universidad Iberoamericana, Ciudad de México. ISSN (Versión electrónica): 2007-0675

HERNÁNDEZ, Luisa (2010) Procesos de retornos y reubicación de dos comunidades victimizadas por el desplazamiento forzado en Los Montes de María, Actores sociales y proyectos políticos. Trabajo de grado para optar al título de Magíster en Estudios Políticos. Instituto de Estudios Políticos y Relaciones Internacionales -IEPRI, Universidad Nacional de Colombia.

HERRERA Marta (2002) Ordenar para controlar. Ordenamiento espacial y control político en las llanuras del Cribe y en los Andes centrales neogranadinos. Siglo XVIII. Academia Colombiana de Historia - Instituto Colombiano de Antropología e Historia. Colección espiral Titulo 1. ISBN 958-8181-01-1

HERRERA, Juan (sf) La cartografía social. En http://www.juanherrera.files.wordpress.com/2008/01/cartografia-social.pdf

IBAÑEZ, Ana María \& MOYA, Andrés (2006). ¿Cómo el desplazamiento forzado deteriora el bienestar de los hogares desplazados? Análisis y determinantes del bienestar en los municipios de recepción. Documentos CEDE No. 26. Bogotá: Universidad de los Andes. 
IBAÑEZ, Ana María \& QUERUBIN, Pablo (2004) Acceso a tierras y desplazamiento forzado en Colombia. Universidad de los Andes, Documento CEDE Mayo 2004-23 ISSN 1657-5334.

(2003) Determinantes del deseo de retorno de los hogares desplazados en Colombia. Revista Planeación y Desarrollo, DNP Vol 34, No2 (Jul-Dic 2003) p 269-306

------ (2010) ¿qué hacer con el retorno? Los programas de retorno para la PD en Colombia, En: Más allá del desplazamiento forzado [Rodriguez, coor] Universidad de los Andes - CIJUS- ACNUR. Ediciones Uniandes. Bogotá. ISBN: 978-958-695-482-2. (p.224- 257)

------ (2008) El desplazamiento forzoso en Colombia: Un camino sin retorno hacia la pobreza. Universidad de los Andes, Colección CEDE. ISBN: 9789586953641. P 277

------- (2004) Génesis del desplazamiento forzado en Colombia: sus orígenes, sus consecuencias y el problema del retorno. Revista Coyuntura Social, Fedesarrollo No 30 (Junio-2004) p 87-104.

IDEPAZ (2011) Análisis regional de Los Montes de María, Septiembre. En http://www.ideaspaz.org/, consultado el 20 de abril de 2013.

ILSA (2006) Desplazamiento y Retorno. Balance de una política. Libro 1, 2, 3 y 4. Comité Editorial ILSA. ISBN 958-9262-28-7. P 183.

(2012) Montes de María: Entre la consolidación del territorio y el acaparamiento de tierras. Aproximación a la situación de Derechos Humanos y del Derecho Internacional Humanitario en la región (2006-2012). Publicaciones ILSA, Bogotá.

LEFEBVRE Henri (1994) [1를. ed.1974] La producción del espacio, Oxford.

(1976) Reflexión y política del espacio. Antipode.

LÓPEZ, Eloy (2010) Territorio como espacio de construcción del sujeto social, producto y producente del desarrollo: una reflexión desde las comunidades campesinas e indígenas. Universidad Veracruzana Intercultural. Colección 
parcela digital.

MACHADO Absalón [comp] (2002) De la estructura agraria al sistema agroindustrial. Universidad Nacional de Colombia. ISBN 958-7010135-X, 325p

[comp] (1994) El agro y la cuestión social. Bogotá, Tercer Mundo Editores. p417

MANÇANO Bernardo (2008) Movimentos socioterritoriais no campo brasileiro: contribuição para leitura geográfica dos movimentos camponeses. En: OLIVEIRA, Márcio Piñon de; COELHO, Maria Célia Nunes; CORRÊA, Aureanice de Mello. O Brasil, a América Latina e o mundo: espacialidades contemporâneas (II). Rio de Janeiro: pp. 385-404

(2010) Territorios en disputa: campesinos y agrobusiness. En Land Research Action Network. Versión digital http://www.landaction.org/spip.php?article515\&lang=en

(2005) "Movimentos socioterritoriais e movimentos socioespaciais", en Observatorio Social de América Latina, Buenos Aires, v. 16, 2005 p. 273-284

(2002) Movimento social como categoría geográfica. Terra Livre, São Paulo,n.15, p.59-85, 2000.

MERRIFIELD Andrew (1993) "Place and space: a lefebvrian reconciliation", en Transactions of the Institute of British Geographers, v. 18, No. 4, 1993, pp. 516531

MININ Andrey (2008) TERRA, TRABALHO E FAMÍLIA: considerações sobre a (re) criação do campesinato brasileiro nos movimentos sociais rurais, Revista História em Reflexão: Vol. 2 n. 4 - UFGD - Dourados jul/dez

MONDRAGÓN, Héctor. (2002) La organización campesina en un ambiente de terror. En Web: www.kus.uu.se/CF/Oganizacion_campesina.pdf

MOSQUERA, Juan de Dios (2001) Boletín del movimiento nacional afrocolombiano cimarrón: estudios afrocolombianos. Recuperado en http://www.banrepcultural.org/blaavirtual/sociologia/estudiosafro/estudiosafro15.h $\mathrm{tm}$ 
MUÑOZ Armando (2007) Historia y Evolución de la Estructura Agraria en Colombia. Universidad Pedagógica y Tecnológica de Colombia, Unidad de educación virtual-Agronomía. En http://virtual.uptc.edu.co/drupal/files/205/contenido/index.swf.

NACIONES UNIDAS (1998) Principios rectores de los desplazamientos internos, ECN.4/1998/53/Add.2, de 11 de febrero de 1998

NANTES Beatris (2001) "Temas y Variaciones" en Territorialidades reconstruidas. Grupo de investigación territorialidades. Universidad de Caldas.

OBSERVATORIO DE DDHH Y DIH DE LA VICEPRESIDENCIA (2003) Panorama actual de la región de Montes de María y su entorno.

OSLENDER Ulrich (2008a) Comunidades negras y espacio en el pacífico colombiano. Hacia un giro geográfico en el estudio de los movimientos sociales. Colección ICAHN.

(2008b) Geografías del terror. Un marco de análisis para el estudio del terror. Universidad de Barcelona. ISSN: 1138-9788. Depósito Legal: B. 21.74198 Vol. XII, núm. 270 (144), 1 de agosto de 2008

(2002) Espacio, lugar y movimientos sociales: hacia una "espacialidad de resistencia". Universidad de Barcelona. ISSN: 1138-9788. Depósito Legal: B. 21.741-8 Vol. VI, núm. 115, 1 de junio de 2002

OSPINA, Byron (2011) Espacializando la memoria: Reflexiones sobre el tiempo, el espacio y el territorio en la constitución de la memoria. Revista Aletheia, volumen 2, número 3, noviembre 2011. ISSN 1853-3701.

PALACIOS, Marco (2011) ¿De quién es la tierra? Propiedad, politización y protesta campesina en la década de 1930. Universidad de los Andes. Ediciones Fondo de Cultura Económica. Bogotá.

PNUD (2011) Montes de María. Retos y propuestas para la construcción colectiva de sus programas de gobierno. Programa de Naciones Unidas para el Desarrollo - Pnud- y Fondo de Población de las Naciones Unidas, Unfpa. Consultado 
http://pnudcolombia.org/elecciones2011/pdf/separata_montes_de_maria.pdf PNUD. (2009). "Las caras del despojo de tierras" y Sucre: en Busca de la protección de la tierra", en boletín Hechos del Callejón No. 47 - Junio de 2009. Bogotá: Editorial El Malpensante S.A.

PNUD-EXPOPAZ (2010). Los Montes de María. Consultado el 15 de diciembre de 2013.2 En web http://redes.pnudcolombia.org/index.php?option=com_content\&view=category\&la yout=blog\&id $=10 \& \mid$ temid $=24$

PNUD-Universidad de Cartagena (2003) Promontes. Programa de Desarrollo y Paz de Los Montes de María. Bogotá. Consultado el 17 de diciembre de 2012, en: www.pnud.org.co http://www.pnud.org.co/img_upload/9056f18133669868e1cc381983d50faa/prom ontes.pdf

POSADA, Marcel (1997) Teoría y sujetos sociales. Algunas consideraciones acerca de los estudios sobre el campesinado en Argentina. Enhttp://ddd.uab.es/pub/papers/02102862n51/02102862n51p73.pdf

PROGRAMA PRESIDENCIAL DE DERECHOS HUMANOS Y DERECHO INTERACIONAL HUMANITARIO (2003) Los Derechos Humanos en el Departamento de Sucre.

PROGRAMA PRESIDENCIAL DE DERECHOS HUMANOS Y DERECHO INTERACIONAL HUMANITARIO (2010) Diagnóstico Sucre. En www.derechoshumanos.gov.co/Pna/documents/2010/sucre/sucre.pdf

PUELLO D, Amaranto (2005) El conflicto Armado y el desplazamiento en Bolívar. En: BELLO A. Martha N; VILLA M, Marta I [comp] Desplazamiento en Colombia. Regiones, ciudades y políticas públicas. Edición REDIF -ACNURCORPORACIÓN REGIÓN. P 213-244

REVISTA SEMANA (2008) Chengue, un pueblo sin justicia ni perdón. Edición electrónica http://www.semana.com/on-line/articulo/chengue-pueblo-justicia-niperdon/90620-3 
RIAÑO, Pilar \& VILLA, Marta (2008) Poniendo tierra de por medio. Migración forzada de colombianos en Colombia, Ecuador y Canadá. Corporación Región UCB. Medellín. ISBN. 978-958-8134-48-2.

RUDQVIST Anders (1983) La Organización Campesina y la Izquierda ANUC en Colombia 1970 - 1980. Informes de investigación. Centro de Estudios Latinoamericanos, CELAS Universidad de Uppsala

RUIZ José María (2008) ¿De qué hablamos cuando hablamos de "memoria histórica"? reflexiones desde la psicología cognitiva. Entelequia. Revista Interdisciplinar: Monográfico, № 7, septiembre 2008.

RUIZ, Nubia (2006) "Desplazamiento Forzado en Colombia, 2000 -2004. Aportes teóricos, análisis demográfico y territorial", En Ruiz R, Nubia et al (2006) Desplazamiento, movilidad y retorno en Colombia. Dinámicas migratorias recientes. Centro de Investigaciones Sobres Dinámica Social CIDS. Universidad Externado de Colombia. Bogotá. P9-55. ISBN 958-710-104-9

SANTOS Milton (2000) La naturaleza del espacio. Técnica y tiempo. Razón y emoción. Editorial Ariel «traducción María Laura Silveira» BARCELONA. ISBN: 84-344-3460-1

SASTOQUE Ángel; OSPINA Byron; CARDENAS Francys; HEREDIA Douglas; CASTRO Sandra. (2010) Crímenes de Estado y configuración territorial en la región de Sumapaz y Tequendama, Proyecto Colombia Nunca Más, Bogotá.

SHANIN, Teodor. 1979. "El campesinado como factor político", Shanin, Teodor, compilador (1979), Campesinos y sociedades campesinas", El Trimestre Económico, 29, FCE, México

SHARP William (2000) "En-tanglements of power: geographies of domination/resistance", Londres.

SNAIP, Sistema Nacional de Atención Integral a la Población Desplazada (2009) Política Publica de Retorno para la población en situación de desplazamiento (PPR). Acción Social. Documento en línea http://www.accionsocial.gov.co/documentos/4636_Pol\%C3\%ADtica_P\%C3\%BAb lica_de_Retornos.pdf 
SOJA, Eduard (1985) La espacialidad de la vida social: hacia una reteorización transformativa. En Gregory \& Urry (eds) Social Relations and Spatial Structures, Londres. [traducción: H.A. Torres]

SUAREZ, Andrés (2008) La sevicia en las masacres de la guerra colombiana. Revista Análisis Político IEPRI-Universidad Nacional de Colombia. vol.21 no.63 Bogotá May/Aug.

TORRES, Alfonso \& TORRES Juan Carlos (sf) Subjetividad y sujetos sociales en la obra de Hugo Zemelman. Revista Folios. Universidad Pedagógica Nacional. En http://www.pedagogica.edu.co/storage/folios/articulos/fol12_04arti.pdf

TULVING, E. (1985) "Memory and consciousness" en Canadian Psychology, vol. XXVI, pp.1-12.

VELASCO, David (1998). La fórmula generadora del sentido práctico. Una aproximación a la filosofía de la práctica de Pierre Bourdieu. Espiral, mayoagosto, 33-80

VERDADABIERTA (2010) ¿Cómo se fraguó la tragedia de Los Montes de María?. Jueves, 02 de septiembre de 2010. Consultado 27 de abril, 2013, en http://www.verdadabierta.com/despojo-de-tierras/2676-icomo-se-fraguo-latragedia-de-los-montes-de-maria

ZAMBRANO, Fabio (2000) Historia del poblamiento del territorio de la región Caribe en Colombia. En ABELLO Alberto, GIAIMO, Silvana (comp) Poblamiento y ciudades del Caribe colombiano. Observatorio del Caribe Colombiano. Gente Nueva Editores. Cartagena. ISBN: 958-8096-13-8

ZEMELMAN, Hugo \& LEON, Emma (1997) Subjetividad: umbrales del pensamiento social. Anthropos, Barcelona.

ZEMELMAN, Hugo (1996). Problemas antropológicos y utópicos del conocimiento. El Colegio de México, México. 